\title{
EXPERIMENTAL RESEARCHES ON SKIN EFFECT IN CONDUCTORS
}

\author{
BY A. E. KENNELLY, F. A. LAWS AND P. H. PIERCE
}

\section{Abstract of PaPer}

The results are given of about one hundred series of tests, each covering a range in frequency up to about 5000 cycles per second, on the impedance of long loops of parallel conductors of different metals, sizes, and cross-sectional forms. The measuring apparatus is detailed. The theory of the skin effect in solid rods and in indefinitely wide flat strips is appended in a new and simplified form.

7

HE FOLLOWING researches were conducted, under an appropriation from the American Telephone and Telegraph Co., at the Massachusetts Institute of Technology in the Research Division of the Electrical Engineering Department, during the year 1914-15. In the early part of 1914, they were carried on under the directorship of Prof. Harold Pender. They date their origin, however, to M. I. T. thesis work undertaken in 1912-13.

Brief Early Historical Outline of Skin Effect Research. The first mathematical discussion of auto-distorted alternatingcurrent density in a wire appears to have been given by Maxwell in 1873. Heaviside contributed an extensive mathematical literature to the whole subject in 1884-1887. J. H. Poynting also contributed to the mathematics of the subject in 18841885. Hughes developed the experimental side of the subject in 1886. Lord Rayleigh in 1886 first gave the formula for skin effect in an infinitely wide strip. Dr. H. F. Weber in 1886, J. Stefan in 1887 and O. Lodge in 1888 contributed further material. Lord Kelvin gave the expression in ber-bei functions in 1889. Hertz in 1889 and Sir J. J. Thomson in 1893 discussed the subject both from the experimental and mathematical standpoints. Mr. J. Swinburne used the term " skin-effect" in 1891.1

1. Discussion on the paper of Dr. J. A. Fleming, "On Some Effects of Alternating-Current Flow in Circuits having Capacity and Self-Induction," Journal Institution of Electrical Engineers, London, Vol. XX, May 1891, p. 471. 
Current-Distortion Effects. The phenomena to be discussed relate to distortions in the distribution of current-density over the cross-section of conductors, and may therefore be summed up under the title of "current-distortion effects." These effects may be subdivided into three classes as follows:

1. An effect due to disturbance of current density in a conductor due to the alternating magnetic flux linked with the same, as in the case of simple, straight, round wires remote from return conductors. This is the "skin-effect." It may be regarded as due either to imperfect penetration of electric current into the conductor, or to the greater reactance of the central core of the conductor with respect to the surface layer, whereby the current density is less on the inside than on the outside.

In a uniform solid round wire, the skin effect is symmetrical with respect to its axis. In solid wires of other than circular form, the skin effect is, in general, dissymmetrical.

2. An effect found in spiralled stranded conductors and due to the reactance of the spirals. This has been called the "spirality effect."

3. An effect found in parallel linear conductors of any crosssectional form when in proximity, owing to the alternating magnetic flux from one penetrating the other. This may be called the "proximity effect."

The entire phenomenon of current-distortion effect, including the skin effect as a subtype, may nevertheless be referred to broadly as "skin effect" in conformity with current usage, unless a distinction is called for.

\section{Apparatus Employed}

The Mutual Inductance Bridge. Professor Hu'ghes, on assuming the presidency of the Society of Telegraph Engineers in 1885, delivered an address on "The Self-Induction of an Electric Current in Relation to the Form of its Conductor." In carrying out the experiments there described, he used a form of bridge, which is diagrammatically shown in Fig. 1. Its peculiarity is that an e.m.f. is introduced into the detector circuit by means of a variable-ratio air-core transformer, or mutual inductance, shown at $m$ in the diagram. The detector current can be brought to zero by adjusting the bridge arms and the mutual inductance. In the original paper, owing to an inadequate examination of the theory of this arrangement, 
the results obtained were misinterpreted. Professor Hughes's paper precipitated a lively discussion, in which Lord Rayleigh, Sir Oliver Heaviside and Professor H. F. Weber participated.

One of the by-products of this discussion was the formulation of the complete theory of the Hughes bridge, by Professor Weber and Lord Rayleigh. Mr. Heaviside also showed that the arrangement used by Professor Hughes was not as simple in its action as that obtained if the mutual inductance is inserted between either the supply circuit or the detector circuit, and one of the bridge arms. Both the Hughes and Heaviside bridges are shown in Fig. 1. The Heaviside bridge has been employed in all the work here reported.

The conditions for balance in the Heaviside bridge may be deduced thus:
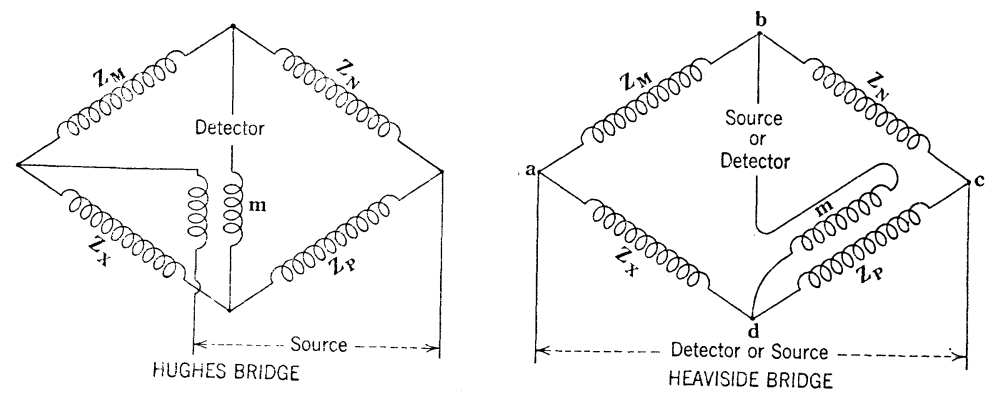

FIG. 1

The impedances of the bridge arms are denoted by $Z$ and the mutual inductance by $m$. The r.m.s. current in any arm is denoted by $I$ with the subscript designating the arm.

At balance, the currents in the arms $M$ and $N$ are equal, likewise those in $X$ and $P$.

The potential difference between $a$ and $b$, reckoned through the $\operatorname{arm} Z_{\mathrm{M}}$, must be the same as that via the $\operatorname{arm} Z_{\mathrm{x}}$, and the detector circuit, and that between $b$ and $c$, reckoned through the $\operatorname{arm} N$, must be the same as that via the detector circuit and the $\operatorname{arm} P$. Consequently

$$
\begin{aligned}
& Z_{\mathrm{M}} I_{\mathrm{M}}=Z_{\mathrm{x}} I_{\mathrm{x}}+j m \omega I_{\mathrm{x}} \\
& Z_{\mathrm{N}} I_{\mathrm{M}}=Z_{\mathrm{P}} I_{\mathrm{x}}-j m \omega I_{\mathrm{x}}
\end{aligned}
$$$$
\text { volts } \angle
$$

2. The $\operatorname{sign} \angle$ following the unit of an equation indicates that each side of the equation and every separate term thereof is to be considered as a "complex quantity," or plane vector. 
Therefore

$$
\frac{Z_{\mathrm{M}}}{Z_{\mathrm{N}}}=\frac{Z_{\mathrm{x}}+j m \omega}{Z_{\mathrm{P}}-j m \omega}
$$

In these experiments, an equal-arm bridge was used, with reference both to resistance and inductance; so that

$$
Z_{\mathrm{M}}=Z_{\mathrm{N}}
$$

ohms $\angle$

and the condition for balance becomes

$$
Z_{\mathrm{P}}-Z_{\mathrm{X}}=2 j m \omega
$$

If $R_{\mathrm{P}}{ }^{\prime \prime}, L_{\mathrm{P}}{ }^{\prime \prime}, R_{\mathrm{x}}{ }^{\prime \prime}$ and $L_{\mathrm{x}}{ }^{\prime \prime}$, are the total resistances and inductances of their respective bridge arms, then

$$
R_{\mathrm{P}}{ }^{\prime \prime}-R_{\mathrm{x}}{ }^{\prime \prime}+j \omega\left(L_{\mathrm{P}}{ }^{\prime}-L_{\mathrm{x}}{ }^{\prime \prime}-2 m\right)=0
$$

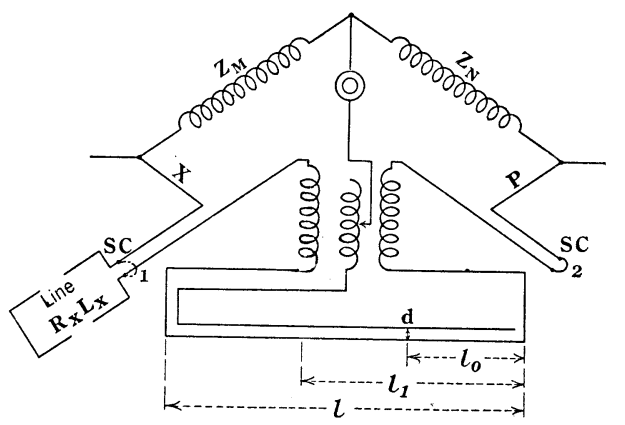

Fig. 2-Arrangement of Heaviside Bridge

Separating the quadrature components, we have

$$
\begin{aligned}
& R_{\mathrm{P}}{ }^{\prime \prime}=R_{\mathrm{x}}{ }^{\prime \prime} \\
& L_{\mathrm{P}}{ }^{\prime \prime}=L_{\mathrm{x}}{ }^{\prime \prime}+2 m
\end{aligned}
$$

as the conditions for balance.

As we have to deal with small resistances, the most satisfactory method of varying the resistances of the bridge arms is to use a slide wire, as indicated in Fig. 2. Also, to eliminate extraneous resistances and inductances, it is advisable to work by the method of differences, two balancings being taken, the first, with the loop short circuited, the second, with the short circuit removed.

Actual Construction and Arrangement of the Bridge. To avoid trouble from stray fields, the various fixed coils of the bridge were wound on wooden rings, as indicated at $M, N, X$ and $P$, Fig. 3 . 
The turns were fixed in position, by being wound in carefully spaced saw-cuts. Eddy current effects in the mutual inductance (arms $X$ and $P$ ) were avoided, by using for the primary winding a conductor made of 90 strands of No. $30 \mathrm{~B}$ and $\mathrm{S}$ enamelled copper wire (diameter of each strand $0.255 \mathrm{~mm}$.).

The primary winding of the mutual inductance was covered with a layer of tape. A thin, hard rubber ring with equally spaced radial saw-cuts served definitely to fix the secondary winding, which was carefully wound outside of the primary; so that it was spaced as nearly uniformly as possible, the aim being to obtain a uniform mutual inductance per turn. By means of the radial arm, $A$, the number of active secondary turns can be varied form 0 to 89 , by single-turn steps. Values

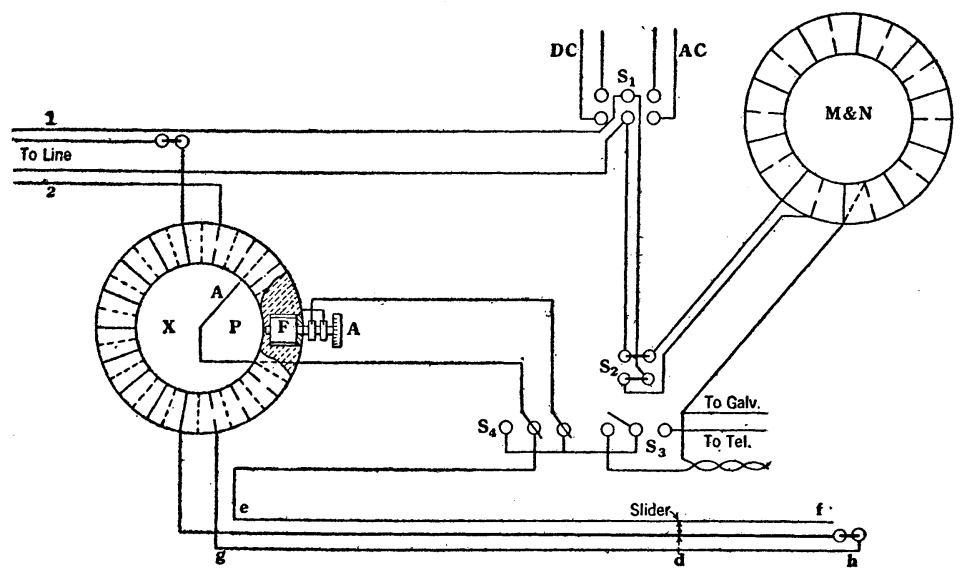

Fig. 3-Actual Arrangement of Bridge

intermediate between those given by two consecutive turns, are obtained by the use of the fine adjustment coil, shown at $F A$. This coil of three rectangular turns, each $2.5 \mathrm{~cm}$. $\times 3.5 \mathrm{~cm}$., is mounted within the wooden ring, as shown, and in such a manner that it can be rotated about its longer axis, to include a greater or lesser amount of the flux within the primary winding.

The change of mutual inductance due to turning the small coil, from the position of minus maximum to that of plus maximum, is somewhat greater than that due to one turn of the fixed secondary. The head, by which the position of the small coil is read off, is so graduated that one reads directly to tenths of a fixed turn, and, by estimation, to hundredths.

Twisted pairs of wires are used for all connections, and are 
cleated to the table, so that they occupy fixed positions. The positions of the leads $e f$ and $g h$, are fixed with reference to the slide wire. Any induction effects are thus rendered definite, and independent of the position of the telephone, which was used as the a-c. detector. Contact between the slide wire and the lead $e f$ is made by a sliding spring clip. The functions of the switches shown in Fig. 3 are as follows:

By means of $S_{1}$ either direct or alternating current may be supplied to the bridge.

$S_{2}$ is a mercury switch, with ample contacts, by which the arms $M$ and $N$ may be.reversed.

$\mathrm{S}_{3}$ allows either the galvanometer or the telephone to be used as a detector, for d-c. and a-c. bridge balances, respectively.

$S_{4}$ reverses the terminals of the secondary winding of the mutual inductance.

In order to cover the entire range of the loop resistances in these experiments, it was necessary to use two different slide wires. Each wire was arranged together with its lead, ef, on a meter stick, so that the change from one to the other could be effected with little trouble. To avoid any indefiniteness due to contacts, the joints at the ends of the slide wire were always soldered. Table I gives the data of the slide wires used.

Check measurements of standard resistances and inductances were made at different times with the testing apparatus to make sure that it was in good order.

TABLE I. SLIDE-WIRE DATA.

\begin{tabular}{|c|c|c|c|c|}
\hline $\begin{array}{l}\text { Slide wire } \\
\text { number }\end{array}$ & $\begin{array}{c}\text { Gage } \\
\text { B. \& S. }\end{array}$ & Material & $\begin{array}{c}\text { Resistance } \\
\text { ohms per cm. } \\
\frac{k}{2}\end{array}$ & $\begin{array}{l}\text { Change in induct- } \\
\text { ance by moving } \\
\text { slider } 2 \mathrm{~cm} . \\
\mu \\
\text { abhenrys }\end{array}$ \\
\hline 1 & 8 & German silver & 0.000280 & 8.9 \\
\hline 2 & 11 & German silver & 0.000810 & 8.2 \\
\hline
\end{tabular}

Change of inductance per turn of the mutual inductance winding, $K=1342$ abhenrys per turn.

The Loop of Conductors under Test. The conductors under test were arranged in a single long loop, with parallel sides. They were placed out of doors, about four meters from the ground, and 
plate CXXIX.

A. I. E. E.

VOL. XXXIV, 1915

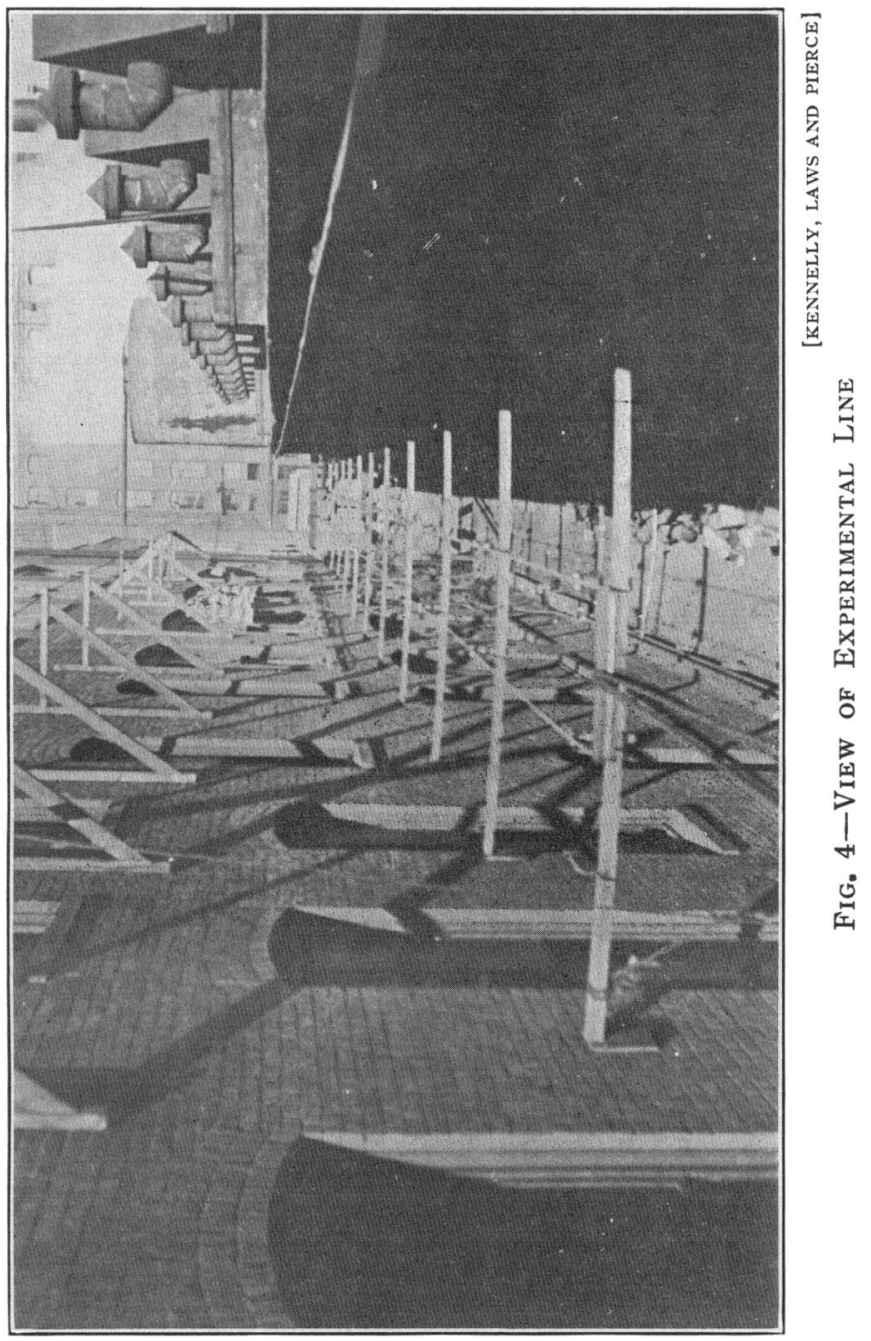


rested either on glass insulators or on dry wooden supports, as occasion offered. By the use of tackles, the wires could be drawn taut, their positions being thus rendered definite. Fig. 4 is from a photograph of the loop, taken from one end of the alley. Fig. 5 (which is not drawn to scale) shows the arrangement of the line terminals. The short links allow the line to be transferred from position 1 to position 2 in the bridge, see Fig. 3 . The link, mounted on the spring, is for the purpose of short circuiting the line, as above mentioned. Its action is controlled at the observer's position in the testing room by the use of the electromagnet $M$.

The observations are made as follows: The test loop is connected by the mercury cups to the bridge leads 1 , (Fig. 3) while

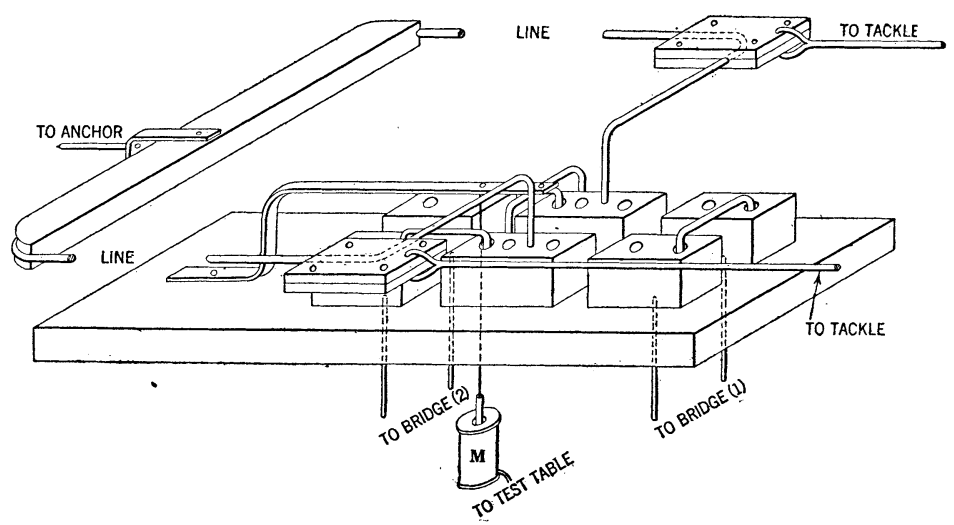

Fig. 5-Line Terminals

the bridge leads 2 , are short-circuited. Two sets of readings are then made, first with direct and then alternating currents; one set with the line short-circuited, and the other with the shortcircuit removed. The ratio arms, $M$ and $N$, are then reversed and the readings repeated. The line is then transferred to the other side of the bridge; that is, to the leads 2 , while leads 1 are short-circuited, and four more sets of readings are taken. The arithmetical mean result, given by the various sets of readings, is used in the computation.

During the balancings, the frequency is determined by the arrangement later described. A typical set of readings is shown in Table II. The theory of the a-c. bridge balance, applied to the actual construction, is given in Appendix I. 


\section{TABLE II.}

Sample of a set of observations and calculations at one frequency in determining the skin eff ect of the No. 0000 solid copper wire, spaced $60 \mathrm{~cm}$. between conductors.

\begin{tabular}{|c|c|c|c|c|c|c|c|c|c|c|c|}
\hline \multicolumn{12}{|c|}{ Using Slide Wire No. 1.} \\
\hline $\begin{array}{l}\text { Temp } \\
\text { deg. } \\
\text { cent. }\end{array}$ & Freq. & Arms & $l_{0}{ }^{\prime}$ & $l_{1}^{\prime}$ & $n_{0}$ & $n_{1}$ & $l_{0}$ & $l_{1}$ & $\mid \begin{array}{c}l_{1}^{\prime}-l_{0}^{\prime} \\
\mathrm{cm} .\end{array}$ & $\begin{array}{c}l_{1}-l_{0} \\
\mathrm{~cm}\end{array}$ & $\begin{array}{c}n_{1}-n_{0} \\
\text { turns }\end{array}$ \\
\hline \multirow[t]{5}{*}{25.6} & \multirow{5}{*}{1600} & \multirow{5}{*}{$\begin{array}{r}\text { I } \\
\text { II } \\
\text { III } \\
\text { IV }\end{array}$} & \multirow{5}{*}{$\begin{array}{l}51.42 \\
54.25 \\
50.66 \\
53.51\end{array}$} & \multirow{5}{*}{$\begin{array}{l}84.62 \\
88.40 \\
18.55 \\
22.12\end{array}$} & \multirow{5}{*}{$\begin{array}{l}4.32 \\
4.47 \\
5.28 \\
5.12\end{array}$} & \multirow{5}{*}{$\begin{array}{l}43.32 \\
43.58 \\
44.33 \\
44.07\end{array}$} & \multirow{5}{*}{$\begin{array}{l}53.15 \\
58.15 \\
52.55 \\
57.56\end{array}$} & \multirow{5}{*}{$\begin{array}{l}69.22 \\
74.35 \\
36.60 \\
41.72\end{array}$} & 33.20 & 16.07 & 39.00 \\
\hline & & & & & & & & & 34.15 & 16.20 & 39.11 \\
\hline & & & & & & & & & 32.11 & 15.95 & 39.05 \\
\hline & & & & & & & & & 31.39 & 15.84 & 38.95 \\
\hline & & & & & & & & & 32.71 & 16.02 & 39.03 \\
\hline
\end{tabular}

D.C. Resistance

$$
\begin{aligned}
R & =k\left(l_{1}-l_{0}\right) \\
& =0.00056 \times 16.02=0.008972 \mathrm{ohms}
\end{aligned}
$$

Skin Effect Resistance Ratio $\frac{R^{\prime}}{R}=\frac{l_{1}^{\prime}-l_{0}^{\prime}}{l_{1}-l_{0}}=\frac{32.71}{16.02}=2.042$

Total Inductance of Loop

$$
\begin{aligned}
L & =K\left(n_{1}-n_{0}\right)+\mu\left(l_{1}^{\prime}-l_{0}^{\prime}\right) \\
& =1342 \times 39.03+8.9 \times 32.71 \\
& =52378+291=52669 \text { abhenrys }
\end{aligned}
$$

\section{Calculation of Inductance of Loof}

In the calculation of the inductance of the rectangle of conductor, the following formula was used. It is a slightly modified form of formula 107 by Rosa and Grover in the Bulletin of the Bureau of Standards, vol. 8, p. 155.

$$
\begin{aligned}
L & =4 a\left[\log _{e} \frac{2 b}{d}+\frac{b}{a} \log _{e} \frac{4}{d\left(1+\frac{b}{a}\right)}-\frac{2 b}{a}+\frac{d}{a}\right]+C(a+b) \\
& =A+C(a+b)
\end{aligned}
$$

where $a=\mathrm{cm}$. length of rectangle

$b=\mathrm{cm}$. distance between axes of wires

$\boldsymbol{d}=\mathrm{cm}$. diameter of wires

$A=$ abhenrys external inductance

$C=\frac{L_{i}^{\prime}}{L_{i}}=$ skin effect inductance ratio

$C(a+b)=$ abhenrys internal inductance

$L=$ abhenrys total inductance

In the sample case given above

$$
\begin{aligned}
a & =2703.6 \mathrm{~cm} . \\
b & =61 \mathrm{~cm} . \\
d & =1.168 \mathrm{~cm} . \\
L & =51082+2764 C
\end{aligned}
$$

At 0 frequency $C=1$

$$
\text { and } L_{i}=2764
$$

At $1600 \sim L_{i}^{\prime}=52669-51082=1587$ abhenrys

$$
\frac{L_{i}^{\prime}}{L_{i}}=\frac{1587}{2764}=0.5742
$$


Electromagnetic Revolution-Counter. It was necessary for the observer to work in a soundproof room, distant from the machinery of the laboratory. Therefore, to facilitate the determination of the frequency, which must be measured with precision, the following arrangement was designed and constructed, with the object of determining by means of a stop watch, the time necessary for the completion of a given number of hundreds of revolutions of the generator. The device (Fig. 6) consists of two members-a contact device which closes a circuit at the

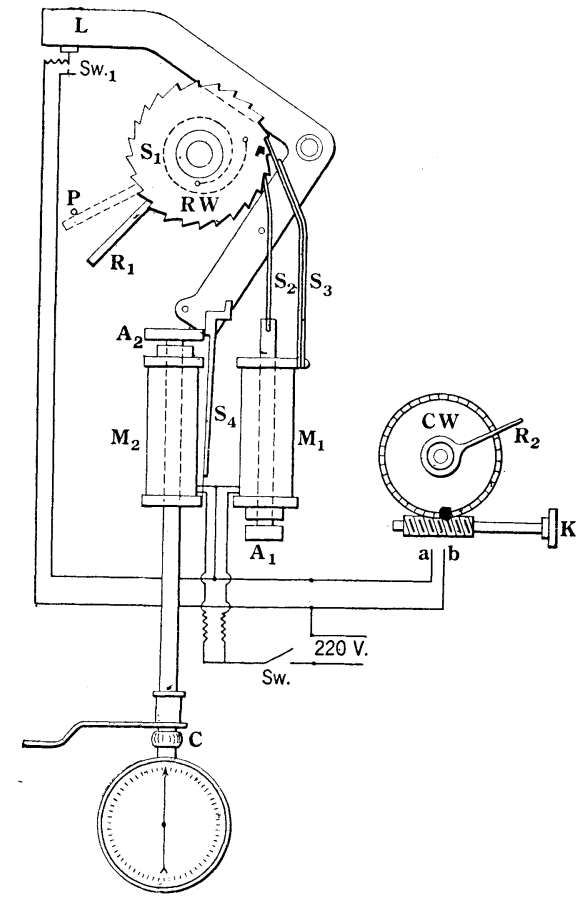

Fig. 6-Electromagnetic Revolution Counter

completion of each one hundred revolutions of the generator shaft, and a device for properly pressing the catch of the stopwatch. Fig. 6 is a schematic diagram of the apparatus. The contactor is at $C W$. It consists of a worm and wheel, with a ratio of 100 to 1 . The wheel carries an arm which, once every revolution, completes the circuit between $a$ and $b$. The magnets $M_{1}$ and $M_{2}$ are thus energized. The gearing runs in a grease box, and a simple coupling, $K$, permits of its ready attachment to any machine. The function of the magnet $M_{2}$, 
is to press the catch of the stopwatch. The watch, being set at zero, on the first contact after closing the switch, $S W$, the armature $A_{2}$ is drawn down, and the stop watch is started. As $A_{2}$ moves down, the latch $S_{4}$ slips over it, and holds it in the depressed position. This prevents the succeeding contacts from stopping and restarting the watch. At the initial, and at every succeeding contact, the magnet $M_{1}$ is energized, and, by means of the ratchet spring $S_{2}$. advances the wheel $R W$ one tooth, in opposition to the spring $S_{1} . S_{3}$ is the retaining pawl, which bears so heavily on $R W$, that it also serves as a brake, and prevents sudden impulses of $M_{1}$ from advancing $R W$ more than one tooth at a time. After a definite number of contacts determined by the position of the pin $P$, the arm $R_{1}$ engages with $S_{4}$, and allows the armature $A_{2}$ to rise. At the next contact, the armature is again depressed and locked. The watch is thus stopped at, say, the completion of 1000 revolu-

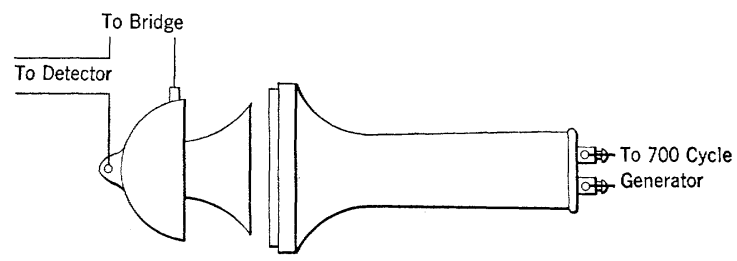

Fig. 7-Telephone Sensitivity Magnifier

tions of the generator. Further operation of the device is then prevented, for the arm $R$ is arrested against the spring $S_{2}$.

The resetting is accomplished by depressing the lever $L$. The springs $S_{2}$ and $S_{3}$ and the latch are thus lifted, and spring $S$, returns the $\operatorname{arm} R$, to the dotted position. At the same time $S W$, makes contact, $M_{2}$ is energized, and the watch reset to zero.

Detectors. The range of frequencies covered was from 60 to $5000 \sim$. A pair of head telephones were used as the detector, both for direct and alternating currents. The telephones were sufficiently sensitive for the frequency range of from 200 to $5000 \sim$. At $60 \sim$ and with direct currents, the arrangement shown in Fig. 7 was used to increase the sensitivity. A telephone transmitter is inserted in the detector circuit. Immediately in front of it is placed a hand telephone, which is traversed by a current from a 700 -cycle generator. It therefore emits a loud sound. The low-frequency current in the detec- 
tor circuit is thus broken up into alternations of that frequency and the effective sensitivity of the telephone to low frequencies is greatly increased. This device is set up in a distant room, and is properly muffled, so that it does not disconcert the observer.

Generators. To cover the range of frequencies, from 60 to $5000 \sim$, three motor-driven a-c. generators were employed; (1) for $60 \sim$, a Mordey machine which forms a part of the regular equipment of the laboratory; (2) for the range 200 to $700 \sim$, a small motor-generator set, originally designed for telephonic work; and (3) for the range from 1000 to $5000 \sim$, a high frequency generator capable, at full speed, (3750 rev. per min.), of giving $10,000 \sim$.

In all cases, speed variations were obtained by the use of resistances in series with the armature of the d-c. driving motor.

The waves of alternating current supplied by these generators to the Heaviside bridge were fairly sinusoidal. Although faint harmonic tones could often be detected in the observer's telephones, there was no difficulty in balancing the bridge to the fundamental tone.

\section{Tests on Round Solid Copper Wires}

Tests were made on a loop of two parallel copper wires, each No. 0000 A.W.G., diameter 0.46 inch $(1.168 \mathrm{~cm}$.), cross-section 1.072 sq. cm., and also on two solid parallel aluminum wires of the same size.

Copper Wires. The loop of copper wire had a length of about 27 meters, differing slightly in different tests. The wire was provided in lengths of 20 feet $(6.1 \mathrm{~m}$.) in selected straight rods. Five tests were made at as many different spacings between the sides of the loop. These spacings or clearances between conductors, were $60 \mathrm{~cm} ., 20 \mathrm{~cm} ., 6.4 \mathrm{~cm} ., 0.8 \mathrm{~cm}$. and $0.03 \mathrm{~cm}$. respectively. Scarfed soldered joints were made between successive rods. The measurements were made in each case at a time of day when the loop was not in sunshine, and when the loop was consequently at a fairly constant and observed temperature. The following Table III gives the results obtained in these tests, at the spacing of $60 \mathrm{~cm}$. Column I gives the spacing, or the distance between adjacent surfaces of the two conductors in the loop. Column II gives the temperature of the wire, by thermometer observation at one point on the loop. Column III gives the frequency. Column IV gives the total 
d-c. resistance of the loop between its terminals, in microhms or thousands of absohms. Column $\mathrm{V}$ gives the skin-effect resistance ratio of the wire in the loop, as obtained from bridge measurement at each frequency. ${ }^{3}$ Column VI gives the corresponding computed resistance skin-effect ratio by formula (71). Column VII gives the ratio of observed to computed values, as appearing in V and VI respectively. Column VIII gives the total measured inductance of the loop, between its terminals, in abhenrys. Column IX gives the total inductance of the loop, within the substance of the wire, after deducting 51,082 abhenrys, the total computed external inductance, including end effect, in the loop. Column $\mathrm{X}$ gives the ratio of the internal inductance at each frequency, to the internal inferred inductance at zero frequency ( 2764 abhenrys) by dividing the entries in IX by 2764 . The last column, No. XI, gives the same ratio as computed through formula (76.)

It will be seen from Column VII, that the observed skineffect resistance ratio differs from the computed value by not more than 1 per cent at any of the observations. Also, comparing Columns $\mathrm{X}$ and XI, it will be seen that the skin-effect reactance-ratio, as observed, is in satisfactory agreement with the calculated value. The percentage agreement is not so close for the reactances as for the resistances; but the internal inductance, varied by skin effect, is only about 2 per cent of the total inductance measured, and consequently, the changes deduced in this small internal inductance cannot be predicted with the same precision as changes in the total apparent resistance. The results on this loop of solid round copper wires, at $60 \mathrm{~cm}$. separating distance, are therefore in very satisfactory accordance with the Bessel-function theory as developed by Heaviside and Kelvin.

The test was repeated with the sides of the loop brought to a separating distance of $20 \mathrm{~cm}$., by fastening the two wires to the edges of a wooden framework $20 \mathrm{~cm}$. wide, and approximately 27 meters long. The same procedure was followed in the third and fourth tests, the wires being fastened to separating wooden strips at distances of 6.4 and $0.8 \mathrm{~cm}$. apart, respectively. In a fifth test, the wires were separated only by a strip

3. In the discussion of skin effect, it is customary to express the conductance effect through the ratio $R^{\prime} / R$. For some purposes, however, its reciprocal, the conductance ratio, $R / R^{\prime}$ is preferable. In this paper the customary expression is given throughout. 


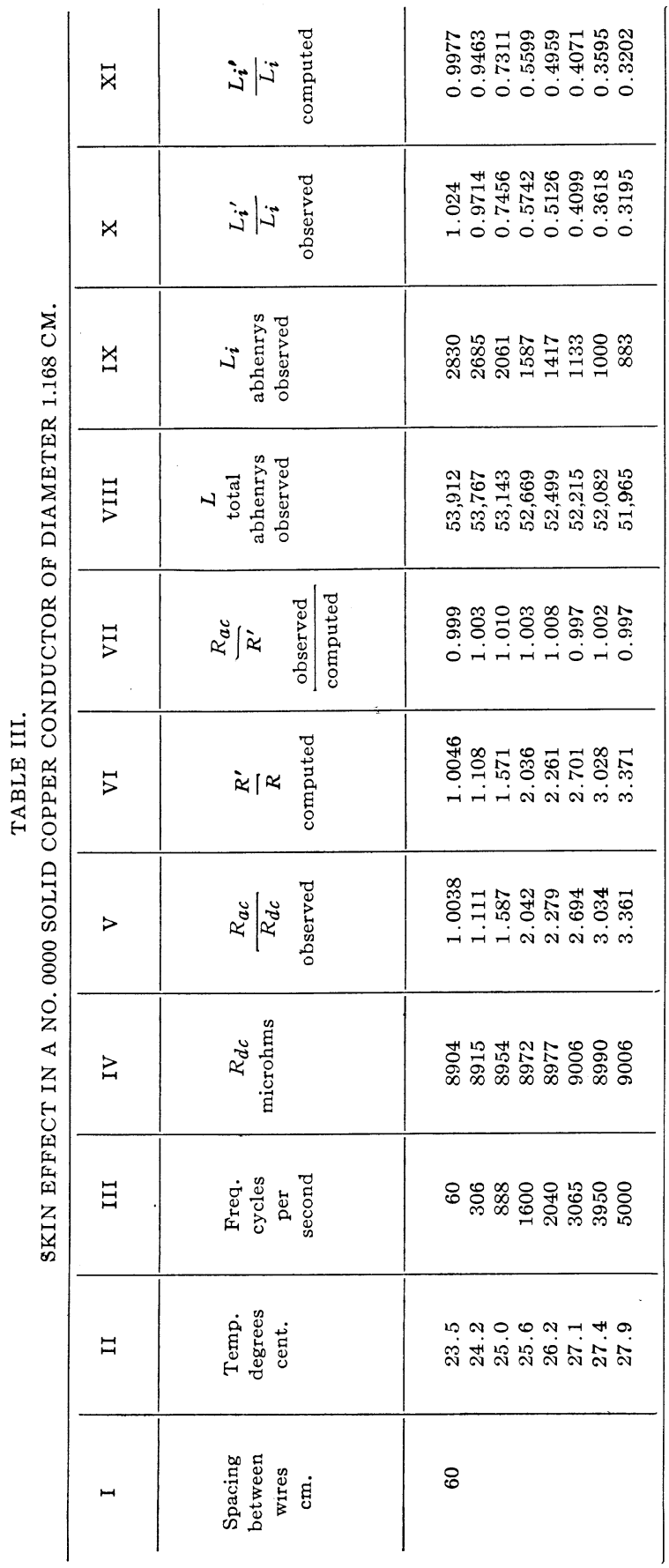


of thin paper, the wires being fastened together over the paper, by insulating tapes at frequent intervals.

The results of the successive tests are recorded in Table IV.

TABLE IV.-SKIN EFFECT IN A NO. 0000 SOLID COPPER CONDUCTOR

\begin{tabular}{|c|c|c|c|c|c|}
\hline $\begin{array}{c}\text { Spacing } \\
\text { cm. } \\
\text { between } \\
\text { conductors }\end{array}$ & $\begin{array}{l}\text { Temp. } \\
\text { degrees } \\
\text { centi- } \\
\text { grade }\end{array}$ & $\begin{array}{c}\text { Frequency } \\
\text { cycles } \\
\text { per } \\
\text { second }\end{array}$ & $\begin{array}{c}R \\
\text { microhms }\end{array}$ & $\frac{R^{\prime}}{R}$ & $\begin{array}{c}L \\
\text { total } \\
\text { abhenrys } \\
\text { observed }\end{array}$ \\
\hline \multirow[t]{10}{*}{20.} & & & & & \\
\hline & 17.2 & 60 & 8640 & 1.0058 & 41,874 \\
\hline & 15.2 & 288 & 8518 & 1.106 & 41,698 \\
\hline & 15.2 & 868 & 8500 & 1.584 & 41,099 \\
\hline & 15.0 & 1663 & 8495 & 2.120 & 40,576 \\
\hline & 14.9 & 2061 & 8512 & 2.313 & 40,437 \\
\hline & 15.2 & 3063 & 8512 & 2.755 & 40,202 \\
\hline & 15.4 & 3112 & 8440 & 2.781 & 40,149 \\
\hline & 15.3 & 3860 & 8440 & 3.067 & 40,071 \\
\hline & 15.4 & 5040 & 8456 & 3.446 & 39,910 \\
\hline \multirow[t]{10}{*}{6.4} & 18.5 & 60 & 8378 & 1.0087 & 30,528 \\
\hline & 18.9 & 266 & 8388 & 1.100 & 30,320 \\
\hline & 19.3 & 582 & 8383 & 1.354 & 30,038 \\
\hline & 20.4 & 923 & 8434 & 1.640 & 29,728 \\
\hline & 20.7 & 1465 & 8411 & 2.037 & 29,352 \\
\hline & 20.9 & 2019 & 8316 & 2.344 & 29,108 \\
\hline & 21.0 & 1992 & 8132 & 2.322 & 29,096 \\
\hline & 21.0 & 3028 & 8132 & 2.851 & 28,819 \\
\hline & 21.6 & 3960 & 8343 & 3.145 & 28,688 \\
\hline & & 5320 & 8472 & 3.558 & 28,546 \\
\hline \multirow[t]{5}{*}{0.8} & & 60 & 8612 & 1.0124 & 15,894 \\
\hline & & 239 & 8612 & 1.132 & 15,602 \\
\hline & & 671 & 8596 & 1.604 & 14,793 \\
\hline & 16.3 & 1068 & 8618 & 1.981 & 14,350 \\
\hline & 16.5 & 1509 & 8624 & 2.330 & 14,007 \\
\hline \multirow[t]{6}{*}{ ' } & 16.9 & 1991 & 8635 & 2.643 & 13,782 \\
\hline & 17.2 & 1988 & 8602 & 2.638 & 13,722 \\
\hline & 17.8 & 2486 & 8626 & 2.912 & 13,560 \\
\hline & 18.0 & 3028 & 8642 & 3.179 & 13,301 \\
\hline & 18.3 & 3880 & 8642 & 3.587 & 13,284 \\
\hline & 18.4 & 4900 & . 8654 & 3.995 & 13,127 \\
\hline \multirow[t]{9}{*}{0.03} & 21.1 & 60 & 8696 & 1.0172 & 10,379 \\
\hline & 21.4 & 236 & 8700 & 1.244 & 9,851 \\
\hline & 21.5 & 740 & 8716 & 2.231 & 8,143 \\
\hline & 21.5 & 1000 & 8735 & 2.688 & 7,594 \\
\hline & 21.2 & 1473 & 8724 & 3.460 & 6,889 \\
\hline & 21.0 & 2038 & 8708 & 4.272 & 6,374 \\
\hline & 20.9 & 3058 & 8716 & 5.522 & 5,805 \\
\hline & 21.0 & 3918 & 8700 & 6.449 & 5,558 \\
\hline & 21.1 & 5170 & 8729 & 7.512 & 5,297 \\
\hline
\end{tabular}

At $20 \mathrm{~cm}$ spacing, the skin-effect resistance ratio does not differ appreciably from the ratio at $60 \mathrm{~cm}$. until the frequency of about $800 \sim$ is reached. Above this frequency, the ratio rises slightly, but distinctly, above the $60 \mathrm{~cm}$. ratio, and at 5000 
$\sim$ exceeds the latter by 2.2 per cent. This increase is to be attributed to proximity effect; i.e. to the effect of the magnetic field from the parallel return conductor.

As the conductors were brought closer, Table IV shows that the skin-effect resistance ratio increased considerably, owing to proximity effect. With the separating distance of $6.4 \mathrm{~cm}$., the rise in resistance ratio was still hardly appreciable below $800 \sim$, and only amounted to 3.3 per cent at $5000 \sim$. With a separation of $8 \mathrm{~mm}$., however, the ratio increased markedly, being 1 per cent extra at $60 \sim$ and 20 per cent extra at $5000 \sim$. At the very small separating distance of about $0.3 \mathrm{~mm}$., the ratio was greatly increased, being 1.3 per cent extra at $60 \sim, 35$ per cent extra at $400 \sim$, and 119.7 per cent extra at $5000 \sim$. While, therefore, to the or- $\dot{x} \mid$ dinary light-and-power frequency of $60 \sim$, the proximity between going and return conductors has very little influence on the skin-effect resistance ratio $R^{\prime} / R$ of these rods, at higher frequencies, the degrees of proximity has a noteworthy effect on this ratio, at separations below $6 \mathrm{~cm}$, as in cabled or flexible-cord conductors.

The ratios of the skin-effect

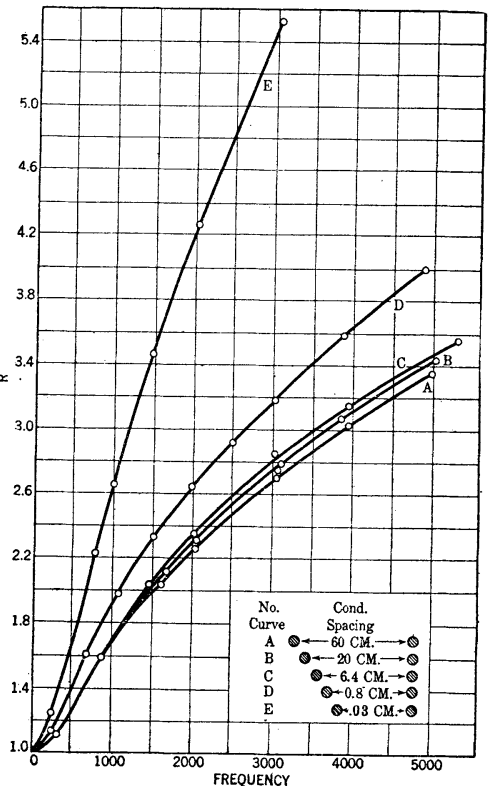

Fig. 8-No. 0000 Solid Copper Conductor

Change of resistance with frequency for different spacing of conductors.

on resistance at different loop widths to that at $60 \mathrm{~cm}$. width are collected in Table V. It will be seen that beyond the frequency of $3000 \sim$, the ratio of increase due to proximity is but slightly affected by further increase in frequency. Thus, while between $60 \sim$ and $3000 \sim$, the effect of bringing the distance between going and returning conductors down to $8 \mathrm{~mm}$. increases the skin-effect resistance ratio from 1.009 to 1.190 times what it would be at $60 \mathrm{~cm}$., and further increase in frequency to $5000 \sim$ only increases the ratio from 1.190 to 1.201 .

Fig. 8 shows the skin-effect resistance ratio $R^{\prime} / R$ for the data 
contained in Tables I, II and III, with ordinates $R^{\prime} / R$ and abscissas impressed frequency.

In regard to parallel solid round wires, at $60 \mathrm{~cm}$. separation,

TABLE V.-SKIN EFFECT IN A NO. 0000 SOLID COPPER CONDUCTOR Data Taken from Curves Showing Relations Between skin Effect and Spacing of Conductors For VARIOUS Frequencies.

\begin{tabular}{|c|c|c|c|}
\hline $\begin{array}{l}\text { Frequency } \\
\text { cycles per } \\
\text { second }\end{array}$ & $\begin{array}{l}\text { Spacing, } \\
\mathrm{cm} \text {. between } \\
\text { wires }\end{array}$ & $\frac{R^{\prime}}{R}$ & $\begin{array}{c}\text { Ratio of skin effect } \\
\text { to that at } 60 \mathrm{~cm} . \\
\text { spacing }\end{array}$ \\
\hline 60 & $\begin{array}{l}0.03 \\
0.8 \\
6.4 \\
20 \\
60\end{array}$ & $\begin{array}{l}1.0172 \\
1.0124 \\
1.0087 \\
1.0058 \\
1.0038\end{array}$ & $\begin{array}{l}1.013 \\
1.009 \\
1.005 \\
1.002 \\
1.00\end{array}$ \\
\hline 400 & $\begin{array}{l}0.03 \\
0.8 \\
6.4 \\
20 \\
60\end{array}$ & $\begin{array}{l}1.590 \\
1.295 \\
1.184 \\
1.180 \\
1.175\end{array}$ & $\begin{array}{l}1.353 \\
1.102 \\
1.008 \\
1.004 \\
1.00\end{array}$ \\
\hline 1000 & $\begin{array}{l}0.03 \\
0.8 \\
6.4 \\
20 \\
60\end{array}$ & $\begin{array}{l}2.688 \\
1.928 \\
1.700 \\
1.690 \\
1.670\end{array}$ & $\begin{array}{l}1.611 \\
1.154 \\
1.017 \\
1.012 \\
1.00\end{array}$ \\
\hline 2000 & $\begin{array}{l}0.03 \\
0.8 \\
6.4 \\
20 . \\
60 .\end{array}$ & $\begin{array}{l}4.210 \\
2.650 \\
2.335 \\
2.295 \\
2.250\end{array}$ & $\begin{array}{l}1.870 \\
1.177 \\
1.037 \\
1.019 \\
1.00\end{array}$ \\
\hline 3000 & $\begin{array}{l}0.03 \\
0.8 \\
6.4 \\
20 . \\
60 .\end{array}$ & $\begin{array}{l}5.450 \\
3.185 \\
2.800 \\
2.740 \\
2.676\end{array}$ & $\begin{array}{l}2.040 \\
1.190 \\
1.048 \\
1.024 \\
1.00\end{array}$ \\
\hline 4000 & $\begin{array}{l}0.03 \\
0.8 \\
6.4 \\
20 . \\
60 .\end{array}$ & $\begin{array}{l}6.530 \\
3.640 \\
3.164 \\
3.112 \\
3.048\end{array}$ & $\begin{array}{l}2.14 \\
1.193 \\
1.038 \\
1.021 \\
1.00\end{array}$ \\
\hline 5000 & $\begin{array}{l}0.03 \\
0.8 \\
6.4 \\
20 . \\
60 .\end{array}$ & $\begin{array}{l}7.380 \\
4.040 \\
3.472 \\
3.430 \\
3.361\end{array}$ & $\begin{array}{l}2.197 \\
1.201 \\
1.033 \\
1.022 \\
1.00\end{array}$ \\
\hline
\end{tabular}

Mr. C. P. Eldred, in preliminary work, during 1914, on the same research, at the Massachusetts Institute of Technology, obtained observations over the range between $60 \sim$ and $5000 \sim$ of the skin-effect resistance ratio in wires of both copper and 
aluminum, which check satisfactorily the Bessel-function calculations. The sizes of wire tested were No. 0 A.W.G. (diameter 0.325 inch, $0.826 \mathrm{~cm}$; 105,500 cir. mils, 0.5345 sq. cm.) and also No. 0000 A.W.G. (diameter 0.46 inch, $1.168 \mathrm{~cm}$.; 211,600 cir. mils $1.072 \mathrm{sq} . \mathrm{cm}$.) in copper and in aluminum.

While, therefore, the Maxwell-Heaviside-Kelvin theory for solid round wires has been checked within the degree of precision of the observations, both for copper and aluminum, up to $5000 \sim, 1.17 \mathrm{~cm}$. diameter, and $60 \mathrm{~cm}$. spacing, very considerable deviations from that theory have been found with closer spacings, owing to proximity effect. This deviation was predicted by Heaviside ${ }^{4}$ in 1884 . Up to the present time, the authors have not found a formula for skin effect in parallel round wires which will take the proximity effect into account.

Stranded Conductors. The stranded conductors tested were of copper and of aluminum.

Copper Stranded Conductor. The copper strand consisted of seven copper wires of the same size (diameter $0.442 \mathrm{~cm}$.), six of these being spiralled around the central one, with a pitch of approximately $14.5 \mathrm{~cm}$. The cross-section of one of these wires is $0.1532 \mathrm{sq} . \mathrm{cm}$. and taking seven times this amount às the cross-section of the strand, we have $1.072 \mathrm{sq} . \mathrm{cm}$., which is the same (to four digits) as that of a No. 0000 A.W.G. solid wire. The results of the tests on a loop of 31.5 meters of this stranded conductor are given in Table VI, for two different spacings; namely, $60.9 \mathrm{~cm}$. and $2.4 \mathrm{~cm}$.

Referring to the observations at $60.9 \mathrm{~cm}$. spacings, it will be observed that the resistance skin-effect ratio $R^{1} / R$, at $60 \sim$, is 1.0052 , representing an increase of only half of one per cent. At $5000 \sim$, however, this ratio increased to 3.54. In Fig. 9, curve $B$ connects the observations here referred to. The broken curve $A$ gives the corresponding skin effect for a solid conductor of equal cross-section, as taken from Tables I and II, or Fig. 8, using the same linear resistance for both the solid and stranded conductors. It appears, therefore, that above $1200 \sim$, the skineffect resistance ratio of this stranded conductor was slightly greater than that of the equi-sectional solid wire, owing apparently to spirality effect, the difference increasing towards higher frequencies.

As is demonstrated in the Appendix, and has already been

4. Bibliography No. 2. 
made known from earlier experimental work in this research, ${ }^{5}$ the skin-effect impedance ratio, as well as its component ratios, is the same for a uniformly and symmetrically subdivided conductor, without twist or helical lay, as in the solid round conductor of the same material and cross-section. In any actual stranded conductor, however, whether of concentric-lay, or rope-lay, there is helical twist in some or all strands. This spiraling of some of the strands necessarily introduces an al-

TABLE VI.-SKIN EFFECT IN 7-STRAND COPPER CABLE

Equivalent to No. 0000 Solid Wire.

\begin{tabular}{|c|c|c|c|c|c|c|c|c|}
\hline I & II & III & IV & $\mathrm{V}$ & VI & VII & VIII & IX \\
\hline \multirow[b]{2}{*}{$\begin{array}{c}\text { Spacing } \\
\mathrm{cm} .\end{array}$} & \multirow[b]{2}{*}{$\mid \begin{array}{c}\text { Temper- } \\
\text { ature } \\
\text { deg. cent }\end{array}$} & \multirow[b]{2}{*}{$\begin{array}{c}\text { Fre- } \\
\text { quency }\end{array}$} & \multirow[b]{2}{*}{$\begin{array}{c}\text { d-c. re- } \\
\text { sistance } \\
\text { ohms }\end{array}$} & \multirow[b]{2}{*}{$\frac{R^{\prime}}{R}$} & \multirow[b]{2}{*}{$\begin{array}{c}L, \text { total } \\
\text { abhenrys }\end{array}$} & \multicolumn{2}{|c|}{$\begin{array}{l}\text { Calculated for } \\
\text { Solid No. } 0000\end{array}$} & \multirow{2}{*}{$\begin{array}{c}\begin{array}{c}\text { Ratio } \\
\text { VI }\end{array} \\
\text { VIII }\end{array}$} \\
\hline & & & & & & $\frac{R^{\prime}}{R}$ & $\begin{array}{l}L, \text { total } \\
\text { abhenrys }\end{array}$ & \\
\hline \multirow{4}{*}{ - } & 12.0 & 60 & 0.00991 & 1.005 & 61,661 & 1.005 & 62,703 & 0.983 \\
\hline & 25.7 & 207 & 0.01051 & 1.035 & 61,578 & 1.051 & 62,627 & 0.983 \\
\hline & 27.0 & 475 & 0.01054 & 1.233 & 61,274 & 1.227 & 62,350 & 0.983 \\
\hline & 26.8 & 925 & 0.01061 & 1.582 & 60,770 & 1.584 & 61,827 & 0.983 \\
\hline \multirow[t]{9}{*}{60.9} & 27.0 & 1468 & 0.01061 & 1.966 & 60,335 & 1.945 & 61,384 & 0.983 \\
\hline & 27.0 & 2010 & 0.01063 & 2.295 & 60,053 & 2.236 & 61,118 & 0.983 \\
\hline & 27.7 & 3065 & 0.01063 & 2.802 & 59,719 & 2.685 & 60,815 & 0.982 \\
\hline & 27.5 & 3920 & 0.01064 & 3.151 & 59,539 & 2.989 & 60,673 & 0.981 \\
\hline & 27.2 & 5040 & 0.01061 & 3.552 & 59,371 & 3.360 & 60,531 & 0.981 \\
\hline & 20.0 & 60 & 0.01004 & 1.004 & 26,017 & & & \\
\hline & 12.4 & 189 & 0.00953 & 1.063 & 25,829 & & & \\
\hline & 12.3 & 682 & 0.00958 & 1.458 & 25,271 & & & \\
\hline & 15.8 & 1090 & 0.01017 & 1.789 & 24,812 & & & \\
\hline \multirow[t]{5}{*}{2.4} & 16.2 & 1540 & 0.00996 & 2.177 & 24,513 & & & \\
\hline & 17.2 & 2010 & 0.01026 & 2.470 & 24,257 & & & \\
\hline & 18.9 & 3112 & 0.01024 & 3.103 & 23,893 & & & \\
\hline & 17.8 & 3960 & 0.00992 & 3.615 & 23,666 & & & \\
\hline & 14.4 & 5040 & 0.00972 & 4.130 & 23,351 & & & \\
\hline
\end{tabular}

ternating magnetic force, or forces, into the interior of the conductor, thereby superposing a "spirality-effect"6 upon the regular skin-effect of the same conductor unspiraled. These two effects are also capable of mutually modifying each other. The subject of "total skin-effect" in spiralled stranded conductors is therefore more complicated than that presented in

5. Pender, Bibliography No. 101.

6. Stirnimann, Bibliography No. 52, and Alfred Hay, No. 70. 
unspiralled stranded or in solid conductors. It is proposed to carry further investigation into this question. Up to the present time, the seven-strand spiralled conductors tested, have shown practically the same skin-effect resistance ratios as equisectional solid wires, up to say $1200 \sim$; while between 1200 and $5000 \sim$, the ratio for the spiralled strands has been slightly greater than that of the solid wires, indicating in these instances, therefore, an added spirality effect. It may be mentioned that both the spirality effect and the skin effect of a subdivided conductor may be substantially annulled by insulating its strands and so transposing them that any one

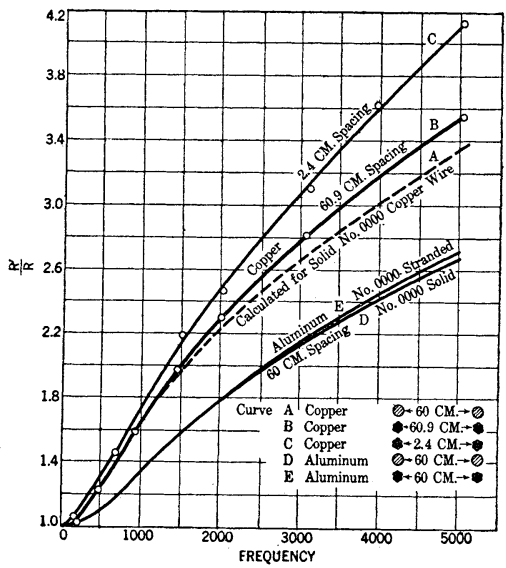

Fig. 9-Seven-Strand CableEquivalent No.0000 Solid Wire

Change of resistance with frequency for different spacing of conductors. strand occupies, in succession, different positions in the cross-section.

Table VI shows, in its last column, that the total loop inductance of the loop of stranded wire appeared to be about 98.3 per cent, or 1.7 per cent less than, the inductance of an equi-sectional solid wire at the same spacing and frequency as calculated by formula ( $D$ Table II.) This result is in substantial conformity with the deductions of $\mathrm{Mr}$. H. B. Dwight ${ }^{7}$, which are to the effect that a loop of two parallel unspiralled seven-strand conductors has 1.3 per cent less linear inductance than the equisectional solid conductors, all other conditions remaining unchanged. The change is attributable to the geometry of the loop system, and is independent of skin effect.

Aluminum Stranded Conductor. The results obtained on two loops of aluminum conductor, one of solid wires, No. 0000 A.W.G. (diameter 0.46 inch $1.168 \mathrm{~cm}$; cross section 211,600 cir. mils 1.072 sq.cm.) and the other of seven-equal-strand conductors, of very nearly equal total cross-section $(1.074 \mathrm{sq} . \mathrm{cm}$. 211,950 cir. mils), are given in Fig. 9 . It will be seen that the skin-effect resistance ratio of the stranded conductor, which

7. Bibliography No. 90 . 
had a lay of $23 \mathrm{~cm}$., is slightly greater than that of the solid conductor above $2000 \sim$, and at $60 \mathrm{~cm}$. spacing.

Strip Conductors. It is generally accepted among electrical engineers, that the skin-effect resistance ratio of flat strip conductors is less than that of equisectional solid round conductors. This proposition has been verified in the tests here reported, except at frequencies below $1000 \sim$, in which a higher skineffect has been observed, in certain copper strips, than is obtained, by calculation, for equisectional round copper wires.

TABLE VII.-SKIN EFFECT IN COPPER STRIPS WITH 60-CM. SPACING BETWEEN CONDUCTORS

\begin{tabular}{|c|c|c|c|c|c|}
\hline $\begin{array}{l}\text { Strip size } \\
\mathrm{cm} .\end{array}$ & $\begin{array}{c}\text { Tem- } \\
\text { perature } \\
\text { deg. cent. }\end{array}$ & $\begin{array}{c}\text { Fre- } \\
\text { quency } \\
\text { cycles per sec. }\end{array}$ & $\begin{array}{l}R, \mathrm{~d} \text {-c. re- } \\
\text { sistance, } \\
\text { ohms }\end{array}$ & $\frac{R^{\prime}}{R}$ & $\begin{array}{c}L, \text { total } \\
\text { abhenrys }\end{array}$ \\
\hline $1.26 \times 0.1575$ & $\begin{array}{l}+6.8 \\
-2.0 \\
-1.8 \\
+6.0 \\
-1.5 \\
-5.0 \\
-1.3\end{array}$ & $\begin{array}{r}225 \\
708 \\
1188 \\
1900 \\
2980 \\
3690 \\
5169\end{array}$ & $\begin{array}{l}0.0563 \\
0.0539 \\
0.0541 \\
0.0554 \\
0.0541 \\
0.0534 \\
0.0543\end{array}$ & $\begin{array}{l}1.004 \\
1.038 \\
1.085 \\
1.161 \\
1.261 \\
1.326 \\
1.426\end{array}$ & $\begin{array}{l}71,291 \\
71,147 \\
70,970 \\
70,679 \\
70,383 \\
70,247 \\
68,765\end{array}$ \\
\hline $2.52 \times 0.158$ & $\begin{array}{r}+0.9 \\
0.5 \\
0.1 \\
0.2 \\
0.0 \\
0.0\end{array}$ & $\begin{array}{r}491 \\
1022 \\
2007 \\
3078 \\
3920 \\
4980\end{array}$ & $\begin{array}{l}0.0260 \\
0.0259 \\
0.0259 \\
0.0259 \\
0.0259 \\
0.0259\end{array}$ & $\begin{array}{l}1.065 \\
1.169 \\
1.314 \\
1.430 \\
1.506 \\
1.593\end{array}$ & $\begin{array}{l}60,482 \\
60,083 \\
59,699 \\
59,512 \\
59,402 \\
59,349\end{array}$ \\
\hline $3.81 \times 0.159$ & $\begin{array}{l}5.0 \\
0.4 \\
5.0 \\
1.9 \\
5.2 \\
1.8\end{array}$ & $\begin{array}{r}229 \\
1136 \\
1730 \\
2645 \\
3787 \\
5050\end{array}$ & $\begin{array}{l}0.0173 \\
0.0171 \\
0.0173 \\
0.0172 \\
0.0174 \\
0.0172\end{array}$ & $\begin{array}{l}1.042 \\
1.283 \\
1.363 \\
1.478 \\
1.588 \\
1.697\end{array}$ & $\begin{array}{l}55,576 \\
54,766 \\
54,586 \\
54,422 \\
54,303 \\
54,241\end{array}$ \\
\hline
\end{tabular}

Three copper-strip conductors were employed in the different tests, each approximately $1 / 16$ inch, $(1.59 \mathrm{~mm}$.) in thickness; namely, nominal $\frac{1}{2}$-inch, 1 -inch, and $1 \frac{1}{2}$-inch; actually $1.26 \times$ $0.1575 \mathrm{~cm}$., $2.52 \times 0.158 \mathrm{~cm}$. and $3.81 \times 0.159 \mathrm{~cm}$. One strip at a time was supported by vertical slits in wooden blocks, to form a straight loop, with parallel sides at the proper separating distance. Commencing with $60-\mathrm{cm}$. spacing, it was found to make no appreciable difference whether the strips forming the loop were in the same horizontal, or in parallel vertical 
planes. When, however, the separating distance was about $10 \mathrm{~cm}$., the relative setting of the two strips began to make a difference in the results, owing to proximity effects. This difference became very large when the separating distance was reduced to about $1 \mathrm{~mm}$.

Table VII gives the results of the observations for the above mentioned sizes of strip, at the separating distance of approximately $60 \mathrm{~cm}$. It will be seen that the skin-effect resistance ratio of the narrowest strip was only 1.0043 at $225 \sim$; so that no attempt was made to measure this ratio at $60 \sim$. The records in the table are plotted in the curves of Fig. 10, at $A, B$ and $C$ respectively, Curve $D$, which is slightly concave upwards, represents the corresponding computed ratio for infinitely

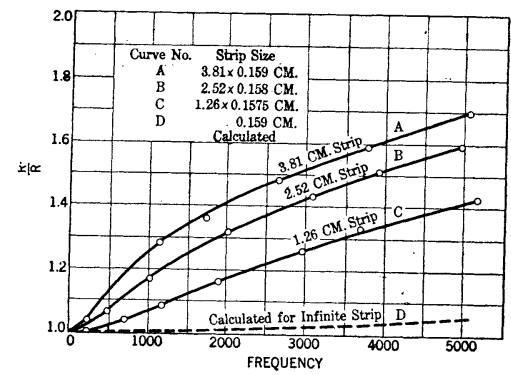

Fig. 10-Copper Strips Spaced $60 \mathrm{cM}$.

Change of resistance with frequency for different width strips. wide copper strip, by formula (103).

It is evident that at $60 \mathrm{~cm}$. spacing, which is practically equivalent to infinite spacing, the calculated resistance ratio $R^{\prime} / R$ is very much less than the observed ratio, particularly at the higher frequencies. Moreover, it might be supposed at first thought, that a strip nearly $4 \mathrm{~cm}$. wide, would approach the behavior of an infinitely wide strip more closely than a strip $1.26 \mathrm{~cm}$. wide; whereas the reverse was the case, in these observations. The large deviations from theory here presented, at first threw some doubt on the measurements. These were, however, repeated, with substantially the same results, not only on the same bridge by different observers, and under different conditions at the Massachusetts Institute of Technology, Boston, but also upon another loop of the same strip, with entirely different measuring apparatus, at Pierce Hall, in Cambridge. There is at present no reason to doubt the results indicated in Fig. 10 outside the range of the usual small errors of observation. The authors have not been able to discover any published measurements of the skin effect in linear flat strips, at any spacing.

The reason for the large discrepancies between the theory for infinite strips, and the observations for strips of one to four 
cm. width, is believed to be that the alternating magnetic flux surrounding the active strips, being more or less cylindrical in distribution, cuts through the substance of the strip to a greater or less extent, and in so doing dissipates power by eddy currents. Only in the case of extremely wide strips, may the alternating magnetic flux be properly regarded as lying in planes parallel to the surfaces of the strip, so as not appreciably to intersect therewith. There are two experimental evidences for this belief; namely (1) the distribution of magnetic flux paths around the active strips, as obtained by the method of scattering iron filings and (2) the fact that with the parallel strips brought close together, the skin effect was much greater when they lay in one and the same plane, than when they were supported in parallel planes.

Fig. 11 shows the magnetic flux distribution around a 2.5-cm. strip, $1.6 \mathrm{~mm}$. thick, when carrying $107 \mathrm{am}$ peres at $838 \sim$, the return conductor being remote. It is evident that a considerable amount of this flux cuts the substance of the strip near the edges; so that it is not surprising that the extra power loss due to eddy currents in the strip should markedly increase the skin-effect.

Fig. 12 shows that when the two parallel strips forming the loop are placed in the same plane, edge to edge, and nearly touching, with 120 amperes at $858 \sim$, practically all the magnetic flux threading through the loop has to cut some portion of the strip. We might, therefore, reasonably expect a relatively large excess loss of power by eddy currents in such a case, as observation actually showed.

Fig. 13 shows on the other hand, that when the two parallel strips forming the loop are placed in parallel planes, and separated only by a strip of paper, the alternating magnetic flux, with 120 amperes and $858 \sim$, was very feeble. We should, therefore, expect to find comparatively little excess loss of power by eddy currents under such conditions, as actual observation revealed.

The results for the 2.5 -cm. strips, at different spacings and relative positions, are given in Fig. 14 . It will be seen that the smallest skin-effect ratio is with the shortest spacing $(0.5 \mathrm{~mm}$.) and with the strips in parallel planes as in Fig. 13. This is the result nearest to that given by the theory for infinitely wide strips. On the other hand, the largest ratio is at nearly the same spacing (one mm.), but with the strips lying in one and 
PLATE CXXX,

A. I. E. E.

VOL. XXXIV, 1915

Magnetic Fields Surrounding Copper Strips

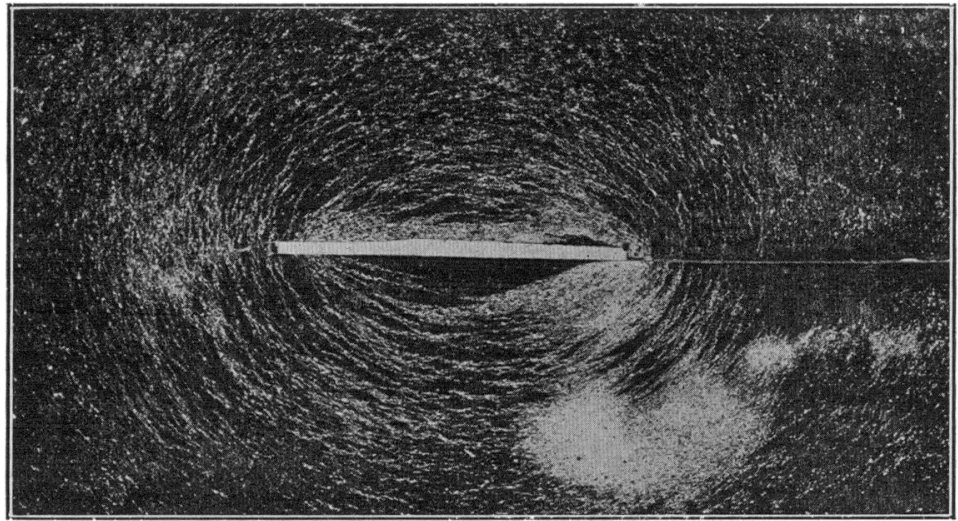

Fig. 11-Strip Carrying 107 Amperes at $838 \sim$ A-C.

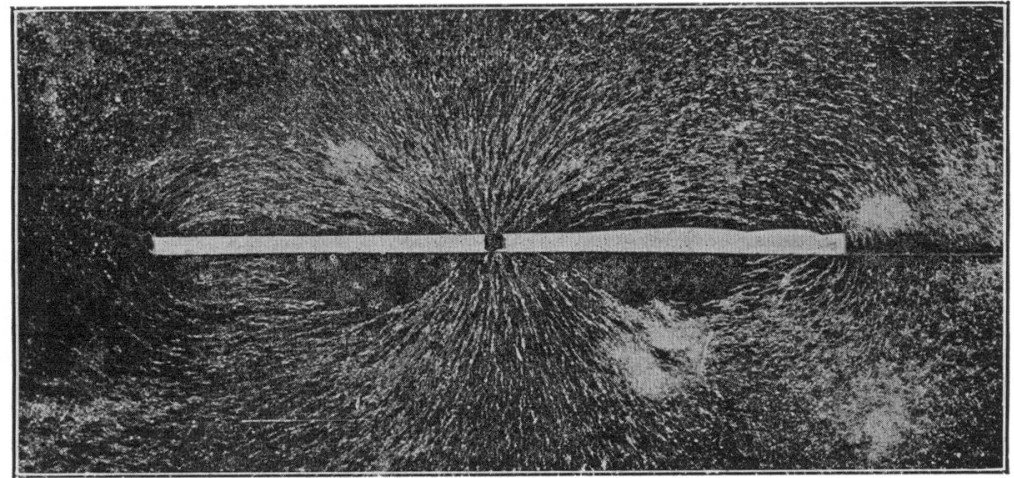

Fig. 12-Outgoing and Return Strips Carrying 120 Amperes at $858 \sim \mathrm{A}-\mathrm{C}$.

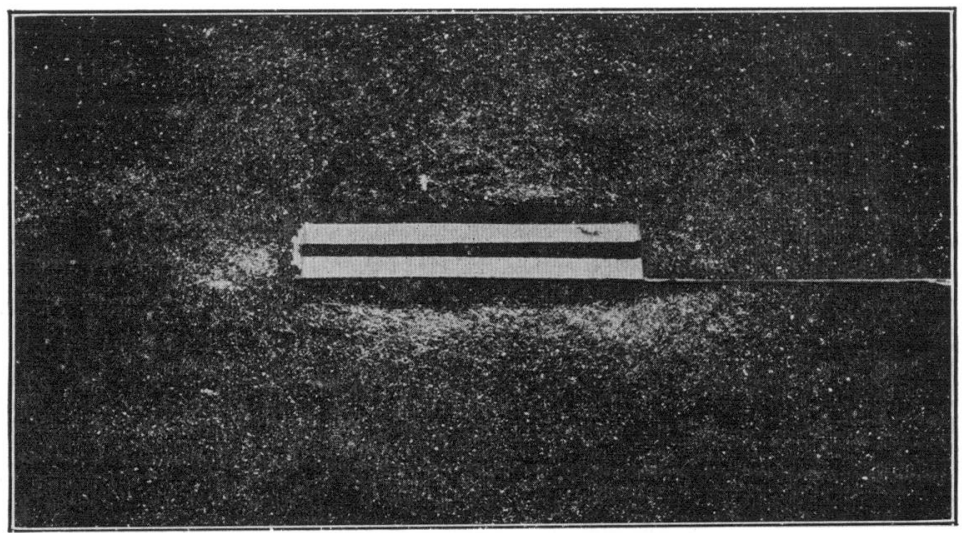

[KENNELLY, LAWS AND PIERCE]

Fig. 13-Outgoing and Return Strips Adjacent Carrying 120 AmPERES AT $858 \sim$ A-C. 
the same plane as in Fig. 12. Between these extreme limits, lie all the other series, at least within the range of 0 to $4000 \sim$. The curve belonging to the series with 0.5 - $\mathrm{mm}$. spacing bends upwards, whereas all the others bend downwards beyond $500 \sim$. This appears to be related to the distributions of alternating magnetic fields. The theoretical curve also bends upwards. The broken line gives the ratios for a circular wire of the same cross-section as the strip, and at large spacing.

Corresponding results for the $3.8-\mathrm{cm}$. strips are indicated in Fig. 15. Here again, the difference is very marked between

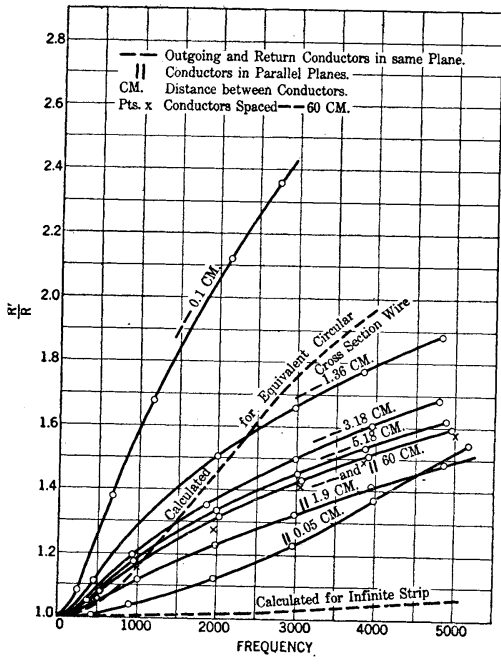

Fig. 14-Copper Strip 2.52 By $0.158 \mathrm{CM}$.

Change of resistance with frequency for different spacing of conductors.

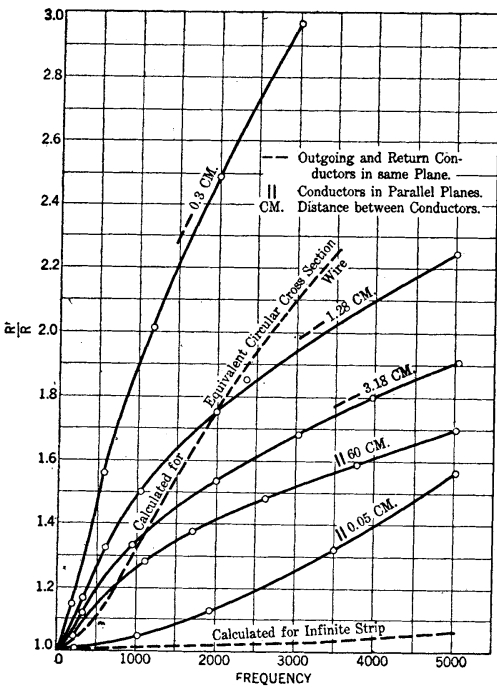

Fig. 15-Copper Strip 3.81 BY 0.159 C.M.

Change of resistance with frequency for different spacing of conductors.

the ratios for the smallest spacings $3 \mathrm{~mm}$. and $0.5 \mathrm{~mm}$., in the same and in parallel planes respectively, due to proximity effects. At $4000 \sim$, the former is about 3.4 and the latter 1.4; while the theoretical value for infinite strip of the same thickness is about 1.04 .

The results concerning the total loop inductances for the $3.8-\mathrm{cm}$. strip, at different spacings and settings, are given graphically in Fig. 16. It will be seen that not only is the total inductance a minimum for the case of parallel spacing at 0.5 $\mathrm{mm}$., but also the change of inductance with frequency; whereas 
the greatest change of inductance with frequency is in the case of $3-\mathrm{mm}$. spacing in the same plane.

It is evident from the foregoing results that in the case of parallel flat strips, the proximity effects are very variable, may be relatively large, and depend in large measure upon the relative disposition of the two conductors.

It is open to discussion whether the proximity effect in such conductors is materially affected by the current strength in

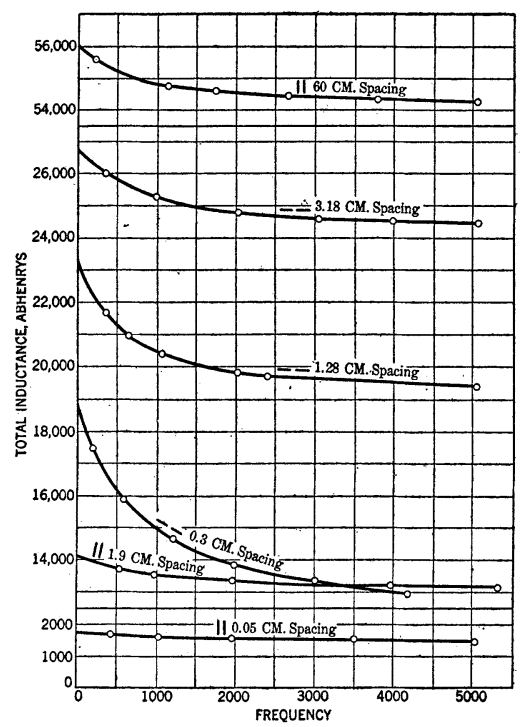

Fig. 16-Copper Strip 3.81 BY $0.159 \mathrm{CM}$.

Change of inductance with frequency for different spacing and positions of conductors.

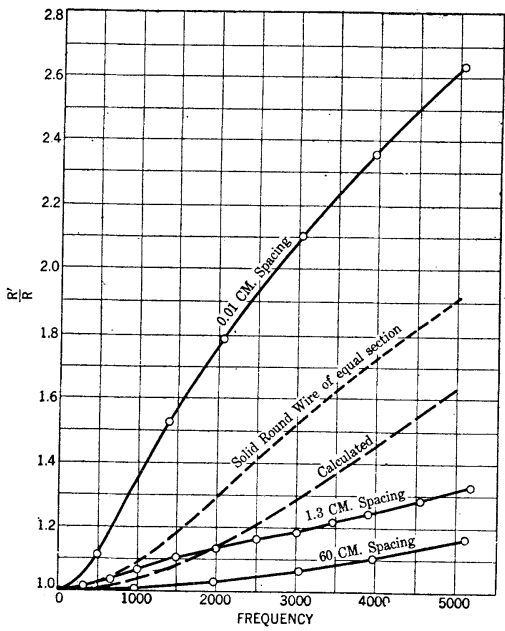

Fig. 17-Whole Copper TubeOutside Diameter 1.266 cm., WALLS $0.159 \mathrm{CM}$.

Change of resistance with frequency for different spacing of conductors.

the loops. Between the limits of about 0.1 ampere and 3.0 amperes in the loops, at any frequency within the reported range, no change in the impedance ratio with current was observable.

\section{Tubular Conductors}

In order to measure skin effect in copper tubes, 90 feet $(27.4$ m.) of hard copper tube was obtained, $\frac{1}{2}$ inch in external diameter $(1.26 \mathrm{~cm}$.) with $.1 / 16$ inch wall $(1.6 \mathrm{~mm}$.) in selected 15 -foot lengths $(4.56 \mathrm{~m}$.), and supported on insulators in a rec- 
tangular loop, like the other conductors. The tubes were jointed by means of thin sleeves of copper, soldered over the ends. The loop had square ends, and was $13.1 \mathrm{~m}$. long. Tests were made at three spacings between parallel tubes, namely, $60 \mathrm{~cm} ., 1.3 \mathrm{~cm} ., 0.1 \mathrm{~mm}$. The results of these tests are given in the accompanying Table No. VIII and Fig. 17. It will be observed that at $60-\mathrm{cm}$. spacing, where the proximity effect is

TABLE VIII.-SKIN EFFECT IN A COPPER TUBE.

$1.266 \mathrm{CM}$. OUTSIDE DIAMETER 0.159 CM. WALl.

\begin{tabular}{|c|c|c|c|c|c|}
\hline $\begin{array}{l}\text { Spacing } \\
\mathrm{cm} .\end{array}$ & $\begin{array}{l}\text { Temperature } \\
\text { deg. cent. }\end{array}$ & $\begin{array}{c}\text { Frequency, } \\
\text { cycles per sec. }\end{array}$ & $\begin{array}{l}R \text {, d-c. resist- } \\
\text { ance, ohms }\end{array}$ & $\frac{R^{\prime}}{R}$ & $\begin{array}{l}L, \text { total } \\
\text { abhenrys }\end{array}$ \\
\hline \multirow[t]{7}{*}{60.} & 4.2 & 222 & 0.01636 & 1.0004 & 25,125 \\
\hline & 6.0 & 385 & 0.01626 & 1.0015 & 25,143 \\
\hline & 4.8 & 963 & 0.01634 & 1.0088 & 25,121 \\
\hline & 5.4 & 1967 & 0.01637 & 1.0298 & 25,108 \\
\hline & 5.9 & 3030 & 0.01647 & 1.0633 & 25,109 \\
\hline & 5.8 & 3962 & 0.01646 & 1.1046 & 25,098 \\
\hline & 5.2 & 5120 & 0.01635 & 1.167 & 25,053 \\
\hline \multirow[t]{11}{*}{1.3} & 7.5 & 320 & 0.01580 & 1.013 & 7,583 \\
\hline & 7.4 & 994 & 0.01580 & 1.067 & 7,461 \\
\hline & 7.7 & 1987 & 0.01580 & 1.132 & 7,361 \\
\hline & 7.5 & 3004 & 0.01578 & 1.188 & 7,311 \\
\hline & 6.2 & 3915 & 0.01575 & 1.241 & 7,285 \\
\hline & 5.5 & 5180 & 0.01572 & 1.327 & 7,090 \\
\hline & -0.2 & 4540 & 0.01559 & 1.288 & 7,279 \\
\hline & -0.1 & 3467 & 0.01559 & 1.216 & 7,303 \\
\hline & 0.0 & 2482 & 0.01559 & 1.160 & 7,343 \\
\hline & 0.0 & 1482 & 0.01560 & 1.102 & 7,405 \\
\hline & 0.7 & 658 & 0.01561 & 1.039 & 7,519 \\
\hline \multirow[t]{6}{*}{0.01} & 8.3 & 488 & 0.01532 & 1.114 & 3,443 \\
\hline & 8.7 & 1384 & 0.01530 & 1.524 & 2,825 \\
\hline & 8.8 & 2040 & 0.01530 & 1.787 & 2,543 \\
\hline & 8.6 & 3030 & 0.01530 & 2.104 & 2,258 \\
\hline & 8.8 & 3930 & 0.01528 & 2.364 & 2,079 \\
\hline & 8.7 & 5040 & 0.01526 & 2.630 & 1,950 \\
\hline
\end{tabular}

negligible, the skin-effect resistance-ratios are all relatively small, and much lower than those of other types of conductor tested in this research. With the spacing of only $0.1 \mathrm{~mm}$; i.e. with the tubes lashed side by side, and separated only by a thin strip of paper, the proximity effect was very marked, and was also sensitive to changes in the temperature of the surrounding air.

The theory of tubular conductors remote from disturbing 
magnetic fields, has been given by Heaviside ${ }^{8}$ and by Russell. ${ }^{9}$ It involves Bessel functions of both the first and second kinds, and is complicated relatively to that of solid wires. The formulas developed for resistance-ratio are relatively lengthy and are only approximations. A much simpler approximate resistance-ratio formula for engineering purposes, is obtained by considering a tube as the equivalent of a strip with no disturbance at edges; i.e., behaving like a strip of infinite width. Strictly speaking, the curvature of the tubular conductor prevents the rigid application of the flat-strip theory; so that this theory can only be expected to apply to tubes of thin wall and large diameter. The formula for the resistance ratio of a flat strip is given in (103) of the Appendix. The full wall thickness of the tube is here regarded as corresponding to $X$, the half-strip thickness. ${ }^{10}$ Applying this formula to the case considered, we obtain the broken line marked "calculated" in Fig. 17. It will be seen that the calculated ratios are all much larger than the observed ratios; although the shapes of the two curves considered, are similar. It was found, however, that if instead of taking the full wall thickness $0.16 \mathrm{~cm}$. for $X$, we take two thirds of that thickness in the formula, i.e., $X=$ $0.106 \mathrm{~cm}$., the resistance ratio thus calculated agrees satisfactorily with the observed values over the entire range of frequency investigated. It is not, however, apparent why only twothirds of the wall thickness should be included in the formula, and perhaps this fraction applies only to the particular size of tube employed; so that this must be regarded as an empirical rule for the present.

Slotted Tube. Seeing that the resistance ratios for copper tubes were less than those offered by flat-strip theory; whereas actual narrow copper strips gave ratios in excess of that theory, it was decided to follow the behavior of the tubes as they were mechanically altered towards the form of flat strips. The first step in this mechanical transformation was to cut a single slot 0.02 inch wide $(0.5 \mathrm{~mm}$.) along the entire length on one side of the tube. The slotted tubes were then rejointed and supported in a long rectangular loop of the same length as before (13.1 m.), and the tests repeated for two spacings; namely, 60 $\mathrm{cm}$. and $0.1 \mathrm{~mm}$. In the latter case, two tests were made, one

8. Bibliography No. 2.

9. Bibliography No. 51.

10. Pender, Bibliography No. 101. 
with the slots turned in, and the other with the slots out; i.e. with the slots at their minimum and maximum permissible distances apart, respectively. It was found that, at $60 \mathrm{~cm}$., there was no perceptible change from the previous test at that spacing. That is, the skin-effect impedance-ratio of the tube, remote from disturbing a-c. magnetic fields, was as nearly as could be determined the same, whether the tube was complete, or had a thin slot cut in it longitudinally. At the $0.1-\mathrm{mm}$. spacing, however, the resistance ratio appeared to be distinctly less than in the unslotted condition; but seeing that the loop

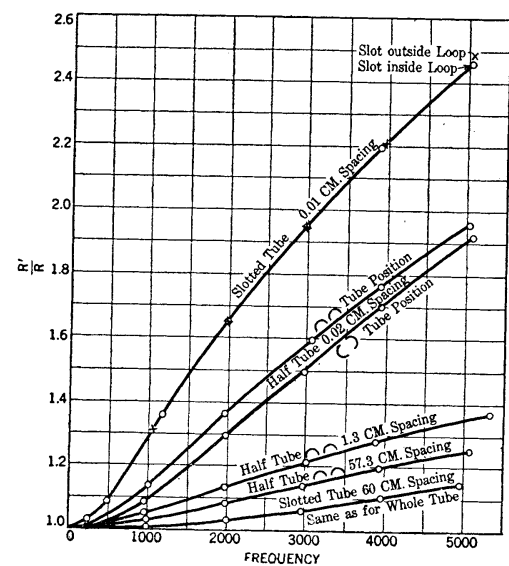

Fig. 18-Slotted and Half CopPer Tubes-Outside Diameter 1.266 cM., Walls 0.159 cM., Slot $0.0508 \mathrm{CM}$.

Change of resistance with frequency for different spacing and positions of conductors. had to be taken down, reassembled and reerected between the two tests, with perhaps somewhat different mechanical pressures on the separating paper strip, in the two cases, it is considered unsafe to rely upon the deduction that slotting a tube reduces its proximity effect, as is apparently indicated in Fig. 18. There was no appreciable difference between the results in the two tests at $0.1 \mathrm{~mm}$., with the slots turned inwards and outwards respectively.

Half Tubes. The loop of slotted tube was again disassembled, and the conductor split into two half tubes, by cutting a new horizontal slot on the opposite side to the first. The halftubes were then jointed together to form a rectangular loop $13.1 \mathrm{~m}$. long. This half-tube conductor loop was then tested at three spacings; namely, $57.3 \mathrm{~cm}$., $1.3 \mathrm{~cm}$. and $0.2 \mathrm{~mm}$. The results of these tests are indicated in Fig. 18. It will be observed that at $57.3 \mathrm{~cm}$., with negligible proximity effect, the resistance ratios are markedly higher than with whole tubes. At 1.3 cm., with the half tubes placed as though lying inverted, side by side, on a table, the resistance ratios were distinctly, although not greatly, increased-by proximity effect. At the $0.2 \mathrm{~mm}$. spacing, two tests were made, i.e., one with the halftubes placed opposite each other, as though to form the original 
tube, and the other as in the test at $1.3-\mathrm{cm}$. spacing. The former condition had a lower proximity effect than the latter, at least as far as $5000 \sim$, as indicated in Fig. 18.

Summing up, therefore, the results with tubes and half tubes, it may be stated that the skin-effect of tubes is much less than that of other forms of equisectional conductor. When the tube is cut into longitudinal halves, and one of the halves is removed, the skin-effect of the remaining half tube is considerably increased, and approaches, but is always less than, that of an equisectional flat strip.

In conclusion, we desire to express our acknowledgments to Prof. Harold Pender for his valuable contribution to the earlier stages of this research, both in design and in direction; also to Prof. D. C. Jackson for valuable suggestions during the progress of the work, also to the thesis work of Messrs. F. H. Achard and H. E. Randall in 1912-1913, on the preliminary work. We are also indebted to Dr. S. B. Jewett for help in procuring special apparatus, and to Dr. E. B. Rosa of the Bureau of Standards, for the courteous loan of inductance standards.

\section{Conclusions}

1. The skin effect impedance-ratio of solid round wires of copper and aluminum, have been found to be in close accordance with the Bessel-function Heaviside-Kelvin theory, up to the highest frequency used in the tests $(5000 \sim)$.

2. At frequencies below $100 \sim$, the proximity effect is relatively small. That is, the close proximity of the going and returning parallel conductors does not greatly increase the skin effect. At higher frequencies, however, the proximity effect becomes very marked. All the forms of conductors tested developed marked proximity effects, near the higher frequencies, when brought close together. The proximity effect was usually imperceptible at separating distances above say $20 \mathrm{~cm}$.

3. Stranded copper or aluminum conductors, without twists, appear to have the same skin-effect impedance-ratio as their equisectional solid conductors. Twisting and spiraling the strands, introduces a change in the ratio, called the spirality effect. In the very few cases of stranded conductors, thus far tested, the spirality effect added slightly to the skin effect.

4. Flat copper strips possess a much larger skin-effect resistance-ratio than corresponds to the theory for indefinitely wide strips. The discrepancy has shown itself to be due to the eddy- 
current losses from the alternating magnetic flux linked with the strips, and intersecting them, especially near their edges. The proximity effect in strips is large near the higher frequencies, and is considerably affected by the relative positions of the going and returning strip-conductors.

5. Copper tubes have less skin effect than equisectional conductors of any other form tried. In the single size tested, the skin effect. was that corresponding to indefinitely wide strip of thickness 33 per cent greater than that of the tube wall.

6. Half tubes, prepared by slitting a copper tube, have much more skin effect than the whole tube from which they are made. They have however less skin effect than flat strips of the same thickness and cross-section.

7. To reduce skin-effect in a pair of straight parallel singlephase conductors at frequencies up to $5000 \sim$, the tests have corroborated the existing belief that the conductors should be tubular, or hollow cylinders, separated by more than $20 \mathrm{~cm}$. On the other hand, to obtain the maximum current-distortion effect, solid rods of large diameter should be used, in close mutual proximity. Copper strips while showing, in most cases, less skin effect than equisectional solid rods, have much more skin effect than is generally supposed.

\section{APPENDIX I}

\section{Theory of Conditions for Balance on the Heaviside BRIDGE}

With the arrangement shown in Figs. 1 and 2, a shifting of the balance point, $d$, to the left, transfers resistance from the arm $X$ to the $\operatorname{arm} P$. At the same time, a certain amount of inductance in the slide wire, and in the mutual induction between the slide-wire and the detector circuit is also transferred.

To obtain $R$ and $L$, the resistance and the inductance of the loop under test:

let $r=$ the resistance per centimeter of the slide wire (ohms per $\mathrm{cm}$.)

$\mu=$ twice the inductance change per centimeter of the slide wire, due to the change in position of the slider (henrys per $\mathrm{cm}$.)

$k=$ twice the resistance per unit length of the slide wire (ohms per cm.)

$L_{\mathrm{P}}{ }^{\prime}=$ the inductance of the $\operatorname{arm} P$, excluding the slide wire (henrys.) 
$L_{\mathbf{x}}{ }^{\prime}=$ the inductance of the arm $X$, excluding the slide wire and the inductance $L_{\mathbf{x}}$ (henrys.)

$L_{\mathbf{x}}=$ inductance of the experimental line to be determined. (henrys).

$R_{\mathrm{x}}=$ resistance of the experimental line, to be determined (ohms).

$m_{0}=$ mutual inductance necessary to balance bridge, when the line is short-circuited (henrys).

$m_{1}=$ mutual inductance necessary to balance bridge when the line is in circuit (henrys).

$K=$ twice the mutual inductance per turn of the secondary winding (henrys per turn).

$n_{0}-n_{1}=$ change in the number of turns on the secondary of the mutual inductance, which is necessary to restore balance when the short circuit is removed.

$R_{\mathrm{P}}{ }^{\prime}=$ resistance of the $\operatorname{arm} P$, excluding the slide wire (ohms) $R_{\mathbf{x}}{ }^{\prime}=$ resistance of the arm $X$ excluding the slide wire and the resistance $R_{\mathrm{x}}$ (ohms).

$l_{0}=$ reading of slide wire when the line is short-circuited (cm.).

$l_{1}=$ reading of slide wire when the line is in circuit $(\mathrm{cm}$.$) ,$

$l=$ total length of slide wire $(\mathrm{cm}$.)

By (7) from the first balancing

$$
R_{\mathbf{P}}{ }^{\prime}+l_{0} r=R_{\mathbf{x}}{ }^{\prime}+\left(l-l_{0}\right) r
$$

from the second balancing

$$
\begin{array}{rlr} 
& R_{\mathrm{P}}{ }^{\prime}+l_{1} r=R_{\mathrm{x}}{ }^{\prime}+\left(l-l_{1}\right) r+R_{\mathrm{x}} & \multicolumn{2}{c}{\text { ohms (10) }} \\
\therefore & R_{\mathrm{x}}=2 r\left(l_{1}-l_{0}\right) & \text { “ } \\
\text { or } \quad & R_{\mathrm{x}}=k\left(l_{1}-l_{0}\right) & \text { “ }
\end{array}
$$

By (8), from the first balancing

$$
L_{\mathrm{P}}{ }^{\prime}+\frac{\mu l_{0}}{2}=L_{\mathbf{x}^{\prime}}{ }^{\prime}+\frac{\mu}{2}\left(l-l_{0}\right)+2 m_{0} \quad \text { henrys }
$$

from the second balancing

$$
\begin{aligned}
L_{\mathrm{p}}{ }^{\prime}+\frac{\mu l_{1}}{2} & =L_{\mathbf{x}}{ }^{\prime}+\frac{\mu}{2}\left(l-l_{1}\right)+2 m_{1}+L_{\mathbf{x}} \\
L_{\mathbf{x}} & =2\left(m_{0}-m_{1}\right)+\mu\left(l_{1}-l_{0}\right) \\
\text { and } \quad L_{\mathbf{x}} & =K\left(n_{0}-n_{1}\right)+\mu\left(l_{1}-l_{0}\right)
\end{aligned}
$$

The working formulas are therefore (12) and (16). 


\section{APPENDIX II}

Theory of Skin Effect in Solid Cylindrical Uniform Conductors with Remote Return

This theory was originally developed by Clerk Maxwell in 1873 , and has, under certain variations of detail, been given by a number of writers since that date, as an examination of the references mentioned in the Bibliography will reveal. The essential steps of the reasoning are, however, repeated here; because the final solutions offered are believed to have certain advantages for engineering computations.

In Fig. 19, let $A B C$ be the cross-section of a uniform straight cylindrical conductor of radius $X \mathrm{~cm}$. with axis at 0 , and surrounded by air, oil, or other non-magnetic dielectric. Let the

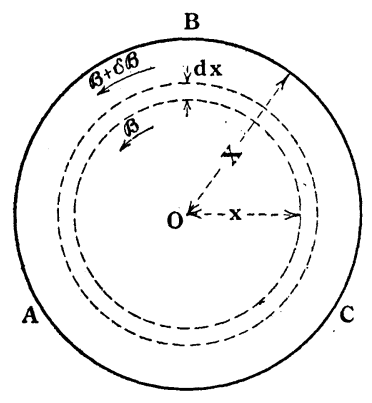

Fig. 19

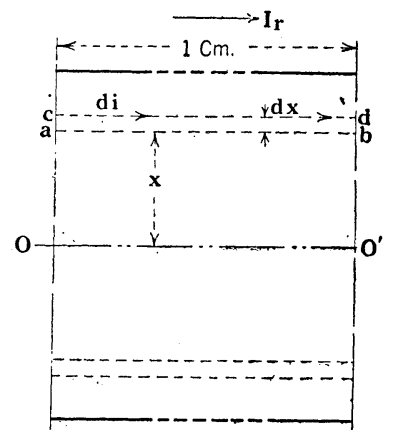

FIG. 20

wire be supposed to carry a sinusoidal alternating current $I_{r}$, r.m.s. absamperes ${ }^{11}$, and to be so far remote from the parallel return conductor, that the magnetic field from the latter is insignificant at the region occupied by $A B C$. Then the external alternating magnetic field of this conductor $A B C$ will be just the same in magnitude and phase as the alternating current $I_{r}$ would produce if there were no skin effect. That is, the skin effect is confined within the radius $X$. It affects the magnitudes and phases of the electric and magnetic fluxes within the conductor; but we may assume that (1), by symmetry, these fluxes are symmetrically distributed with respect to the axis $O$; so that if either the magnetic flux-density, or the current density, has a given instantaneous value at some radius $x$; then the same value will be developed, at that instant, at all points whose radius is $x ;(2)$,

11. The prefix ab- or abs- indicates a C.G.S. magnetic unit. 
that there is at no time during the steady state, a radial component of electric or magnetic flux, that is, all fluxes are either parallel to the axis, or in cylindrical lines around the axis. By the "steady state" is meant the alternating-current state which is finally reached after the application of impressed alternating voltage in the circuit.

Let $i_{x}=$ the instantaneous current density at radius $x$ (absamperes per sq. cm.)

$\mathfrak{F}_{x}=$ the magnetic intensity at radius $x$ (gilberts per $\mathrm{cm}$.)

$\beta_{x}=$ magnetic flux density at radius $x$ (gausses).

$\gamma=$ the conductivity of the material in the conductor (abmhos per $\mathrm{cm}$.).

$\rho=1 / \gamma$ the resistivity (absohm-cm).

$\mu=$ the permeability $\left(\frac{\text { gausses }}{\text { gilberts per } \mathrm{cm} .}\right)$

$f=$ the frequency of the impressed alternating current (cycles per second).

$\omega=2 \pi f$, the angular velocity (radians per second).

$\eta_{\mathrm{x}}=\eta_{\mathrm{x} m} \cdot \boldsymbol{\epsilon}^{j \omega t}$ the electric alternating intensity externally impressed on the conductor $\left(\frac{\text { abvolts }}{\text { linear } \mathrm{cm} .}\right)$

$j=\sqrt{-1}$

$\epsilon=2.71828$. . . the Napierian base.

Then, if we integrate the magnetic intensity $\mathfrak{H}_{x}$ around the circle of radius $x$, we obtain $2 \pi x \mathfrak{F}_{x}$ gilberts, and this must be equal to $4 \pi$ times the total vector current strength within this circle; that is

$$
2 \pi x \mathcal{H C}_{x}=4 \pi \int_{0}^{x} 2 \pi x \cdot i_{x} \cdot d x
$$

absamperes $\angle(\mathbf{1 7})$

or $\quad \frac{d\left(x \cdot \mathcal{F}_{x}\right)}{d x}=4 \pi x \cdot i_{x}$

absamperes/cm $\angle(\mathbf{1 8})$

and $\quad i_{x}=\frac{\dot{1}}{4 \pi}\left(\frac{\mathfrak{F}_{x}}{x}+\frac{d \mathcal{H}_{x}}{d x}\right)$

$\frac{\text { absamperes }}{\text { sq. } \mathrm{cm}}$

If we take one $\mathrm{cm}$. length of the conductor, as indicated in Fig. 20, and suppose that, at radius $x$, the current density directed from $O$ to $O^{\prime}$ is rising at the instant considered; then magnetic 
flux will be entering the rectangle $a b c d$ towards the observer at the rate $\mu \cdot d x \cdot \frac{d \mathcal{H}_{x}}{d t}$ maxwells per second, and generating a momentary e.m.f. of this numerical value around this rectangle, in the direction of the arrows. In order that there shall be no radial component of current flow in this rectangle, the total e.m.f. around this rectangle must be zero. The electric intensity $\eta_{x}$, or the e.m.f. in the centimeter $a b$ will be $\rho i_{x}$ abvolts, directed with the current, or from $a$ to $b$. Similarly, the electric intensity in $d c$ will be $\rho\left(i_{x}+\frac{d i_{x}}{d x} \cdot d x\right)$, directed from $c$ to $d$.

The total e.m.f. in the rectangle is then by Ohm's law,

$$
\begin{array}{rrr}
\mu \cdot d x \cdot \frac{d \mathcal{H}_{x}}{d t}-\frac{d i_{x}}{d x} \cdot d x \cdot \rho=0 & \text { abvolts } \angle(20) \\
\text { or } \quad \rho \frac{d i_{x}}{d x}=\mu \frac{d \mathcal{H}_{x}}{d t} & \frac{\text { abvolts }}{\text { radial cm. }} \angle(\mathbf{2 1})
\end{array}
$$

Differentiating (19) with respect to time, we obtain

$$
\frac{d i_{x}}{d t}=\frac{1}{4 \pi}\left(\frac{d^{2} \mathcal{H}_{x}}{d x \cdot d t}+\frac{1}{x} \frac{d \mathcal{H}_{x}}{d t}\right) \quad \frac{\text { absamperes }}{\text { sq. cm. sec. }}<
$$

Substituting (21)

$$
\frac{d i_{x}}{d t}=\frac{\rho}{4 \pi \mu}\left(\frac{d^{2} i_{x}}{d x^{2}}+\frac{1}{x} \frac{d i_{x}}{d x}\right) \quad \frac{\text { absamperes }}{\text { sq. cm. sec. }}
$$

or

$$
\begin{aligned}
\frac{d^{2} i_{x}}{d x^{2}}+\frac{1}{x} \frac{d i_{x}}{d x}=\frac{4 \pi \mu}{\rho} \cdot \frac{d i_{x}}{d t}=4 \pi \gamma \mu \cdot \frac{d i_{x}}{d t} & \frac{\text { absamperes }}{\mathrm{cm} . .^{4}}
\end{aligned}
$$

But $i_{x}$ is varying sinusoidally, at any radius; so that

$$
\frac{d i_{x}}{d t}=j \omega i_{x} \quad \frac{\text { absamperes }}{\text { sec. cm. } .^{2}} \angle
$$


and

$$
\begin{aligned}
& \frac{d^{2} i_{x}}{d x^{2}}+\frac{1}{x} \frac{d i_{x}}{d x}+(-j 4 \pi \gamma \mu \omega) i_{x}=0 \quad \frac{\text { absamperes }}{\text { cm. }^{4}} \angle \\
& \text { If we denote }(-j 4 \pi \gamma \mu \omega) \text { by } \alpha_{0}{ }^{2} \quad \frac{1}{\mathrm{~cm}^{2}} \angle
\end{aligned}
$$

then

$$
\frac{d^{2} i_{x}}{d x^{2}}+\frac{1}{x} \frac{d i_{x}}{d x}+\alpha_{0}^{2} i_{x}=0 \quad \frac{\text { absamperes }}{\mathrm{cm} .^{4}} \angle
$$

This is a well known typical form of second-order Bessel differential equation, whose solution may conveniently be expressed in Bessel functions

$$
i_{x}=A \cdot J_{0}\left(\alpha_{0} x\right)+B \cdot K_{0}\left(\alpha_{0} x\right) \quad \frac{\text { absamperes }}{\mathrm{cm} .^{2}} \angle
$$

where $J_{0}\left(\alpha_{0} x\right)$ is a zero-order Bessel function of $x$ of the first kind, and $K_{0}\left(\alpha_{0} x\right)$ is a zero-order Bessel function of $x$ of the second kind, while $A$ and $B$ are arbitrary constants.

Similarly, differentiating (19) with respect to $x$, we have

$$
\frac{d i_{x}}{d x}=\frac{1}{4 \pi}\left(\frac{1}{x} \frac{d \mathfrak{H}_{x}}{d x}-\frac{\mathfrak{H}_{x}}{x^{2}}+\frac{d^{2} \mathfrak{H C}_{x}}{d x^{2}}\right) \frac{\text { absamperes }}{\mathrm{cm}^{3}} \angle
$$

and substituting from (21)

$$
\frac{d \mathfrak{H}_{x}}{d t}=\frac{1}{4 \pi \gamma \mu}\left(\frac{1}{x} \frac{d \mathcal{F}_{x}}{d x}-\frac{\mathfrak{F}_{x}}{x^{2}}+\frac{d^{2} \mathfrak{F}}{d x^{2}}\right) \frac{\text { gilberts }}{\mathrm{cm} . \text { sec. }} \angle
$$

and remembering that $\mathfrak{H}_{x}$ is a sinusoidal quantity of angular velocity $\omega$,

$$
\begin{array}{r}
j \omega \mathcal{K}_{x}=\frac{1}{4 \pi \gamma \mu}\left(-\frac{\mathcal{F}_{x}}{x^{2}}+\frac{1 d \mathcal{H}_{x}}{x d x}+\frac{d^{2} \mathfrak{H}_{x}}{d x^{2}}\right) \\
\frac{\text { gilberts }}{\mathrm{cm} . \mathrm{sec} .}<
\end{array}
$$

or

$$
\begin{array}{r}
\frac{d^{2} \mathcal{H}_{x}}{d x^{2}}+\frac{1}{x} \frac{d \mathcal{H}_{x}}{d x}+\mathcal{H}_{x}\left(-j 4 \pi \gamma \mu \omega-\frac{1}{x^{2}}\right)=0 \\
\frac{\text { gilberts }}{\mathrm{cm} .^{3}} \angle
\end{array}
$$

$$
\frac{d^{2} \mathcal{H}_{x}}{d x^{2}}+\frac{1}{x} \frac{d \mathcal{F}_{x}}{d x}+\mathfrak{H}_{x}\left(\alpha_{0}^{2}-\frac{1}{x^{2}}\right)=0 \quad \frac{\text { gilberts }}{\text { cm. } .^{3}} \measuredangle
$$


A typical Bessel differential equation of the second order, whose solution is

$$
\mathfrak{H}_{x}=A^{\prime} \cdot J_{1}\left(\alpha_{0} x\right)+B^{\prime} \cdot K_{1}\left(\alpha_{0} x\right) \quad \frac{\text { gilberts }}{\mathrm{cm} .} \angle
$$

where $J_{1}\left(\alpha_{0} x\right)$ is a first-order Bessel's function of $x$, of the first kind, and $K_{1}\left(\alpha_{0} x\right)$ is a first-order Bessel's function of $x$, of the second kind. It can be shown that in order to comply with the physical conditions of the problems, both $B$ and $B^{\prime}$ must vanish; so that we obtain

$$
\begin{array}{ll}
i_{x}=A \cdot J_{0}\left(\alpha_{0} x\right) & \frac{\text { absamperes }}{\text { sq. cm. }}< \\
\mathfrak{H C}_{x}=A^{\prime} \cdot J_{1}\left(\alpha_{0} x\right) & \frac{\text { gilberts }}{\mathrm{cm} .}<
\end{array}
$$

where $A$ and $A^{\prime}$ are constants determined by the particular conditions of each case, and $\alpha_{0}$ is the "semi-imaginary" quantity $\alpha_{2}-j \alpha_{2}$

$$
\alpha_{0}=\sqrt{2 \pi \gamma \mu \omega}-j \sqrt{2 \pi \gamma \mu \omega}=\sqrt{4 \pi \gamma \mu \omega} \backslash \overline{45^{\circ}} \mathrm{cm}^{-1} \angle
$$

i. e., a complex quantity, whose real and imaginary components are equal. The current density $i_{x}$ at radius $x$, is therefore a constant $A$ times the zero-Bessel function of the semi-imaginary $\alpha_{0} x$, and $\mathfrak{H}_{x}$, the magnetic intensity at radius $x$, is a constant $A^{\prime}$ times the first-Bessel function of the same semi-imaginary. Similarly, the electric intensity at radius $x$ is

$$
\eta_{x}=A \rho \cdot J_{0}\left(\alpha_{0} x\right) \quad \frac{\text { abvolts }}{\mathrm{cm} .} \angle
$$

and the magnetic flux-density at radius $x$ is

$$
B_{x}=A^{\prime} \mu \cdot J_{1}\left(\alpha_{0} x\right)
$$

gausses $\angle$

If we take $x=X$, the radius of the conductor, we obtain from (36)

$$
i_{X}=A \cdot J_{0}\left(\alpha_{0} X\right)
$$$$
\frac{\text { absamperes }}{\text { sq. } \mathrm{cm} .}
$$

and dividing (36) by (41)

$$
\frac{\eta_{x}}{\eta_{X}}=\frac{i_{x}}{i_{X}}=\frac{J_{0}\left(\alpha_{0} x\right)}{J_{0}\left(\alpha_{0} X\right)}
$$


Similarly

$$
\frac{B_{x}}{B_{X}}=\frac{\mathfrak{F}_{x}}{\mathfrak{H}_{X}}=\frac{J_{1}\left(\alpha_{0} x\right)}{J_{1}\left(\alpha_{0} X\right)}
$$

For the benefit of those who are not familiar with Bessel's functions, a few definitions may here be given. For any real quantity $z$,

$J_{0}(z)=1-\frac{\left(\frac{z}{2}\right)^{2}}{1 ! 1 !}+\frac{\left(\frac{z}{2}\right)^{4}}{2 ! 2 !}-\frac{\left(\frac{z}{2}\right)^{6}}{3 ! 3 !}+\ldots$. numeric

and

$J_{1}(z)=\frac{z}{2}\left\{\frac{1}{1 !}-\frac{\left(\frac{z}{2}\right)^{2}}{1 ! 2 !}+\frac{\left(\frac{z}{2}\right)^{4}}{2 ! 3 !}-\frac{\left(\frac{z}{2}\right)^{6}}{3 ! 4 !}+\ldots\right.$ numeric Similarly

$$
J_{p}(z)=\sum_{n=0}^{n=\infty}\left(\frac{z}{2}\right)^{p}\left\{\frac{(-1)^{n}\left(\frac{z}{2}\right)^{2 n}}{n !(p+n) !}\right\} \quad \text { numeric }
$$

If $z$ is a complex quantity of the type $z / \delta, z$ being the modulus and $\delta$ the argument, then

$$
J_{0}(z / \delta)=1-\frac{\left(\frac{z}{2}\right)^{2} / 2 \delta}{1 ! 1 !}+\frac{\left(\frac{z}{2}\right)^{4} / 4 \delta}{2 ! 2 !}-\frac{\left(\frac{z}{2}\right)^{6} / 6 \delta}{3 ! 3 !}
$$

and

$$
\begin{aligned}
J_{1}(z / \delta)= & \frac{z}{2} \frac{\delta \delta}{1 !}-\frac{\left(\frac{z}{2}\right)^{2} / 2 \delta}{1 ! 2 !} \\
& +\frac{\left(\frac{z}{2}\right)^{4} ! 4 \delta}{2 ! 3 !}-\frac{\left(\frac{z}{2}\right)^{6} / 6 \delta}{3 ! 4 !}+\ldots \text { numeric } \angle
\end{aligned}
$$

Similarly

$$
J_{p}(z \underline{/ \delta})=\sum_{n=0}^{n=\infty}\left(\frac{z}{2}\right)^{p} / p \delta\left\{\frac{(-1)^{n}\left(\frac{z}{2}\right)^{2 n} / 2 n \delta}{n !(p+n) !}\right\} \quad \text { numeric } \angle
$$


It is evident, therefore, that a Bessel's function of any complex quantity is an infinite ascending series of powers of that quantity, the coefficients being formed on a definite schedule, depending on the order of the function.

Turning now to (43), we know that if the total maximum cyclic vector current strength carried by the conductor is $I_{m}$ absamperes, the maximum cyclic magnetic intensity $\mathfrak{H}_{x}$ at the surface is

$$
\mathfrak{H}_{\mathrm{x} m}=\frac{2 I_{m}}{X}
$$$$
\frac{\text { gilberts }}{\mathrm{cm}}<
$$

in phase with the current $I_{m}$. If, however, we prefer to consider not the maximum cyclic, but the root-mean-square value of the total vector current

$$
I_{r}=I_{m} / \sqrt{2}
$$

r.m.s. absamperes $\angle$

Then the corresponding r.m.s. value of the magnetic intensity at the surface is

$$
\mathfrak{F}_{\mathrm{x} r} \rightleftharpoons \frac{2 I_{r}}{X} \quad \frac{\text { gilberts }}{\mathrm{cm} .}<
$$

and the r.m.s. flux-density at the surface, to current phase as standard,

$$
\beta_{\mathrm{x} r}=\frac{2 \mu I_{r}}{X}
$$

gausses $\angle$

Consequently, the r.m.s. value of the magnetic intensity $\mathcal{H}_{x r}$, at radius $x \mathrm{~cm}$, is by $(43)$

$$
\mathfrak{H}_{x r}=\frac{2 I_{r} J_{1}\left(\alpha_{0} x\right)}{X J_{1}\left(\alpha_{0} X\right)} \quad \frac{\text { r.m.s. gilberts }}{\mathrm{cm} .}<
$$

to current standard phase. Thus, if a copper rod $1 \mathrm{~cm}$. in diameter $(X=0.5)$ has a resistivity of 1724 absohm-cm. $(\gamma$ $\left.=1 /(1724)=0.580 \times 10^{-3}\right)$, a permeability $\mu=1$, and is traversed by a r.m.s. sinusoidal current of 20 amperes, $\left(I_{r}=2\right.$ absamperes) at a frequency of 786 cycles per second, $(\omega=$ 4938 radians/sec.) Then

$$
\begin{aligned}
\alpha_{0}=\sqrt{ } & -j 12.57 \times 0.58 \times 10^{-3} \times 4.938 \times 10^{3} \\
& =\sqrt{12.57 \times 0.58 \times 4.938 \sqrt{90^{\circ}}} \\
& =\sqrt{\frac{}{36.0 \sqrt{90^{\circ}}}=6.0 \sqrt{45^{\circ}} \quad \mathrm{cm} .^{-1} ;}
\end{aligned}
$$


so that

$$
\alpha_{0} X=3.0 \sqrt{45^{\circ}}=2.121-j 2.121 \quad \text { numeric } \angle
$$

by appended Table IX of $J_{1}\left(z \sqrt{45^{\circ}}\right)$, we find $J_{1}\left(3.0 \sqrt{45^{\circ}}\right.$ $=1.8 / 15^{\circ} .714$

Consequently,

$$
\begin{array}{r}
\mathfrak{H}_{x r}=\frac{2 \times 2 \times J_{1}\left(\alpha_{0} x\right)}{0.5 \times 1.8 / 15^{\circ} .714}=4.444 \sqrt{15^{\circ} .714 .} J_{1}\left(\alpha_{0} x\right) \\
\frac{\text { r.m.s. gilberts }}{\mathrm{cm} .}
\end{array}
$$

At the axis of the wire, or $x=0, J_{1}\left(0 \backslash \overline{45^{\circ}}\right)=0 \backslash \overline{45}^{\circ}$ and

$$
\mathfrak { H } _ { 0 r } = 0 . 0 \longdiv { 6 0 ^ { \circ } . 7 1 4 } \quad \frac { \text { r.m.s. gilberts } } { \mathrm { cm } . } \angle
$$

or, the intensity is vanishingly small, lagging $60^{\circ} .7$ behind the total vector current; and also $60^{\circ} .7$ behind the intensity at the surface of the wire. At $x=0.25 \mathrm{~cm}$., or half way down to the axis, $\alpha_{0} x=1.5 \backslash 45^{\circ}$, and

$$
\begin{array}{rlr}
\mathcal{F}_{x r} & = 4 . 4 4 4 \longdiv { 1 5 ^ { \circ } . 7 1 4 } . J _ { 1 } ( 1 . 5 \sqrt { 4 5 ^ { \circ } } ) \\
& = 4 . 4 4 4 \longdiv { 1 5 ^ { \circ } . 7 1 4 } \times 0 . 7 5 9 9 \sqrt { 2 8 ^ { \circ } . 9 5 2 } \\
& = 3 . 3 7 7 \longdiv { 4 4 ^ { \circ } . 6 6 6 } \quad r \text { r.m.s. gilberts/cm. } \angle
\end{array}
$$

i.e., 0.422 of the full surface value. At the surface, $X=0.5$ and $\mathfrak{H} \mathrm{C}_{\mathrm{X}}=8 / 0^{\circ}$ r.m.s. gilberts per $\mathrm{cm}$.

Next considering (42), we are usually unable to apply this formula directly; because we do not know the value of the electric intensity $\eta_{X}$ at the surface, or the current density $i_{X}$ which it produces. It becomes necessary, therefore, to find the average current density, taking skin effect into account. It is evident that the total vector r.m.s. current strength $I_{r}$ (absamperes) in the wire, if $i_{x r}$ is the r.m.s. current density at radius $x$, will be

$$
I_{r}=\int_{0}^{\mathrm{x}} 2 \pi x \cdot i_{x r} \cdot d x=2 \pi \int_{0}^{\mathrm{x}} x \cdot i_{x r} \cdot d_{x}
$$


and dividing this by $\pi X^{2}$, the area of cross-section of the wire, we obtain the average vector r.m.s. current density $i_{q r}$ in the presence of skin effect; namely

$$
i_{q r}=\frac{I_{r}}{\pi X^{2}}=\frac{2}{X^{2}} \int_{0}^{\mathrm{x}} x \cdot i_{x r} \cdot d x \quad \frac{\text { r.m.s.absamperes }}{\text { sq. cm. }}<
$$

Substituting for $i_{x r}$, the value from (42) in terms of $i_{\mathrm{x} r}$ we have

$$
\begin{array}{r}
i_{q r}=\frac{2}{X^{2}} \cdot \frac{i_{X r}}{J_{0}\left(\alpha_{0} \mathrm{X}\right)} \cdot \int_{0}^{\mathrm{x}} x \cdot J_{0}\left(\alpha_{0} x\right) \cdot d x \\
\frac{\text { r.m.s.absamperes }}{\text { sq. cm. }}
\end{array}
$$

It will be found that the integral of $m x / \delta$ times the zero-Bessel function of a complex quantity $m x / \delta$, with modulus $m x$ and argument $\delta$, is

$$
\int m x \underline{1 \delta} \cdot J_{0}(m x \underline{\delta}) \cdot d x=x J_{1}(m x \underline{\delta}) \quad \text { numeric } \angle
$$

Applying this integral, we obtain

$$
\begin{aligned}
i_{q r}= & \frac{2}{X^{2}} \cdot \frac{i_{X r}}{J_{0}\left(\alpha_{0} X\right)} \cdot \frac{1}{\alpha_{0}} \int_{0}^{\mathrm{x}} \alpha_{0} x \cdot J_{0}\left(\alpha_{0} x\right) \cdot d x \\
& =\frac{2}{X^{2}} \cdot \frac{i_{X r}}{J_{0}\left(\alpha_{0} X\right)} \cdot \frac{1}{\alpha_{0}}\left[x \cdot J_{1}\left(\alpha_{0} x\right)\right]_{0}^{\mathrm{x}} \\
& =\frac{2}{X^{2}} \cdot \frac{i_{X r}}{J_{0}\left(\alpha_{0} X\right)} \cdot \frac{X}{\alpha_{0}} \cdot J_{1}\left(\alpha_{0} X\right) \\
& =\frac{2}{\alpha_{0} X} \cdot i_{X r} \cdot \frac{J_{1}\left(\alpha_{0} X\right)}{J_{0}\left(\alpha_{0} X\right)} \quad \frac{\text { r.m.s.absamperes }}{\text { sq. cm. }} \angle
\end{aligned}
$$

whence, with (42)

$$
\frac{i_{x r}}{i_{q r}}=\frac{\alpha_{0} X}{2} \cdot \frac{J_{0}\left(\alpha_{0} x\right)}{J_{1}\left(\alpha_{0} X\right)}
$$




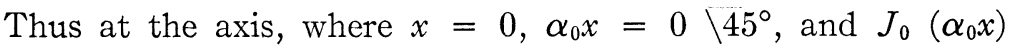
$=1.0 / 0^{\circ}$,

$$
\frac{i_{0 r}}{i_{q r}}=\frac{\alpha_{0} X}{2} \cdot \frac{1}{J_{1}\left(\alpha_{0} X\right)}
$$

In the case above considered with $\alpha_{0} X=3.0 \overline{45}^{\circ}$,

$$
\frac{i_{0 r}}{i_{q r}}=\frac{1.5 \sqrt{45^{\circ}}}{1.8}=0.8333 \sqrt{60^{\circ} .714}
$$

or the axis r.m.s. current density is $83.33 \%$ of the average current density, as deduced from the actual r.m.s. current and the crosssection. At the surface, $J_{0}\left(\alpha_{0} X\right)=J_{0}\left(3.0 \backslash_{4} 5^{\circ}\right)=1.9502$ $\angle 6^{\circ} .518$; so that

$$
\frac{i_{X_{r}}}{i_{q_{r}}}=0.8333 \sqrt{60^{\circ} .714} \times 1.9502 \underline{/ 96^{\circ} .518}=\underset{\text { numeric } \angle(67)}{1.625 / 35^{\circ}}
$$

or the surface density is $62.5 \%$ greater than the average density. If we consider that the surface r.m.s. current density is equal to that which the same numerical continuous electric intensity would produce in the linear d-c. resistance $R$, whereas the average r.m.s. density is that which the r.m.s. a-c. electric intensity actually produces in the presence of the linear internal impedance $Z=R^{\prime}+j X^{\prime}$; it follows that

$$
\frac{Z}{R}=\frac{i_{X r}}{i_{q r}}=\frac{\alpha_{0} X}{2} \cdot \frac{J_{0}\left(\alpha_{0} X\right)}{J_{1}\left(\alpha_{0} X\right)}
$$

Here $\frac{Z}{R}$ is the "skin-effect impedance ratio." The real component of this ratio is $\frac{R^{\prime}}{R}$, the "skin-effect resistance ratio"; while the reactive component of this ratio is $\frac{j X^{\prime}}{R}$ the " skin-ef-. fect reactance ratio."

Thus, in the case considered, by (67)

$$
\frac{Z}{R}=1.625 / 35^{\circ} .804=1.318+j 0.9507 \quad \text { numeric } \angle
$$


so that the skin-effect impedance ratio of the wire at this frequency is 1.625 , its skin-effect resistance ratio 1.318 , and its skin-effect reactance ratio 0.9507 . The apparent a-c. resistance of the wire is therefore 31.8 per cent greater than the $\mathrm{d}$-c. resistance.

If, therefore, we denote the skin-effect impedance ratio as obtained in (68) by the complex quantity $M / \beta^{\circ}$, where $M=|Z / R|$, and $\beta^{\circ}=\overline{Z / R}$,

$$
\frac{Z}{R}=M / \underline{\beta}^{\circ}
$$

then

$$
\frac{R^{\prime}}{R}=M \cos \beta
$$

and

$$
\frac{X^{\prime}}{R}=\frac{L^{\prime} \omega}{R}=M \sin \beta
$$

But the internal linear inductance $L$ of a round wire, in the absence of skin effect, is

$$
L=\frac{\mu}{2}
$$$$
\frac{\text { abhenrys }}{\text { wire } \mathrm{cm} \text {. }}
$$

So that

$$
\begin{aligned}
\frac{L \omega}{R} & =\frac{\mu \omega}{2 R}=\frac{\mu \omega \cdot \pi X^{2}}{2} \gamma \\
& =\frac{4 \pi \mu \gamma \omega X^{2}}{8}=\frac{\left|\alpha_{0} X\right|^{2}}{8} \\
\frac{L^{\prime}}{L} & =\frac{8 M \sin \beta}{\left|\alpha_{0} X\right|^{2}}
\end{aligned}
$$

where $\left|\alpha_{0} X\right|$ denotes the modulus, or length factor, of the plane vector $\alpha_{0} X$. In the case above considered, $\left|\alpha_{0} X\right|=3$, and

$M \sin \beta=0.9507 ;$ so that $\frac{L^{\prime}}{L}=\frac{8 \times 0.9507}{9}=0.8456$ 
The apparent linear internal inductance of the wire in the presence of skin-effect, is 84.56 per cent of that for zero frequency. The radial skin thickness $\delta \mathrm{cm}$., which is equivalent, at full

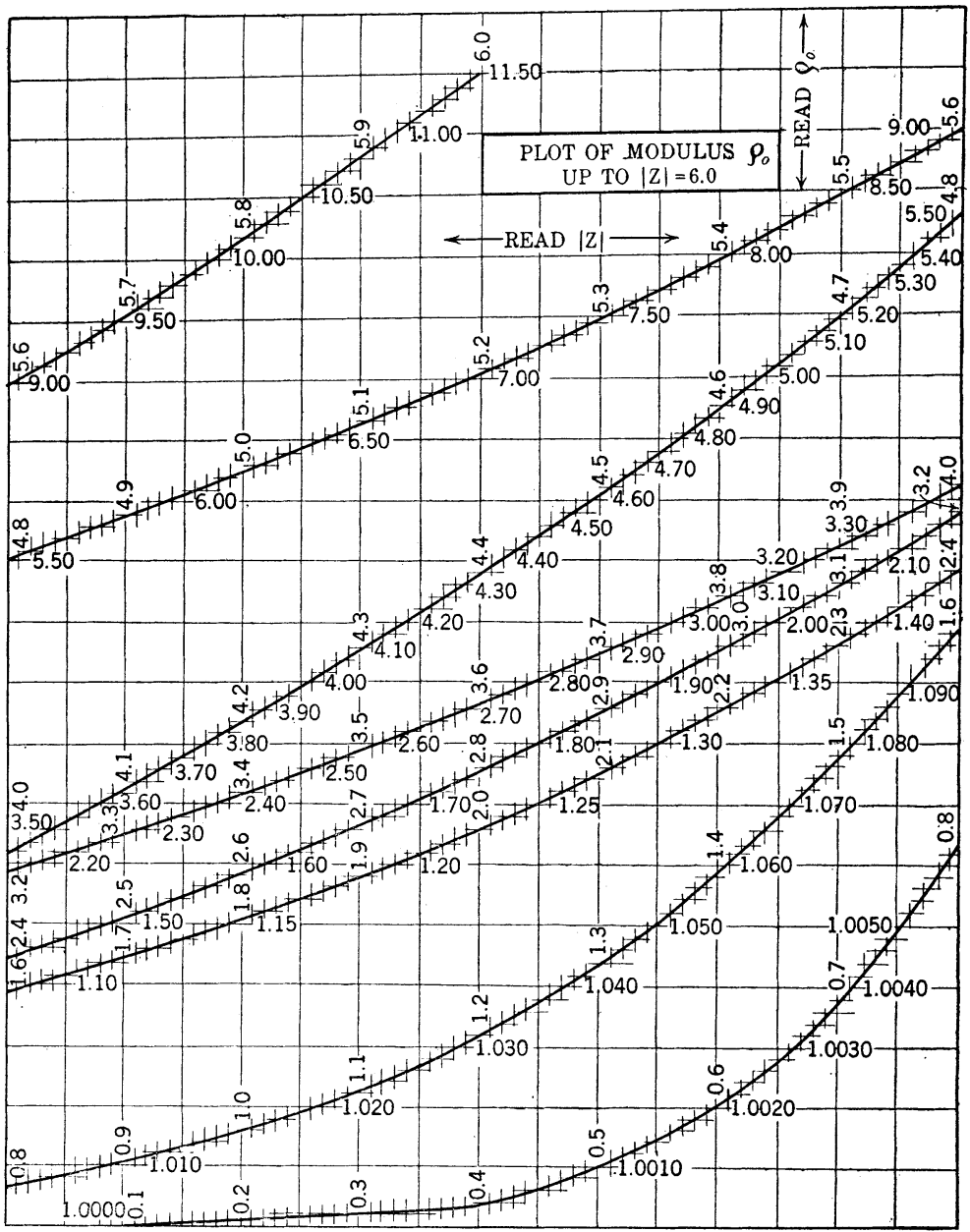

Fig. 21-Interpolation Chart for Bessel Functions of the Zero Order of the Semi-Imaginary Quantity $z \overline{\backslash 45}^{\circ}$

$$
J_{9}\left(\alpha_{0} x\right)=J_{0}\left(x \sqrt{4 \pi r^{\mu \omega}} \backslash \overline{45^{\circ}}\right)=J_{0}\left(z \overline{45^{\circ}}\right)=\rho_{0} / \hat{\theta}_{0}^{\circ}
$$

conductivity, to the actual wire at the average conductivity of skin effect, is given by

$$
\delta=X\left(1-\sqrt{1-\frac{R}{R^{\prime}}}\right)
$$


In the case above considered $\delta=0.2544 \mathrm{~cm}$.

Table IX gives the values of both $J_{0}\left(z \sqrt{45^{\circ}}\right)$ and $J_{1}\left(z \backslash 45^{\circ}\right)$, for the range $z=0$ to $z=10$, by steps of 0.1 ; while Figs. 21 to 24 give curves corresponding to the entries in the table, whereby

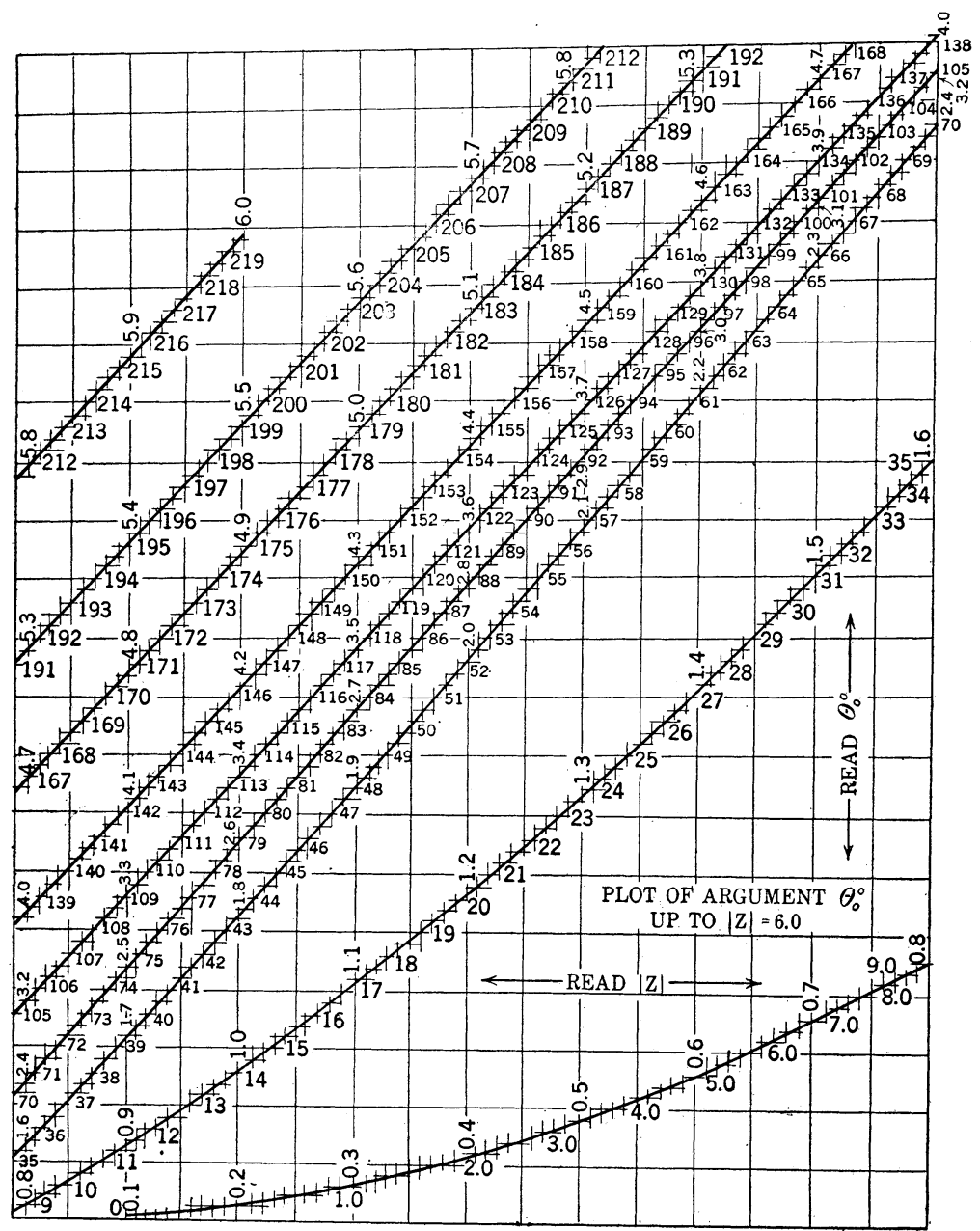

Fig. 22-Interpolation Chart for Bessel Functions of the Zero Order of The Semi-Imaginary Quantity $z \backslash 45^{\circ}$

$$
J_{0}\left(\alpha_{0} x\right)=J_{0}\left(x \sqrt{4 \pi \gamma \mu \omega} \backslash 45^{\circ}\right)=J_{0}\left(z \backslash \overline{45^{\circ}}\right)=\rho_{0} / \theta_{0}^{\circ}
$$

interpolation may be made, by direct inspection, for most engineering purposes. The curves in Fig. 21 give the modulus of $J_{0}\left(z \backslash 45^{\circ}\right)$, in Fig. 22 the amplitude of the same function, in Fig. 23 the modulus of $J_{1}\left(z \backslash 45^{\circ}\right)$, and in Fig. 24 the amplitude 
of the same function. Table IX has been worked outfrom alreadyexisting tables of ber-bei ber'-bei' functions, using (77) and (78). The polar form of the Bessel functions obtained from Table IX gives them distinct arithmetical advantages.

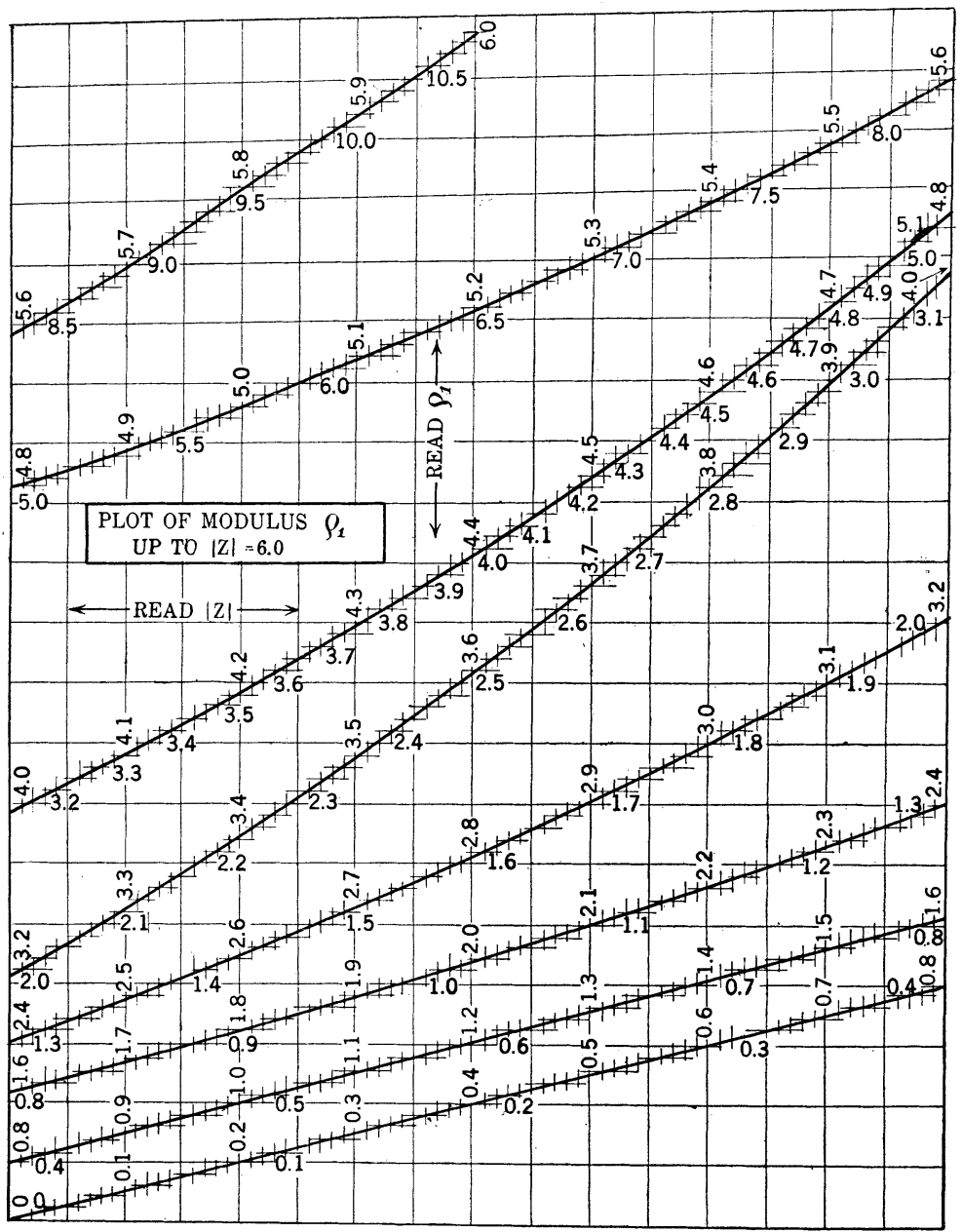

Fig. 23-Interpolation Chart for Bessel Functions of the First Order of the Semi-Imaginary Quantity $v \backslash \overline{45^{\circ}}$

$$
\left.J_{1}\left(\alpha_{0} x\right)=J_{1} x \sqrt{4 \pi \gamma \mu \omega} \overline{\backslash 45^{\circ}}\right)=J_{1}\left(z \backslash \overline{45^{\circ}}\right)=\rho_{1} / \theta_{1}^{\circ} .
$$

Table $X$ gives the value of $\left|\alpha_{0}\right|=\sqrt{4 \pi \gamma \mu \omega}$, the modulus of the propagation constant, for the case of round copper wires, of international standard conductivity at $20^{\circ} \mathrm{C}$., for various values of impressed frequency up to $5000 \sim$. By its use, in conjunction 
with Table IX, the computation of the electric intensity $\eta_{x}$, the electric-current density $i_{x}$, the magnetic intensity $\mathfrak{H}_{x}$, or flux density $B_{x}$, at any radius $x$, in a round wire, is facilitated through

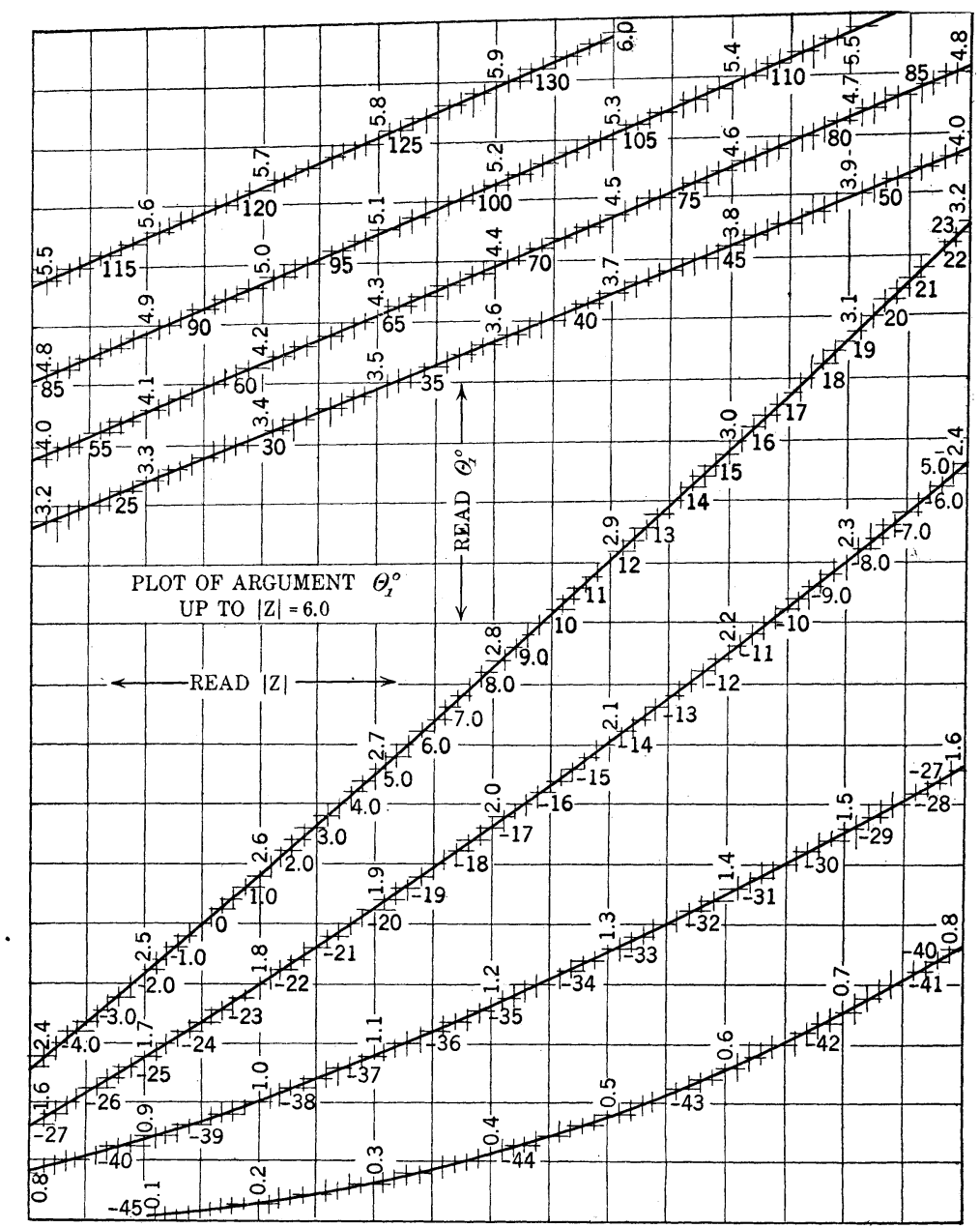

Fig. 24-Interpolation Chart for Bessel Functions of the First Order of the Semi-Imaginary Quantity $z \overline{45}^{\circ}$

$$
J_{1}\left(\alpha_{0} x\right)=J_{1}\left(x \sqrt{4 \pi \gamma \mu \omega} \backslash 45^{\circ}\right)=J_{1}\left(z \overline{\backslash 45^{\circ}}\right)=\rho_{1} /{\underline{\theta_{1}}}^{\circ}
$$

formulas (42), (43), (54), (64) and (65) as well as the skin effect ratios $Z / R, R^{\prime} / R$, and $L^{\prime} / L$.

$B e r, B e i, B e r^{\prime}$ and Bei' Functions. Certain functions, derived from Bessel's functions $J_{0}\left(z \backslash 45^{\circ}\right)$, and $J_{1}\left(z \sqrt{45^{\circ}}\right)$, were intro- 
duced by Lord Kelvin in his classical discussion of skin effect ${ }^{12}$. The ber function is the real component and bei the imaginary component of $J_{0}\left(z \overline{45}^{\circ}\right)$. Analogous relations connect the ber' and bei' functions with the corresponding real and imaginary components of $J_{1}\left(z \sqrt{45^{\circ}}\right)$. Thus, as is shown in Jahnke and Emde's "Funktionentafeln "13 in the discussion of this subject,

$$
J_{0}\left(z \backslash 45^{\circ}\right)=\text { ber } z+j \text { bei } z
$$

numeric $\angle$

and

$$
J_{1}\left(z \sqrt{45^{\circ}}\right) / \frac{3 \pi}{4}=\text { ber' }^{\prime} z+j \text { bei }^{\prime} z \quad \text { numeric } \angle
$$

From which it is shown that

$$
\frac{R^{\prime}}{R}=\frac{\alpha_{0} X}{2} \times \frac{\operatorname{ber}\left(\alpha_{0} X\right) \cdot \operatorname{bei}^{\prime}\left(\alpha_{0} X\right)-\operatorname{bei}\left(\alpha_{0} X\right) \cdot \operatorname{ber}^{\prime}\left(\alpha_{0} X\right)}{\operatorname{ber}^{\prime 2}\left(\alpha_{0} X\right)+\operatorname{bei}^{\prime 2}\left(\alpha_{0} X\right)}
$$

and

$$
\frac{L^{\prime}}{L}=\frac{4}{\alpha_{0}} \bar{X} \times \frac{\operatorname{ber}\left(\alpha_{0} X\right) \cdot \operatorname{ber}^{\prime}\left(\alpha_{0} X\right)+\operatorname{bei}\left(\alpha_{0} X\right) \cdot \operatorname{bei}^{\prime}\left(\alpha_{0} X\right)}{\operatorname{ber}^{\prime 2}\left(\alpha_{0} X\right)+\operatorname{bei}^{\prime 2}\left(\alpha_{0} X\right)}
$$

These formulas have the advantage that they give the solutions for $R^{\prime} / R$ and $L^{\prime} / L$ directly, after $\alpha_{0} X$ is known, from reference to Tables of ber $x$, bei $x$, and ber ' $x$ and bei ' $x$. They have, however, the disadvantage of being longer, and of calling for more numerical work in computation than the corresponding formulas above. presented (68), (71) and (76). Thus, in the case already considered, we find from ber-bei Tables, ber $3 \sqrt{45^{\circ}}=-0.2214$, bei $3 \backslash 45^{\circ}=1.9376$; ber $^{\prime} 3 \backslash 45^{\circ}=-1.5698$, bei ${ }^{\prime} 3 \backslash 45^{\circ}=0.8805$.

Hence by (79)

$$
\frac{R^{\prime}}{R}=\frac{3}{2} \times \frac{-0.2214 \times 0.8805-1.9376 \times(-1.5698)}{(-1.5698)^{2}+(0.8805)^{2}}=1.318
$$

and by $(80)$,

$$
\frac{L^{\prime}}{L}=\frac{4}{3} \times \frac{-0.2214 \times(-1.5698)+1.9376 \times 0.8805}{(-1.5698)^{2}+(0.8805)^{2}}=0.8456
$$

12. Bibliography No. 9 .

13. Bibliography No. 61. 


\section{TABLE IX-BESSEL FUNCTIONS OF THE ZERO AND FIRST ORDERS}

of the semi-imaginary quantity $\left(z \backslash 45^{\circ}\right)$ expressed in polar form $\rho / \theta$ for expression $J_{0}\left(z \overline{45^{\circ}}\right)=\rho_{0} / \theta_{0}$ and $J_{1}\left(z \backslash \overline{45^{\circ}}\right)=\rho_{1} / \theta_{1}$.

\begin{tabular}{|c|c|c|c|c|c|c|c|c|c|}
\hline \multirow[b]{2}{*}{$z$} & \multicolumn{2}{|c|}{$J_{0}\left(z \overline{455_{0}}\right)$} & \multicolumn{2}{|c|}{$J_{1}\left(z \backslash 45^{\circ}\right)$} & \multirow[b]{2}{*}{$z$} & \multicolumn{2}{|c|}{$J_{0}\left(z \backslash \overline{4} \overline{5}^{\circ}\right)$} & \multicolumn{2}{|c|}{$J_{1}\left(z \overline{\backslash 45^{\circ}}\right)$} \\
\hline & $\rho_{0}$ & $\underline{\theta_{0}}$ & $\rho_{0}$ & $/ \underline{\theta}_{1}$ & & $\rho_{0}$ & $\angle \theta_{0}$ & $\rho_{1}$ & $\angle \theta_{1}$ \\
\hline $\begin{array}{l}0.1 \\
0.2 \\
0.3 \\
0.4 \\
0.5\end{array}$ & $\begin{array}{l}1.0000 \\
1.0001 \\
1.0002 \\
1.0003 \\
1.0010\end{array}$ & $\begin{array}{l}0.15 \\
0.567 \\
1.283 \\
2.283 \\
3.617\end{array}$ & $\begin{array}{l}0.0500 \\
0.1000 \\
0.1500 \\
0.2000 \\
0.2500\end{array}$ & $\begin{array}{l}-44.931 \\
-44.714 \\
-44.350 \\
-43.854 \\
-43.213\end{array}$ & $\begin{array}{l}5.1 \\
5.2 \\
5.3 \\
5.4 \\
5.5\end{array}$ & $\begin{array}{l}6.6203 \\
7.0339 \\
7.4752 \\
7.9455 \\
8.4473\end{array}$ & $\begin{array}{l}183.002 \\
187.071 \\
191.140 \\
195.209 \\
199.279\end{array}$ & $\begin{array}{l}6.1793 \\
6.5745 \\
6.9960 \\
7.4456 \\
7.9253\end{array}$ & $\begin{array}{r}97.533 \\
101.518 \\
105.504 \\
109.492 \\
113.482\end{array}$ \\
\hline $\begin{array}{l}0.6 \\
0.7 \\
0.8 \\
0.9 \\
1.0\end{array}$ & $\begin{array}{l}1.0020 \\
1.0037 \\
1.0063 \\
1.0102 \\
1.0155\end{array}$ & $\begin{array}{r}5.150 \\
7.000 \\
9.150 \\
11.550 \\
14.217\end{array}$ & $\begin{array}{l}0.3001 \\
0.3502 \\
0.4010 \\
0.4508 \\
0.5014\end{array}$ & $\begin{array}{l}-42.422 \\
-41.489 \\
-4.0358 \\
-39.207 \\
-37.837\end{array}$ & $\begin{array}{l}5.6 \\
5.7 \\
5.8 \\
5.9 \\
6.0\end{array}$ & $\begin{array}{r}8.9821 \\
9.5524 \\
10.160 \\
10.809 \\
11.501\end{array}$ & $\begin{array}{l}203.348 \\
207.417 \\
211.487 \\
215.556 \\
219.625\end{array}$ & $\begin{array}{r}8.4370 \\
8.9830 \\
9.5657 \\
10.187 \\
10.850\end{array}$ & $\begin{array}{l}117.473 \\
121.465 \\
125.459 \\
129.454 \\
133.452\end{array}$ \\
\hline $\begin{array}{l}1.1 \\
1.2 \\
1.3 \\
1.4 \\
1.5\end{array}$ & $\begin{array}{l}1.0226 \\
1.0319 \\
1.0436 \\
1.0584 \\
1.0768\end{array}$ & $\begin{array}{l}17.167 \\
20.333 \\
23.750 \\
27.367 \\
31.183\end{array}$ & $\begin{array}{l}0.5508 \\
0.6032 \\
0.6549 \\
0.7070 \\
0.7599\end{array}$ & $\begin{array}{l}-36.343 \\
-34.706 \\
-32.928 \\
-31.011 \\
-28.952\end{array}$ & \begin{tabular}{|l}
6.1 \\
6.2 \\
6.3 \\
6.4 \\
6.5
\end{tabular} & $\begin{array}{l}12.239 \\
13.027 \\
13.865 \\
14.761 \\
15.717\end{array}$ & $\begin{array}{l}223.694 \\
227.762 \\
231.830 \\
235.897 \\
239.964\end{array}$ & $\begin{array}{l}11.558 \\
12.313 \\
13.119 \\
13.978 \\
14.896\end{array}$ & $\begin{array}{l}137.450 \\
141.452 \\
145.454 \\
149.458 \\
153.462\end{array}$ \\
\hline $\begin{array}{l}1.6 \\
1.7 \\
1.8 \\
1.9 \\
2.0\end{array}$ & $\begin{array}{l}1.0983 \\
1.1243 \\
1.1545 \\
1.1890 \\
1.2286\end{array}$ & $\begin{array}{l}35.167 \\
39.300 \\
43.550 \\
47.883 \\
52.283\end{array}$ & $\begin{array}{l}0.8136 \\
0.8683 \\
0.9233 \\
0.9819 \\
1.0411\end{array}$ & $\begin{array}{l}-26.768 \\
-24.451 \\
-22.000 \\
-19.428 \\
-16.732\end{array}$ & $\begin{array}{l}6.6 \\
6.7 \\
6.8 \\
6.9 \\
7.0\end{array}$ & $\begin{array}{l}16.737 \\
17.825 \\
18.986 \\
20.225 \\
21.548\end{array}$ & $\begin{array}{l}244.031 \\
248.098 \\
252.164 \\
256.228 \\
260.294\end{array}$ & $\begin{array}{l}15.876 \\
16.921 \\
18.038 \\
19.228 \\
20.500\end{array}$ & $\begin{array}{l}157.469 \\
161.477 \\
165.486 \\
169.498 \\
173.510\end{array}$ \\
\hline $\begin{array}{l}2.1 \\
2.2 \\
2.3 \\
2.4 \\
2.5\end{array}$ & $\begin{array}{l}1.2743 \\
1.3250 \\
1.3810 \\
1.4421 \\
1.5111\end{array}$ & $\begin{array}{l}56.750 \\
61.233 \\
65.717 \\
70.183 \\
74.650\end{array}$ & $\begin{array}{l}1.1022 \\
1.1659 \\
1.2325 \\
1.3019 \\
1.3740\end{array}$ & $\begin{array}{l}-13.923 \\
-11.000 \\
-7.970 \\
-4.838 \\
-1.613\end{array}$ & $\begin{array}{l}7.1 \\
7.2 \\
7.3 \\
7.4 \\
7.5\end{array}$ & $\begin{array}{l}22.959 \\
24.465 \\
26.074 \\
27.790 \\
29.622\end{array}$ & $\begin{array}{l}264.358 \\
268.422 \\
272.486 \\
276.540 \\
280.612\end{array}$ & $\begin{array}{l}21.858 \\
23.308 \\
24.856 \\
26.509 \\
28.274\end{array}$ & $\begin{array}{l}177.523 \\
181.536 \\
185.554 \\
189.571 \\
193.589\end{array}$ \\
\hline $\begin{array}{l}2.6 \\
2.7 \\
2.8 \\
2.9 \\
3.0\end{array}$ & $\begin{array}{l}1.5830 \\
1.6665 \\
1.7541 \\
1.8486 \\
1.9502\end{array}$ & $\begin{array}{l}79.114 \\
83.499 \\
87.873 \\
92.215 \\
96.518\end{array}$ & $\begin{array}{l}1.4505 \\
1.5300 \\
1.6148 \\
1.7045 \\
1.7998\end{array}$ & $\begin{array}{r}1.701 \\
5.099 \\
8.570 \\
12.111 \\
15.714\end{array}$ & $\begin{array}{l}7.6 \\
7.7 \\
7.8 \\
7.9 \\
8.0\end{array}$ & $\begin{array}{l}31.578 \\
33.667 \\
35.896 \\
38.276 \\
40.817\end{array}$ & $\begin{array}{l}284.674 \\
288.736 \\
292.798 \\
296.859 \\
300.920\end{array}$ & $\begin{array}{l}30.158 \\
32.172 \\
34.321 \\
36.617 \\
39.070\end{array}$ & $\begin{array}{l}197.608 \\
201.627 \\
205.646 \\
209.670 \\
213.692\end{array}$ \\
\hline $\begin{array}{l}3.1 \\
3.2 \\
3.3 \\
3.4 \\
3.5\end{array}$ & $\begin{array}{l}2.0592 \\
2.1761 \\
2.3000 \\
2.4342 \\
2.5759\end{array}$ & $\begin{array}{l}100.789 \\
105.032 \\
109.252 \\
113.433 \\
117.605\end{array}$ & $\begin{array}{l}1.9012 \\
2.0088 \\
2.1236 \\
2.2459 \\
2.3766\end{array}$ & $\begin{array}{l}19.372 \\
23.081 \\
26.833 \\
30.622 \\
34.445\end{array}$ & $\begin{array}{l}8.1 \\
8.2 \\
8.3 \\
8.4 \\
8.5\end{array}$ & $\begin{array}{l}43.532 \\
46.429 \\
49.524 \\
52.829 \\
56.359\end{array}$ & $\begin{array}{l}304.981 \\
309.042 \\
313.102 \\
317.162 \\
321.222\end{array}$ & $\begin{array}{l}41.691 \\
44.487 \\
47.476 \\
50.670 \\
54.081\end{array}$ & $\begin{array}{l}217.716 \\
221.739 \\
225.764 \\
229.790 \\
233.815\end{array}$ \\
\hline $\begin{array}{l}3.6 \\
3.7 \\
3.8 \\
3.9 \\
4.0\end{array}$ & $\begin{array}{l}2.7285 \\
2.8895 \\
3.0613 \\
3.2443 \\
3.4391\end{array}$ & $\begin{array}{l}121.760 \\
125.875 \\
129.943 \\
134.096 \\
138.191\end{array}$ & $\begin{array}{l}2.5155 \\
2.6640 \\
2.8226 \\
2.9920 \\
3.1729\end{array}$ & $\begin{array}{l}38.295 \\
42.171 \\
46.067 \\
49.978 \\
53.905\end{array}$ & $\begin{array}{l}8.6 \\
8.7 \\
8.8 \\
8.9 \\
9.0\end{array}$ & $\begin{array}{l}60.129 \\
64.155 \\
68.455 \\
73.049 \\
77.957\end{array}$ & $\begin{array}{l}325.282 \\
329.341 \\
333.400 \\
337.459 \\
341.516\end{array}$ & $\begin{array}{l}57.725 \\
61.618 \\
65.779 \\
70.222 \\
74.971\end{array}$ & $\begin{array}{l}237.842 \\
241.868 \\
245.896 \\
249.925 \\
253.953\end{array}$ \\
\hline $\begin{array}{l}4.1 \\
4.2 \\
4.3 \\
4.4 \\
4.5\end{array}$ & $\begin{array}{l}3.6463 \\
3.8671 \\
4.1015 \\
4.3518 \\
4.6179\end{array}$ & $\begin{array}{l}142.279 \\
146.361 \\
150.444 \\
154.513 \\
158.586\end{array}$ & $\begin{array}{l}3.3662 \\
3.5722 \\
3.7924 \\
4.0274 \\
4.2783\end{array}$ & $\begin{array}{l}57.840 \\
61.789 \\
65.743 \\
69.706 \\
73.672\end{array}$ & $\begin{array}{l}9.1 \\
9.2 \\
9.3 \\
9.4 \\
9.5\end{array}$ & $\begin{array}{r}83.199 \\
88.796 \\
94.781 \\
101.128 \\
108.003\end{array}$ & $\begin{array}{l}345.577 \\
349.566 \\
353.693 \\
357.751 \\
361.811\end{array}$ & $\begin{array}{r}80.048 \\
85.466 \\
91.259 \\
97.449 \\
104.063\end{array}$ & $\begin{array}{l}257.981 \\
262.011 \\
266.041 \\
270.071 \\
274.102\end{array}$ \\
\hline $\begin{array}{l}4.6 \\
4.7 \\
4.8 \\
4.9 \\
5.0\end{array}$ & $\begin{array}{l}4.9012 \\
5.2015 \\
5.5244 \\
5.8696 \\
6.2312\end{array}$ & $\begin{array}{l}162.657 \\
166.726 \\
170.795 \\
174.865 \\
178.933\end{array}$ & $\begin{array}{l}4.5460 \\
4.8317 \\
5.1390 \\
5.4619 \\
5.8118\end{array}$ & $\begin{array}{l}77.638 \\
81.615 \\
85.590 \\
89.571 \\
93.549\end{array}$ & $\begin{array}{r}9.6 \\
9.7 \\
9.8 \\
9.9 \\
10.0\end{array}$ & $\begin{array}{l}115.291 \\
123.110 \\
131.429 \\
140.300 \\
149.831\end{array}$ & $\begin{array}{l}365.868 \\
369.958 \\
373.983 \\
378.002 \\
382.099\end{array}$ & $\begin{array}{l}111.131 \\
118.683 \\
126.752 \\
135.374 \\
144.586\end{array}$ & $\begin{array}{l}278.133 \\
282.164 \\
286.197 \\
290.229 \\
294.266\end{array}$ \\
\hline
\end{tabular}

Examples $J_{0}\left(31 \overline{45}^{\circ}\right)=2.0592 / 100^{\circ} .789 ; \quad J_{1}\left(8.1 \overline{45^{\circ}}\right)=41.691 / 217^{\circ} 716$ 
Rosa and Grover ${ }^{14}$ have worked out tables of $R^{\prime} / R$ and $L^{\prime} / L$ in accordance with formulas (79) and (80), for various values of $\left|\alpha_{0} X\right|$, up to 100 .

TABLE X-PROPAGATION CONSTANT OF THE MODULUS $|\alpha|=\sqrt{4 \pi \gamma \mu \omega}$ FOR COPPER OF STANDARD CONDUCTIVITY, AT $20^{\circ} \mathrm{C}$.

( $\rho=1724$. absohm-cm., $\mu=1.0$ ) for various frequencies $f \sim$.

\begin{tabular}{|c|c|c|c|c|c|c|c|}
\hline$f$ & $|\alpha|$ & $f$ & $|\alpha|$ & $f$ & $|\alpha|$ & $f$ & $|\alpha|$ \\
\hline 5 & 0.4785 & 320 & 3.828 & 820 & 6.128 & 2600 & 10.91 \\
\hline 10 & 0.6767 & 340 & 3.946 & 840 & 6.202 & 2700 & 11.12 \\
\hline 15 & 0.8288 & 360 & 4.060 & 860 & 6.275 & 2800 & 11.32 \\
\hline 20 & 0.9570 & 380 & 4.172 & 880 & 6.348 & 2900 & 11.52 \\
\hline 25 & 1.070 & 400 & 4.280 & 900 & 6.420 & 3000 & 11.72 \\
\hline 30 & 1.172 & 420 & 4.386 & 920 & 6.491 & 3100 & 11.92 \\
\hline 35 & 1.266 & 440 & 4.488 & 940 & 6.560 & 3200 & 12.11 \\
\hline 40 & 1.354 & 460 & 4.590 & 960 & 6.630 & 3300 & 12.29 \\
\hline 45 & 1.436 & 480 & 4.688 & 980 & 6.699 & 3400 & 12.48 \\
\hline 50 & 1.513 & 500 & 4.785 & 1000 & 6.767 & 3500 & 12.66 \\
\hline 60 & 1.658 & 520 & 4.880 & 1100 & 7.097 & 3600 & 12.84 \\
\hline 70 & 1.791 & 540 & 4.973 & 1200 & 7.413 & 3700 & 13.02 \\
\hline 80 & 1.914 & 560 & 5.064 & 1300 & 7.716 & 3800 & 13.19 \\
\hline 90 & 2.030 & 580 & 5.154 & 1400 & 8.007 & 3900 & 13.37 \\
\hline 100 & 2.140 & 600 & 5.242 & 1500 & 8.288 & 4000 & 13.53 \\
\hline 120 & 2.344 & 620 & 5.328 & 1600 & 8.560 & 4100 & 13.70 \\
\hline 140 & 2.532 & 640 & 5.413 & 1700 & 8.823 & 4200 & 13.87 \\
\hline 160 & 2.707 & 660 & 5.498 & 1800 & 9.079 & 4300 & 14.03 \\
\hline 180 & 2.871 & 680 & 5.580 & 1900 & 9.327 & 4400 & 14.20 \\
\hline 200 & 3.026 & 700 & 5.662 & 2000 & 9.570 & 4500 & 14.36 \\
\hline 220 & 3.174 & 720 & 5.742 & 2100 & 9.806 & 4600 & 14.52 \\
\hline 240 & 3.315 & 740 & 5.822 & 2200 & 10.04 & 4700 & 14.67 \\
\hline 260 & 3.451 & 760 & 5.899 & 2300 & 10.26 & 4800 & 14.83 \\
\hline 280 & 3.581 & 780 & 5.976 & 2400 & 10.48 & 4900 & 14.98 \\
\hline 300 & 3.707 & 800 & 6.053 & 2500 & 10.70 & 5000 & 15.13 \\
\hline
\end{tabular}

Example. At $f=2000 \sim, \alpha _ { 0 } = 9 . 5 7 0 \longdiv { 4 5 ^ { \circ } ; \quad \alpha = 9 . 5 7 0 / 4 5 ^ { \circ } }$

Skin-Effect Impedance Ratio for Nonspiralled Stranded Conductors of Non-Magnetic Metal

In order to consider the impedance ratio for a stranded conductor in its simplest case, we may assume that all spirality effects are absent, and, therefore, that the conductor is stranded without any twisting, or, that if twisting occurs, the spirality effects of the twisting may be ignored. The effect of stranding a conductor will then be to increase its effective diameter, with-

14. Bibliography No. 85 . 
out altering the cross-section of metal. Let $A B C$, Fig. 25, be the cross-section of a solid round wire of great length, and remote from its return conductor, or from other disturbing conductors. Let its radius be $X \mathrm{~cm}$., and its substance have a conductivity $\gamma$ abmhos per $\mathrm{cm}$., and a permeability $\mu=1$. Then let the above conductor be divided into a number of parallel strands, symmetrically insulated, spaced, and distributed; so that the total cross-section, including all insulation between strands, of the new stranded conductor $A B C$ is increased $n$ times or

and

$$
\pi X_{1}^{2}=n \pi X^{2}
$$

sq. $\mathrm{cm}$.

$$
X_{1}=X \sqrt{n}
$$

The stranded conductor will not differ in permeability from the
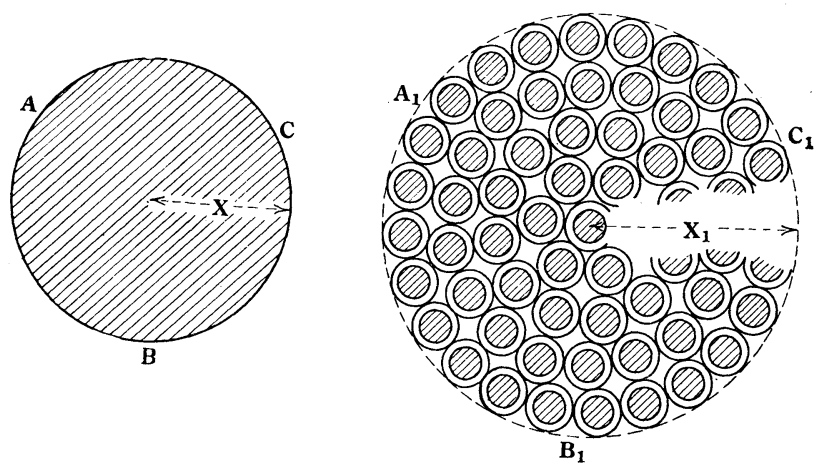

FIG. 25

solid conductor, but will differ therefrom in longitudinal electric conductivity. The stranded conductor will have the same total linear conductance as the solid conductor; but its average conductivity over the cross-section will be $n$ times less. Consequently, the propagation constant $\alpha_{1}$ of the stranded conductor will be:

$$
\begin{array}{r}
\alpha_{1}=\sqrt{4 \pi \gamma_{1} \mu \omega} \sqrt{45^{\circ}}=\sqrt{4 \pi \frac{\gamma}{n} \mu \omega} \sqrt{45^{\circ}}=\frac{\alpha_{0}}{\sqrt{n}} \\
\mathrm{~cm}^{-1} \angle
\end{array}
$$

Therefore the quantity $\alpha_{1} X_{1}$ for the stranded conductor is

$$
\alpha_{1} X_{1}=\frac{\alpha_{0}}{\sqrt{n}} \cdot X \sqrt{n}=\alpha_{0} X
$$


or is the same as for the solid wire. We thus conclude, from an inspection of (68), that the impedance $\operatorname{ratio} Z / R$, as well as its components $R^{\prime} / R$, and $L^{\prime} \omega / R$, are the same as for the metallically equisectional solid conductor. This is a property of conductors already known experimentally. ${ }^{15}$

Moreover, formulas (42) and (43), relating to the electric and magnetic forces and flux densities at any point within a solid conductor, ,clearly apply also to a non-spiralled symmetrically stranded conductor, if the radius $x$ is expressed as a fractional part of the total radius $X$, in each case. Thus the values of $\eta_{x}, i_{x}, \mathfrak{H}_{x}$ and $\mathscr{B}_{x}$, at half radial depth, bear the same complex numerical ratio to the corresponding values at the surface, in both stranded and solid conductors. The actual values of these

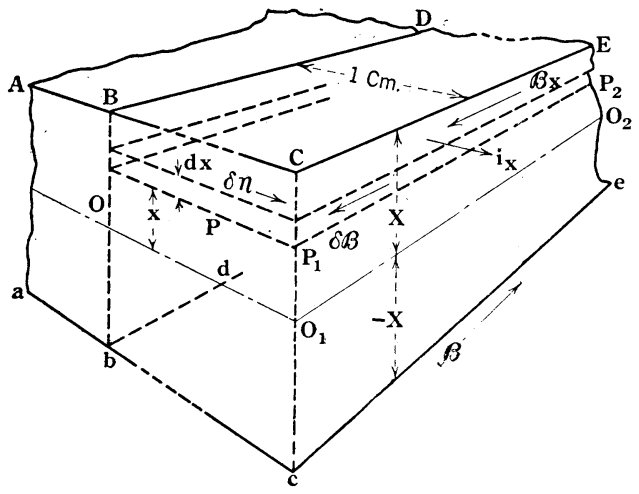

FIG. 26

quantities at the surface will not, however, be the same in both cases, although the computations are readily made with (54) and (64).

Skin Effect on Uniform Flat Strips of Indefinitely GREAT WIDTH

The problem of skin effect in flat strips, of indefinitely great width, remote from disturbing alternating magnetic fields, seems to have first been solved by Lord Rayleigh ${ }^{16}$ in 1886 , and solutions have been given in various forms by a number of writers since that date. The steps in the demonstration are, however, presented here, because the forms of the final results are believed to

15. Pender, Bibliography No. 101.

16. Bibliography, No. 6. 
offer particular advantages for engineers. Let $A B C c b a$, Fig. 26 , be one edge of a long wide and flat strip, of uniform conductor, whose midplane is at $O O_{1} O_{2}$. The length of the strip is parallel to $O O_{1}, B C$, or $b c$. The breadth across the strip is parallel to $\mathrm{O}_{1} \mathrm{O}_{2}, \mathrm{CE}$ or $c e$. Between the cross-sections at $\mathrm{BObdB}$ and C $O_{1} c e E$ there is supposed to be a length of $1 \mathrm{~cm}$. of the strip. The half thickness of the strip $O B$, or $O_{1} C$, is taken as $X \mathrm{~cm}$. and any layer $P P_{1} P_{2}$ in the strip has a distance of $x \mathrm{~cm}$. from the midplane. Let $\gamma$ be the conductivity of the metal, in abmhos per $\mathrm{cm} ., \mu$ the uniform permeability, $\omega$ the impressed angular velocity of the sinusoidal current in the steady state, in the direction $A B C$. Then, if the current density at the layer $x$ is $i_{x}$ absamperes per sq. $\mathrm{cm}$. as indicated by the arrow, the magnetic intensity $\mathfrak{H}_{x}$ will vanish at the midplane, will increase left-handwards as we increase $x$ positively, and also increase right-handwards as we descend to the lower surface at $x=-X$. Then, if we consider an elementary layer of thickness $d x \mathrm{~cm}$. at $P P_{1} P_{2}$, the magnetic flux density on the top of this layer will be greater than that at the bottom, the difference being, by electromagnetic theory:

or

$$
d \wp_{x}=4 \pi \mu i_{x} \cdot d x
$$

gausses $\angle$

$$
\frac{d B_{x}}{d x}=4 \pi \mu i_{x} \quad \frac{\text { gausses }}{\mathrm{cm} . \text { depth }} \angle
$$

The increase of electric intensity $d r_{x}$ in the layer is

$$
\begin{aligned}
& d \eta_{x}=\frac{d \Theta_{x}}{d t} \cdot d x=j \omega B_{x} \cdot d x=\rho . d i_{x} \quad \frac{\text { abvolts }}{\text { linear cm. }} \angle \\
\therefore & \frac{d i_{x}}{d x}=j \frac{\omega \Theta_{x}}{\rho}=j \gamma \omega \Theta_{x} \quad \frac{\text { absamperes }}{\text { cm.depth }{ }^{2}} \angle
\end{aligned}
$$

Differentiating (86) with respect to $x$ and substituting (88)

$$
\frac{d^{2} \Theta_{x}}{d x^{2}}=j 4 \pi \gamma \mu \omega \Theta_{x}=\alpha^{2} \Theta_{x} \quad \frac{\text { gausses }}{\mathrm{cm} .^{2}} \angle
$$

where the propagation constant

$$
\begin{gathered}
\alpha=\sqrt{j 4 \pi \gamma \mu \omega}=\sqrt{4 \pi \gamma \mu \omega} / 45 \\
=\sqrt{2 \pi \gamma \mu \omega}+j \sqrt{2 \pi \gamma \mu \omega}=\alpha_{2}+j \alpha_{2} \quad \mathrm{~cm}^{-1} \angle
\end{gathered}
$$


Differentiating (88) with respect to $x$ and substituting (86),

$$
\frac{d^{2} i_{x}}{d x^{2}}=j 4 \pi \gamma \mu \omega i_{x}=\alpha^{2} i_{x} \quad \frac{\text { absamperes }}{\mathrm{cm}^{4}} \angle
$$

The solutions of (89) and (91) are

$$
i_{x}=A_{1} \cosh \alpha x+B_{1} \sinh \alpha x \quad \frac{\text { absamperes }}{\text { sq. cm. }}
$$

At $x=X, i_{X}=A_{1} \cosh \alpha X+B_{1} \sinh \alpha X \quad$ " " $\angle$ (93)

at $x=-X, i_{-X}=A_{1} \cosh (-\alpha X)+B_{1} \sinh (-\alpha X)$ " " $\angle$ (94)

$$
=A_{1} \cosh \alpha X-B_{1} \sinh (\alpha X) \quad \text { " " } \angle
$$

But $i_{x}$ must have the same value in (93) and (95), which can only be satisfied with $B_{1}=0$. Consequently

$$
i_{x}=A_{1} \cosh \alpha x \quad \frac{\text { absamperes }}{\text { sq. cm. }} \angle
$$

where $\alpha x$ is a semi-imaginary quantity, or has $\angle 45^{\circ}$ as an argument. Dividing by (93), with $B_{1}=0$, we obtain

$$
\frac{i_{x m}}{i_{\mathrm{x} m}}=\frac{i_{x r}}{i_{\mathrm{x} r}}=\frac{i_{x}}{i_{\mathrm{x}}}=\frac{\cosh \alpha x}{\cosh \alpha X} \quad \text { numeric } \angle
$$

where the subscripts $m$ indicate maximum cyclic, and the subscripts $r$ root-mean-square values.

The average r.m.s. current density over the cross-section is

$$
\begin{array}{r}
i_{q r}=\frac{1}{X} \int_{0}^{\mathrm{x}} i_{x r} \cdot d x=\frac{1}{X} \cdot \frac{i_{X r}}{\cosh \alpha X} \cdot \int_{0}^{\mathrm{x}} \cosh \alpha x \cdot d x \\
\frac{\text { absamperes }}{\text { sq. cm. }}< \\
=\frac{1}{\alpha X} \cdot \frac{i_{X r}}{\cosh \alpha X} \cdot \sinh \alpha X=i_{X r} \frac{\tanh \alpha X}{\alpha X} \\
\frac{\text { absamperes }}{\text { sq. cm. }} \angle
\end{array}
$$


But $i_{X r}=\gamma \eta_{X^{r}}$, is the uniform current density which the impressed e.m.f. would produce over the entire cross-section of the strip at zero frequency. Hence

$$
\frac{i_{X r}}{i_{q r}}=\frac{i_{X m}}{i_{q m}}=\frac{Z}{R}=\frac{\alpha X}{\tanh \alpha X} \quad \text { numeric } \angle
$$

When $\alpha X$ has a modulus greater than $6.0, \tanh \alpha X=1.0 / 0^{\circ}$ very nearly, and

$$
\frac{Z}{R}=\alpha X
$$

The skin-effect impedance ratio being $\alpha X / \tanh \alpha X$, let this complex quantity be

$$
\frac{Z}{R}=M / \beta
$$

Then

$$
\frac{R^{\prime}}{R}=M \cos \beta
$$

and

$$
\frac{L^{\prime} \omega}{R}=M \sin \beta
$$

Dividing by $\omega$,

$$
\frac{L^{\prime}}{R}=\frac{M}{\omega} \sin \beta
$$

As an example we may take the case of an indefinitely wide copper strip $0.2 \mathrm{~cm}$. thick and operated at a frequency of $2183 \sim$;

so that

$$
\alpha=\sqrt{4 \pi \cdot 1 \cdot \frac{1}{1724} \cdot 2 \pi \cdot 2183 / 45^{\circ}}=10 \underline{/ 45^{\circ}} .
$$

Then

$$
X=0.1 \mathrm{~cm} \text {. and } \alpha X=1.0 / 45^{\circ} .
$$

By Tables, ${ }^{17} \tanh 1.0 \angle 45^{\circ}=0.9308 / 27^{\circ} .044$ 
so that $\frac{Z}{R}=\frac{1.0 / 45^{\circ}}{0.9308 / 27^{\circ} .044}=1.074 / 17^{\circ} .956$

$$
=1.022+j 0.331 ; \text { and } \frac{R^{\prime}}{R}=1.022
$$

The skin effect resistance ratio is therefore 1.022 .

Again, using (97) and (100)

$$
\frac{i_{x m}}{i_{q m}}=\frac{i_{x r}}{i_{q r}}=\frac{\alpha X}{\sinh \alpha X} \cdot \cosh \alpha x=\frac{\cosh \alpha x}{\left(\frac{\sinh \alpha X}{\alpha X}\right)}
$$

numeric $\angle(105)$

The complex $\frac{\sinh \alpha X}{\alpha X}$ has been tabulated and charted for the argument $/ 45^{\circ}$ up to $|\alpha X|=3.0$. Thus in the case considered, by Tables, $\frac{\sinh 1.0 / 45^{\circ}}{1.0 / 45^{\circ}}=1.0055 / 9^{\circ} .531$; so that in this case

$$
\frac { i _ { x r } } { i _ { q r } } = 0 . 9 9 4 5 \longdiv { 9 ^ { \circ } . 5 3 1 } \operatorname { c o s h } \alpha x
$$

numeric $\angle(106)$

At the midplane, where $x=0$, and $\cosh 0 / 45^{\circ}=1.0 / 0^{\circ}$, the local current density is about 0.5 per cent. less than the average current density and lags behind it $9^{\circ} .5$. At the surface, where $X=0.1$, and $\alpha X=1.0 / 45^{\circ}, \cosh 1.0 / 45^{\circ}=1.080 / 27^{\circ} .487$; so that $\frac{i_{X r}}{i_{q r}}=1.074 / 17^{\circ} .956$ and the surface current density is 7.4 per cent greater than the average and leads it nearly $18^{\circ}$.

The external skin thickness $\delta \mathrm{cm}$., which, carrying the surface current density $i_{X r}$, would be the equivalent of the half thickness of strip carrying the average current density $i_{q r}$, is defined by the condition

$$
\frac{\delta}{X}=\frac{R}{R}
$$

or

$$
\delta=X \frac{R}{R},
$$

or

$$
\delta=\left|\frac{\tanh \alpha X}{\cdot \alpha X}\right| \frac{X}{\cos \beta}
$$


For frequencies sufficiently high to make $|\alpha X|>6.0$, this approximates closely to

$$
\delta=\left|\frac{1}{\alpha}\right| \sqrt{2}=\frac{1}{\alpha_{2}}
$$

Thus, in the case considered, $\frac{\tanh 1.0 / 45^{\circ}}{1.0 \angle 45^{\circ}}$ is, by tables, 0.9308 $\sqrt{17^{\circ} .956}$, and $\delta=0.09308 / \cos \left(17^{\circ} .956\right)=0.09308 / 0.9513$, $=0.0978 \mathrm{~cm}$., approaching more and more nearly to $1 / \alpha_{2} \mathrm{~cm}$. as the frequency increases.

Returning to (89), the solution for $B_{x}$ is

$$
\beta_{x}=A_{2} \cosh \alpha x+B_{2} \sinh \alpha x
$$

where $\alpha$, as before, stands for the semi-imaginary

$$
\sqrt{4 \pi \gamma \mu \omega} / 45^{\circ}=\alpha_{2}+j \alpha_{2} \quad \mathrm{~cm}^{-1} \angle
$$

In order that $\beta_{X}=-\beta_{-X}$; i.e. that the flux-densities at opposite surfaces shall be equal and opposite, it is necessary that $A_{2}$ should vanish, and this leaves

$$
\beta_{x}=B_{2} \sinh \alpha x
$$

gausses $\angle$ (112)

and

$$
\frac{\mathfrak{F}_{x m}}{\mathfrak{H}_{\mathrm{x} m}}=\frac{\mathfrak{F}_{x r}}{\mathfrak{F}_{\mathrm{x} r}}=\frac{\AA_{x r}}{\Theta_{\mathrm{x} r}}=\frac{\sinh \alpha x}{\sinh \alpha X}
$$

The r.m.s. surface flux density $B_{X r}$ is determined by the fact that if $I_{r}$ is the r.m.s. value of the current per unit breadth of strip, in absamperes per $\mathrm{cm}$.

$$
\mathrm{B}_{\mathrm{x} r}=2 \pi \mu I_{r}
$$

and

$$
\wp_{x r}=\frac{2 \pi \mu I_{r}}{\sinh \alpha X} \cdot \sinh \alpha x
$$

Thus in the case considered, if the r.m.s. current carried is say 1 ampere per $\mathrm{cm}$. of breadth, $I_{r}=0.1 / 0^{\circ}$, $\sinh 1.0 / 45^{\circ}=1.0055$ $/ 54^{\circ} .531$. Hence

$$
\Theta_{x r}=\frac{0.6283 / 0^{\circ}}{1.0055 / 54^{\circ} .531} \cdot \sinh \alpha x
$$


At the midplane where $x=0, \sinh \alpha x=0 / 45^{\circ}$, and $\beta_{0 r}=$ $0 \backslash 9^{\circ} .531$, i.e. vanishing flux density, lagging $9 .^{\circ} 53$ behind the phase of average current.

It will thus be observed that the change in form of a linear conductor from a solid cylinder to a wide flat strip, has the effect of substituting hyperbolic functions of a semi-imaginary variable $\alpha x$ for Bessel functions of a closely related semi-imaginary variable $\alpha_{0} x$ where $|\alpha|=\left|\alpha_{0}\right|$, and $\alpha=j \alpha_{0}$, the form of the fundamental equations (42)-(97) and (43)-(113) remaining unchanged.

As was first pointed out by Steinmetz ${ }^{18}$, the conditions of current density as we penetrate into the strip, correspond to those of current strength in a long pair of parallel a-c. lines, with distributed constants, a millimeter of depth corresponding perhaps to hundreds of kilometers of line length. In fact, formula (97) is identical with that which expresses the current strength at any point of a pair of wires in a telephone cable, with negligible inductance and leakance, short circuited at the distant end, which then corresponds to the midplane in the strip. Similarly, formula (113) for the ratio of magnetic voltage gradients in the strip, is identical with the formula for electric voltages across such a pair of wires. The propagation constant $\alpha$ is a semi-imaginary in each case, the linear leakance corresponding to conductivity, and linear resistance to permeability. Just as in the cable, the wave length is ${ }^{19}$

$$
\lambda=\frac{2 \pi}{\alpha_{2}}=\frac{2 \sqrt{2} \pi}{|\alpha|}
$$

so in the strip, the wave length is given by this formula, the $\mathrm{cm}$. or c.g.s. length unit being employed. Thus, in the case considered, where $\alpha=10 / 45^{\circ}$, and $\alpha_{2}$, the imaginary component of $\alpha$ is $7.071,|\alpha|=10$, and $\lambda=\frac{6.283 \times 1.414}{10}=0.8885 \mathrm{~cm}$.

That is, the rate of change of phase in the propagation of electric and magnetic intensities as we penetrate the strip, is one complete cycle, or 360 degrees, for $0.8885 \mathrm{~cm}$. i.e. $405^{\circ}$ per cm., and $40^{\circ} .5$ per $\mathrm{mm}$. Reflections from the midplane in a shallow strip, disturb

18. Bibliography No. 66 .

19. Bibliography No. 84 . 
this relation, which tends to be presented more nearly accurately as the thickness of the strip is increased.

The skin-effect theory of indefinitely wide strips, as outlined above, appears to be of but little service in the actual use of ordinary copper-strip conductors, owing to the large disturbing magnetic effects at the edges. It is, however, useful in relation to the use of copper-tube conductors, and especially when these have large diameter and thin wall. The wall thickness $X \mathrm{~cm}$. should then correspond to the half-thickness $X$ of a wide strip ${ }^{20}$; since the flux density must vanish at the inside wall of such a tube.

There is, however, another reason why the above skin-effect theory of strips should be considered, in spite of its very imperfect application to narrow strips; namely, because it applies with but little modification to the important case of magnetic skin effect in steel strips or laminae of sheet steel, if the permeability can be taken as constant at an average value. The discussion of that theory is out of place here; but it may be permissible to point out that formula (97) applies to the magnetic lamina case, when flux densities $B_{x}$ and $B_{\mathrm{x}}$ substituted for current densities $i_{x}$ and $i_{\mathrm{x}}$, and formula (113) likewise applies to the magnetic case, when electric current densities $i_{x}$ and $i_{\mathrm{x}}$ are substituted for $\Theta_{x}$ and $\Theta_{\mathrm{x}}$. That is, the theory of the magnetic strip case follows the same course as that of the electric strip case, above outlined, when magnetic and electric flux densities are mutually interchanged. Formulas (99), (100), (109), (110), (113) and others, then apply to both cases. It is evident that complex hyperbolic functions are a natural key to the actions in both cases.

Empirical Formula for Narrow Strips $1.6 \mathrm{~mm}$. Thick

The curves of Fig. 10, present the resistance ratios of three widths of $1.6 \mathrm{~mm}$. copper strip up to $5000 \sim$ at $60 \mathrm{~cm}$. spacing. From these curves an approximate empirical relation has been found between about 1000 and $5000 \sim$, namely

$$
\frac{R^{\prime}}{R}=0.308 f^{0 \cdot 21} w^{0 \cdot 163}
$$

numeric (118)

where $f$ is the impressed frequency, and $w$ the strip width in $\mathrm{cm}$. This empirical formula is clearly inapplicable at low frequencies; but serves to indicate the effect of increasing strip width for the range covered in these tests.

20. Bibliography No. 101, p. 1284. 


\section{List of Symbols Employed}

$A$, external inductance of a test loop (abhenrys).

$A, B$, arbitrary constants of electric current density in integration equation (absamperes per sq. cm. $\angle$ ).

$A^{\prime}, B^{\prime}$, arbitrary constants, magnetic intensity in integration equation (gilberts per cm. $\angle$ ).

$A_{1}, B_{1}$, arbitrary constants electric current density in integration equation (absamperes per sq. cm. $\angle$ ).

$A_{2}, B_{2}$, arbitrary constants, magnetic flux density in integration equation (gausses $\angle$ ).

$a$, length of a rectangular loop (cm.).

$\alpha=\sqrt{4 \pi \gamma \mu \omega} / 45^{\circ}$, propagation constant for a flat strip, a positive semi-imaginary $\left(\mathrm{cm} .^{-1} \angle\right)$.

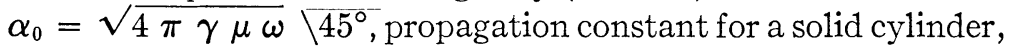
a negative semi-imaginary $\left(\mathrm{cm} .^{-1} \angle\right)$.

$\alpha_{1}$, propagation constant for a stranded cylinder, a negative semi-imaginary $\left(\mathrm{cm}^{-1} \angle\right)$.

$\alpha_{2}, \quad$ imaginary or real component of a semi-imaginary propagation constant $\left(\mathrm{cm} \cdot{ }^{-1}\right)$.

$\beta, \quad$ argument of a complex number expressing a skin-effect impedance ratio (radians or degrees).

$\beta_{x}, \beta_{x m}, \wp_{x r}$, instantaneous, maximum cyclic, and r.m.s. values of flux density at point of radius $x$ (gausses $\angle$ ).

$b$, interaxial distance between two parallel wires $(\mathrm{cm}$.

$\gamma=1 / \rho$, electric conductivity of material (abmhos per $\mathrm{cm}$. )

$C, \quad$ skin-effect inductance ratio $L^{\prime} / L$ (numeric)

$d$, diameter of round conductor $(\mathrm{cm}$.)

also sign of differentiation.

$\delta$, thickness of skin carrying the same current at surface flux density as the whole cross-section at varying densities $(\mathrm{cm})$.

also the argument of a complex quantity $z / \delta$ in a Bessel function (radian or degree).

$\epsilon=2.71828 \ldots$, Napierian base.

$\eta_{x}, \eta_{x m}, \eta_{x}$, instantaneous, maximum cyclic and r.m.s. values of electric intensity at point of radius $x$ (abvolts per $\mathrm{cm} . \angle$ )

$\eta_{\mathrm{x}}, \eta_{\mathrm{x} m}, \eta_{\mathrm{x} r}$, instantaneous, maximum cyclic and r.m.s. values of electric intensity at surface of radius $X$ (abvolts per cm. $\angle$ ).

$f$ frequency of impressed alternating current (cycles per sec.) 
$\mathfrak{F}_{x}, \mathfrak{H}_{x m}, \mathfrak{H}_{x r}$, instantaneous, maximum cyclic and r.m.s. values of magnetic intensity at point of radius $x$ (gilberts per cm. $\angle)$.

$I_{\mathrm{M}}, I_{\mathrm{x}}$, r.m.s. alternating currents in the sides of a Heaviside bridge (amperes $\angle$ ).

$I_{m}, I_{r}$, maximum cyclic and r.m.s. values of alternating current in a conductor (absamperes $\angle$ ).

$i_{\mathrm{x}}, i_{\mathrm{x} m}, i_{\mathrm{x} r}$, instantaneous, maximum cyclic, and r.m.s. values of current density at surface of radius $X$ (absamperes per sq. cm. $\angle$ ).

$i_{x}, i_{x m}, i_{x}$, instantaneous, maximum cyclic, and r.m.s. values of current density at radius $x$ (absamperes per sq. $\mathrm{cm} . \angle$ ). $i_{q}, i_{q m}, i_{q r}$, instantaneous, maximum cyclic, and r.m.s. values of vector average current density over cross-section (absamperes per sq. cm. $\angle$ ).

$j=\sqrt{-1}$

$J_{0}(z)$, zero-order Bessel function of first kind, for a variable $z$ (numeric).

$K_{0}(z)$, zero-order Bessel function of second kind, for a variable $z$ (numeric).

$J_{1}(z), \quad$ first-order Bessel function of first kind, for a variable $z$ (numeric).

$K_{1}(z)$, first-order Bessel function of second kind, for a variable $z$ (numeric).

$K$, twice the mutual inductance per turn of the secondary winding in Heaviside bridge (henrys per turn).

$k$, twice the resistance of one $\mathrm{cm}$. length of Heavisidebridge slide wire (ohms per $\mathrm{cm}$.).

$L$, linear internal inductance of conductor in test loop without skin effect (abhenrys per linear cm.).

$L, \quad$ inductance of the test loop at zero frequency (henrys or abhenrys).

$L^{\prime}, \quad$ inductance of the test loop at test fequency, with skin-effect (henrys or abhenrys).

also linear internal inductance of conductor at test frequency, with skin-effect (abhenrys per linear $\mathrm{cm}$.). $L^{\prime \prime}{ }_{\mathrm{p}}, L^{\prime \prime}{ }_{\mathrm{x}}$, inductance in the $P$ and $X$ arms of a Heaviside bridge (henrys).

$L_{\mathrm{p}}^{\prime}, L^{\prime}{ }_{\mathrm{x}}$, inductances in the $P$ and $X$ arms of a Heaviside bridge excluding slide wire (henrys).

$l_{0}$, reading on Heaviside-bridge slide wire with loop shortcircuited (cm.). 
$l_{1}, \quad$ reading on Heaviside-bridge slide wire with loop inserted (cm.).

$l$, total length of slide wire in Heaviside bridge (cm.).

$\lambda$, wave-length of propagation (cm.).

$M=|Z / R|$, modulus of a complex number expressing a skineffect impedance ratio (numeric).

$\mu, \quad$ permeability of a substance to magnetic force [gausses per (gilbert per $\mathrm{cm}$.)].

also twice the inductance change per $\mathrm{cm}$. of Heaviside bridge slider (abhenrys $/ \mathrm{cm}$ ).

$m$, a constant coefficient of the variable in a Bessel function (numeric $\angle$ ).

$m$, mutual inductance in a Heaviside bridge wire (henrys). $m_{0}$, mutual inductance in a Heaviside bridge wire for balance with loop shorted (henrys).

$m_{1}$, mutual inductance in a Heaviside bridge wire for balance with loop inserted (henrys).

$n$, the general term number in an expanded series, also ratio of amplification of cross-section in stranding a conductor (numeric).

$n_{0}$, number of turns in secondary of mutual inductance in Heaviside bridge wire for balance with loop shorted (numeric).

$n_{1}$, number of turns in secondary of mutual inductance in Heaviside bridge wire for balance with loop inserted (numeric)

p, order of a Bessel function (numeric).

$\pi=3.14159 \ldots$

$R, \quad$ resistance to continuous currents of the test loop without skin effect (ohms).

also linear resistance to continuous currents of the test loop (absohms per linear $\mathrm{cm}$.).

$R^{\prime}$, resistance to alternating currents of the test loop with skin-effect (ohms).

also linear resistance to alternating currents of the test loop with skin effect (absohms per linear $\mathrm{cm}$.).

$R_{\mathrm{P}}{ }^{\prime \prime}, R_{\mathrm{x}}{ }^{\prime \prime}$, resistances in $P$ and $X$ arms of a Heaviside bridge (ohms).

$R_{\mathrm{P}}{ }^{\prime}, R_{\mathrm{x}}{ }^{\prime}$, resistances in $P$ and $X$ arms of a Heaviside bridge excluding slide wire (ohms).

r.m.s., contraction for root-of-mean-square.

$\rho=1 / \gamma$, resistivity of material (absohms $\mathrm{cm}$.). 
$t$, time elapsed from a selected epoch (seconds).

$w, \quad$ width of a flat strip (cm.).

$X, \quad$ external radius of a cylindrical conductor $(\mathrm{cm}$.$) .$

$x$ radial distance of a point on a cylindrical cross-section from the axis $(\mathrm{cm}$.).

$X, \quad$ half thickness of a flat strip conductor (cm.).

$X, \quad$ total radial thickness of the wall of a tubular conductor (cm).

$X^{\prime}$, linear reactance of conductor in test loop, with skineffect (absohms per linear cm.).

$X$, equivalent external radius of a stranded cylindrical conductor (cm.).

$Z=R^{\prime}+j X^{\prime}$, linear impedance of conductor in test loop with skin-effect (absohms per linear cm. $\angle$ ).

$Z_{\mathrm{M}}, Z_{\mathrm{N}}, Z_{\mathrm{P}}, Z_{\mathrm{x}}$, impedances in the four arms of a Heaviside bridge (ohms $\angle$ ).

$\omega=2 \pi f$, angular velocity of impressed alternating current (radians per second). .

$\sim \quad$ sign for " cycles per second."

$|z|, \quad$ sign for the modulus of a complex quantity $z$ (numeric)

$\underline{\bar{z}}, \quad$ sign for the argument of a complex quantity $z$ (radians or degrees).

\section{BIBLIOGRAPHY ON THE SUBJECT OF "SKIN EFFECT"}

Arranged According to Date, without Pretensions as to Completeness.

1873

1. J. Clerk Maxwell, Electricity and Magnetism. Vol. II, p. 291, 1873.

1884

2. Oliver Heaviside, Effective Resistance and Inductance of a Round Wire. The Electrician, 1884, p. 583; 1885, p. 489. Electrical Papers, Vol. I, pp. 353, 429; Vol. II, pp. 50, 97.

3. J. H. Poynting, Phil. Trans. 1884; 1885, p. 277.

1886

4. D. E. Hughes, Journ. Soc. Tel. Eng. Jan. 28, 1886, pp. 6, 354.

5. H. F. Weber, Elec. Review, Vol. XVIII, pp. 30, 321, 1886.

6. Lord Rayleigh, Phil. Mag., 1886, pp. 382, 469. Scientific Papers, Vol. II, pp. 486, 495.

7. J. Stefan, Sitzungsberichte der Wiener Akad. der Wiss. XCV II, p. 917, 1887. Wied. Ann. XLI p. 400, 1890.

8. Oliver Lodge, Journ. of Soc. of Arts, May 1888; Phil. Mag. 26, p. 217, 1888. 


\section{9}

9. Lord Kelvin, Journ. Soc. of Tel. Eng. Vol. 18, p. 36, 1889, Math. and Physical Papers, Vol. III, p. 491, 1889.

10. H. Hertz, Electric Waves, p. 160; Wied. Ann., 1889, p. 395.

11. W. M. Mordey, Inst. El. Eng., May 23, 1889, Electrician, May 21, 1893.

\section{3}

12. V. Bjerknes, Resonators, Wied. Ann., 1893, p. 592.

13. A. Gray, Absolute Measurements in Electricity and Magnetism, Vol. II, part 1, p. 325, 1893.

14. A. E. Kennelly, "Impedance" Trans. A. I. E. E. Vol. 10, Apr. $18,1893$.

15. J. J. Thompson, Recent Researches, 1893.

$$
1894
$$

16. A. E. Kennelly, On the Fall of Pressure in Long Distance Alternating Conductors, El. World, p. 17, Vol. 23, 1894.

1895

17. Eric Gerard, Lecons sur l'Electricité, 1895.

\section{6}

18. D. C. Jackson, Alternating Currents, p. 147, 1896 "A Consideration of 'Skin Effects' ", Electrical World, Jan. 16, 1897.

\section{7}

19. Mascart and Joubert, Calculations of Bessel Functions, l'Electricité et la Magnetisme, Vol. 1, p. 718, 1897.

20. W. H. Preece, "Effective Thickness of Oscillators." Proc. Royal Inst. Vol. XV, p. 472, 1897.

21. I. A. Taylor, Electrical Eng. May 15, 1897.

22. W. L. Emmet, Alternating Current Wiring and Distribution, 1898.

23. A. Righi, Effective Thickness of Oscillators, Optik der electrischen Schwingungen, p. 14, 1898.

\section{9}

24. E. H. Barton, "The Equivalent Resistance and Inductance of a Wire to an Oscillatory Discharge." Phil. Mag. 47, p. 433, 1899.

\section{0}

25. C. Feldmann and J. Herzog, The Resistance Offered by Iron Conductors to Alternating Current, Elektrotech. Zeitsch. Oct. 11, 1900., Electrician, Nov. 23, 1900.

26. B. Hopps, Electrician, Oct. 12, 1900.

27. G. Mie, Electric Waves on Two Parallel Wires, Wied. Ann. 2, p. 201, 1900.

28. E. Neculcea, "Resistance et self induction d'un fil dans une décharge oscillante," La Lumière El. 23, p. 477, 1900.

29. E. Arnold, J. L. la Cour, Table of Skin Effect Calculated for Copper and Aluminum Wires, Die Wechselstromtechnik I, p. 369, III, p. $112,1902$.

30. C. A. Chant, "Skin Effect in Electrical Oscillators," Amer. Journ. of Science, Vol. 13, 1902. 
31. H. M. Macdonald, Oscillators, Current Diffusion, "Electric Waves," p. 76,1902 .

1903

32. F. Dolezalek, Skin Effect in Stranded Conductors to Oscillatory Currents. Ann.d. Phys. (4) 12, p. 1142, 1903.

33. J. Zenneck, Ann. d. Phys. 11, p. 1141, 1903, Elektromagnetische Schwingungen, p. 403.

1904

34. A. E. Kennelly, "The Alternating Current Theory of Transmission Speed over Submarine Telegraph Cables." Proc. Int. Elec. Congress, Sec. A, 1904.

35. H. Poincaré, Oscillations Electriques, p. 246, 1904.

36. H. Poincaré and F. K. Vreeland, Maxwell's Theory and Wireless Telegraphy, pp. 49, 83, 145, 1904.

37. A. Sommerfeld, Long Solenoids at Wireless Frequencies, Ann.d. Phys. (4) 15 p. 673, 1904; 24, p. 609, 1907.

38. M. Wein, Passage of High-Frequency Currents through Coils; Ann. d. Phys. 14, p. 1, May 1904.

1905

39. A. Broca and Turchini, Resistance of Metal Wires for High-Frequency Currents, Comtes Rendus, 140, p. 1238, May 8, 1905.

40. M. Brylinski, Soc. Int. Elect. Bull. 1905, p. 326; 1906, pp. 255-300; Electrician 57, p. 970, Oct. 5, 1906.

\section{6}

41. A. Battelli, Electric Resistances of Solenoids for High-Frequency Currents, Accad. Lincei, Atti: 15, pp. 255, 471, 529; 1906, 17. 61.

42. Th. Black. Long Solenoids at Wireless Frequencies. Ann. $d$. Phys. (4) 19, p. 157; 1906.

43. J. G. Coffin, "The Influence of Frequency upon the Self Inductance of Coils." Bull. Bureau of Standards, Vol. 2, p. 275, 1906.

44. G. Picciati, Resistance of Solenoids for Variable Currents, $N$. Cimento, II, p. 351, May, 1906.

\section{7}

45. L. Cohen, "Effect of Frequency on Resistance and Inductance of Coils," Bureau of Standards Bull. 4, p. 161, 1907. Phys. Review, 25, pp. 143-144, Aug. 1907.

46. F. Dolezalek and H. G. Moller, "Method of Compensating Skin Effect in Cables," Ann. d. Phys. 22, 3 p. 559, 1907.

47. E. Giebe, Physikalisch-Technische Reichsanstalt, 1906, Measurement of Self Inductance at High Frequencies. Zeitschrift f. Instr'kde. 27 p. $153,1907$.

48. O. A. Kenyon, Standard Hand Book, 1907, Sect. (2), 196.

49. A. Sommerfeld, Resistance of a Coil for Alternating Current. Phys. Zeitsch. 8, p. 805, Nov. 1, 1907.

50. L. Lichenstein, Tests on Rails, Electrician, Aug. 23, 1907.

51. A. Russell, Proc. Phys. Soc. of London, Vol. XXI, p. 581, 1907. " Effective Resistance and Inductance of Concentric Mains," Phil. Mag. 17, p. 524, 1909 . Theory of Alternating Currents, Vol. I, pp. 46,376 . 
52. E. Stirnimann, Special Mode of Constructing Cables to Eliminate Skin Effect. Electrotech. Zeitsch., Vol. 28, pp. 581, 610, 1907.

53. M. Wien, Flat Strips at Wireless Frequencies. Jahrb. d. drahtlosen Teleg. 1, p. 469, 1907.

\section{8}

54. P. Boucherot, Bull. de la Soc. Intern. des. Electrs. 1905, p. 326; 1908, p. 663 .

55. A. Esau, Long Solenoids, Diss. Berlin, 1908. F. Piola, Effective Resistance and Reactance of a Solenoid having a conducting Magnetic Core; Atti dell' Assoc. Elettr. Ital., 12, p. 497, 1908.

56. F. Rusch, Electrotech. Zeitsch., 29, p. 1079, Nov. 5, 1908.

57. R. T. Wells, "Impedance of a Solenoid with Cylindrical Metal Core." Phys. Review 26, p. 357, 1908.

58. Sir Luke White's Committee in the House of Lords, London. " Discussion of the Skin Losses in Power-Transmission Cables." Nov., 1908.

1909

59. J. Bethenod, "Resistance of Thin Plates to Alternating Current." Jahrb. d. drahtl. Teleg. 2, 4, p. 397, 1909. La Lumière Electr. 9, p. $232,1909$.

60. W. A. Del Mar, Electric Power Conductors, pp. 42, 284, 1909.

61. E. Jahnke and F. Emde. Functionentafeln mit Formeln and Kurven, p. $142,1909$.

62. R. Lindemann, Resistance of Stranded Cables for High-Frequency Electrical Oscillations. Deutch. Phys. Gesellschaft, Verh. 11, 22, p. 682,$1909 ; 15,7$, p. 219, 1913.

63. Alex. Meissner, Short Solenoid at Wireless Frequencies; Jahrb. d. drahtl. Teleg. 3, p. 57, 1909.

64. J. W. Nicholson, "The Self-Inductance of Two Parallel Wires." Phil. Mag. 17, p. 255, Feb. 1909.

65. Ernst Orlich, Kapazität und Induktivität, p. 134, 1909.

66. C. P. Steinmetz, Transient Electrical Phenomena and Oscillations, 1909 , p. 375 .

\section{0}

67. J. A. Fleming, "Measurement of High-Frequency Resistance of Wires," Electrician, 64, p. 716, Feb. 11, 1910.

68. F. F. Fowle, Electrical World, Vol. 56, 1910, Vol. 57, 1911; Journ. 46 p. 487, April 1911.

69. A. R. Garnière, Ind. Elect. 19, pp. 341, 396, 1910.

70. Alfred Hay, Electrical Distributing Net Works and Transmission Lines, 1910, p. 38.

71. C. E. Hay, "Measurement of Self Induction and Effective Resistance at High Frequency," Elect. Rev. 67, p. 965, 1910.

72. H. G. Savidge, Tables of Bessel Functions, Phil. Mag. 19, p. 49, 1910.

\section{1}

73. P. Girault, "Sur la Comprehension de 1'effet de peau," Bull. de la Soc. Int. des Electrs., 3, 1, p. 543, 1911.

74. A. Hay, "A Graphical Method of Discussing the Skin Effect" Inst. Elect. Engin., Vol. 46, p. 487. 
75. Karl Herrmann, Experimental Results with Calorimeter Method. Verh. d. Phys. Gesellschaft, 13, p. 978, 1911.

76. M. Jouaust, Bull. de la Soc. des Electrs., June 1911, p. 582.

77. H. G. Moller, Coils at High Frequency, Ann. de. Phys. (4) 36, p. 738, 1911.

78. H. Pender, Principles of Electrical Engineering, 1911, p. 222.

79. M. C. Villiers, "Resistance of Steel Rails to Alternating Current" Bull. Soc. Int. des Electrs., June, 1911, p. 529.

\section{2}

80. L. W. Austin, " Suitable Wire Sizes for High-Frequency Resistance." Acad. Sci. Journ. 2, p. 212, March 4, 1912.

81. M. E. Brylinski, " The Resistance of Iron to Alternating Currents," Bull. Soc. Int. d Electrs., March, 1912.

82. H. W. Edwards, " Distribution of Current in Square and Rectangular Cross-sections," Electrician, Feb. 9, 1912.

83. A. C. Jolley and A. F. Burgess, "Experimental Determination of the Inductance of Linear Conductors," Electrician, Nov. 24, 1912.

84. A. E. Kennelly, The Applications of Hyperbolic Functions to Electrical Engineering Problems, 1912, London University Press.

85. E. B. Rosa and F.W. Grover, Bull. Bur. Standards, Vol. 8, p. 172, 1912.

86. D. B. Rushmore, "Frequency", A. I. E. E. Proc. June, 1912.

87. A. G. Webster, Tables of Bessel Functions, British Assoc. for the Advancement of Science, Dundee, 1912 Section A.

88. H. Zahn, "Magnetic Skin Effect in High-Frequency Fields," Science Abstracts, 934 A, 1912.

1913

89. L. W. Austin, "The High-Frequency Resistance of Inductance." Journ. Wash. Acad. 3, p. 94, 1913.

90. H. B. Dwight, "Reactance of Stranded Conductors" Elect. World, April 19, 1913.

91. W. Rogowski, Current Distribution in Copper Conductors Embedded in Slots of A-C. Machines. Archiv f. Elektrotech, 2, p. 81, 1913.

92. W. O. Schumann," Uber die Verteilung des Wechselstromes in Unendlich Ausgedehnten Platten;" Elek. und Masch., July 27, 1913.

93. R. Swyngedauw, La Lumiére Electr. Ser. 2, 24, pp. 40, 74 103, 1913; Comptes Rendus, 157, p. 397, 1913.

94. A. B. Van Deusen, "Discrepancy in Skin Effect Formulas," Elec. World, Vol. 61, p. 459, 1913.

1914

95. L. W. Austin, Jahrbuch d. Drahtlosen Teleg. 8, p. 159, Feb. 1914.

96. H. Fassbender, "Bestimmung der Magnetischen Induktion der Heuslerschen Legierungen bei hohen Frequenzen." Archiv $f$. Elektrotech. 1914, p. 475.

97. L. Fleichmann, Discussion of Skin Effect in Continuous-Current Machines, Archiv f. Elektrotech., 2, p. 387, 1914.

98. A. T. Hinckley, "Skin Effect in Carbon Electrodes," Metallurgical and Chemical Engin., 12, p. 223, 1914.

99. A. E. Kennelly, Tables of Complex Hyperbolic and Circular Functions, 1914, Chart Atlas of Complex Hyperbolic and Circular Functions, 1914; both Harvard University Press. 
100. E. F. Northrup and E. J. Carson, "Skin Effect and AlternatingCurrent Resistance." Franklin Institute Journ., Feb., 1914.

101. H. Pender, American Handbook for Electrical Engineers, pp. 1281-1285, 1914, John Wiley \& Sons, Inc.

102. R. Richter, Extra Copper Losses in A-C. Machines, Archiv f. Elektrotech., 2, p. 518, 1914.

1915

103. G. Dettmar, Steel and Iron Wires for Overhead Lines in Germany. Elektrotech. Zeitsch., Jan. 28, 1915.

104. L. Lombardi, “ Sulla disuniforme distribuzione delle correnti alternate e dei flussi periodici di induzione nelle aste cilindriche di ferro," Rend. della $R$. Accademia delle Scienze Fisiche e Matematiche di Napoli, April, 1915.

105. J. M. Miller, "The Effective Resistance and Inductance of Iron and Bimetallic Wires," Bur. Stand. Bull., 1915, Electrical World, June, 1915. 
Discussion on "Experimental Researches on Skin EFfect in Conductors" (Kennelly, Laws and Pierce), San Francisco, Cal., Sept. 16, 1915.

H. B. Dwight (by letter): In the discussion of the measurement of the skin effect resistance ratio of copper strips, spaced at $60 \mathrm{~cm}$., it is stated that the large discrepancies between the theory for infinite strips, and the observations made, are believed to be due to power being dissipated by eddy currents. All distortions of current connected with skin effect may be called eddy currents, tut where the conductors are far apart and carry sine wave currents, the distortions of current are regular, and this case of skin effect obeys very similar laws to those governing round conductors.

In the case under discussion, formula (103) of the paper is used, which takes into account only the crowding of current, due to skin effect, toward the flat surface of the copper strips. A more important action is the crowding of current toward the edges of the strip, and this accounts for practically all of the skin effect observed at $60 \mathrm{~cm}$. spacing.

If the thickness of the strip is considered to diminish indefinitely, but the conductivity to increase so that the total resistance of the strip remains the same, then the only action is a crowding of current toward the edges of the strip. For this case, the skin effect resistance ratio can be shown mathematically to be the same as that of a round copper wire of $3 / 8$ times the resistance of the strip considered. Figs. 14 and 15 of the paper show that such a formula is inapplicable to strips of appreciable thickness since it gives ratios that are too large. However, it is possibly a closer calculation than the formula for infinite strip used, and it tends to show that if the ratios were calculated by formulas applicable to strips of finite dimensions, the theory would probably check the test results of Table VII as closely as the computed ratios check the tested ratios for round wire given in Table III.

Compact engineering formulas for skin effect of uniform round non-magnetic conductors at commercial frequencies may be expressed in terms of the resistance of the conductor. Thus,

$$
\frac{R_{a c}}{R_{d c}}=1+\frac{11.03}{\left(1000 R_{d c}\right)^{2}}-\frac{100}{\left(1000 R_{d c}\right)^{4}} \text { for } 60 \text { cycles, }
$$

and

$$
\frac{R_{a c}}{R_{d c}}=1+\frac{1.91}{\left(1000 R_{d c}\right)^{2}}-\frac{3}{\left(1000 R_{d c}\right)^{4}} \text { for } 25 \text { cycles, }
$$

where $R_{d c}$ is the resistance of the conductor to direct current in ohms per $1000 \mathrm{ft}$. These formulas are applicable to wire 
or cable, of copper or aluminum, and for sizes of conductors up to $1 \frac{1}{2}$-in. diameter.

J. E. Clem: Although Dr. Kennelly does not discuss the skin effect of conductors located within a-c. machinery, it is worth while to mention the fact that the increase in copper loss in conductors within machines due to current distortion is very much larger than in cables or busbars, on account of what Dr. Kennelly terms "proximity effect." This is due to the fact that within machines a large number of conductors carrying currents at high density are placed in very close proximity to each other and as a result the magnetic field traversing the copper is of considerable value. In generators and transformers this is especially true. In fact, in many cases, unless special precautions are taken in design, the copper loss may be increased 20,30 , or even 50 per cent at 25 or 60 cycles on account of this "proximity effect." Occurring at normal frequency, it is evident that within machines this phenomenon is of the utmost importance to the designer.

The distribution of the flux in a conductor in a machine is very different from the distribution of flux in a conductor in air. In a conductor in air the flux forms cylinders or flattened cylinders around the conductor, depending upon whether the conductor is a round wire or a strip. See Fig. 11 of paper. In machines the presence of iron usually causes the flux to traverse the conductor in approximately straight lines, the flux density increasing from one side of the conductor to the other. This case corresponds approximately to that shown in Fig. 12.

While the cause of the extra loss due to the unequal distribution of current is the magnetic flux in both cases, the mathematical development should be different because of the different flux distribution. Mr. A. B. Field read a good paper on this subject in 1905 before the A. I. E. E., in which he developed a method of determining these losses.

L. P. Ferris: The results of most importance, seem to me to be those which apply to the skin-effect resistance-ratio. We are more interested in the increase of resistance of a conductor due to skin effect than we are in the slight decrease in the inductance due to the same cause. The method by which the skin-effect resistance-ratio was determined experimentally is of considerable interest. The bridge was so arranged that this ratio could be determined by a few settings on a slide wire of the bridge. This is shown in Table II. The simple formula for the skin-effect resistance-ratio involves two functions which are proportional to the a-c. and d-c. resistances, but it is not necessary by the method used to determine the absolute magnitude of either resistance. The accuracy of these results, in so far as the resistance-ratio is concerned, should be very high, and this is shown to be true by the close agreement of the experimentally determined ratios 
with those computed, in the cases where the "proximity effect" is small.

For the inductance-ratio it is necessary actually to determine the magnitude of the inductance at high frequency; the computed external inductance of the circuit, which does not change with the frequency, subtracted from the measured total inductance, leaves the value of the internal inductance which is compared with the computed internal inductance at zero frequency. As the change in inductance is only a small proportion of the total in non-magnetic materials such as were used in these tests, the precision with which the experimental results accord with the computed results is to be considered highly satisfactory.

There is indicated a very ingenious method of increasing the sensitivity of the telephone detector in a-c. bridge work at low frequencies. It is simply to place in series with the detector a telephone transmitter in front of which is a telephone receiver carrying an alternating current at, say, 700 cycles. This device causes a high-frequency variation in the lowfrequency current passing through the detector when the bridge is out of balance. I have had occasion to try this device and found it very successful. The high-frequency effect greatly increases the ease and accuracy of the settings. 